University of Louisville

ThinkIR: The University of Louisville's Institutional Repository

Electronic Theses and Dissertations

$8-2010$

\title{
The electrochemical synthesis, chemical synthesis, and galvanic exchange of silver nanostructures directly on surfaces.
}

Grzegorz W. Slawinski

University of Louisville

Follow this and additional works at: https://ir.library.louisville.edu/etd

\section{Recommended Citation}

Slawinski, Grzegorz W., "The electrochemical synthesis, chemical synthesis, and galvanic exchange of silver nanostructures directly on surfaces." (2010). Electronic Theses and Dissertations. Paper 1341. https://doi.org/10.18297/etd/1341

This Doctoral Dissertation is brought to you for free and open access by ThinkIR: The University of Louisville's Institutional Repository. It has been accepted for inclusion in Electronic Theses and Dissertations by an authorized administrator of ThinkIR: The University of Louisville's Institutional Repository. This title appears here courtesy of the author, who has retained all other copyrights. For more information, please contact thinkir@louisville.edu. 


\title{
THE ELECTROCHEMICAL SYNTHESIS, CHEMICAL SYNTHESIS, AND GALVANIC EXCHANGE OF SILVER NANOSTRUCTURES DIRECTLY ON SURFACES
}

\author{
By \\ Grzegorz W. Sławiński

\begin{abstract}
A Dissertation
Submitted to the Faculty of the

Graduate School of the University of Louisville

in Partial Fulfillment of the Requirements

for the Degree of
\end{abstract}

Ph.D.

Department of Chemistry

University of Louisville

Louisville, Kentucky

August 2010 
Copyright 2010 by Grzegorz W. Sławiński

All rights reserved 



\section{THE ELECTROCHEMICAL SYNTHESIS, CHEMICAL SYNTHESIS, AND GALVANIC EXCHANGE OF SILVER NANOSTRUCTURES DIRECTLY ON SURFACES}

\section{By}

Grzegorz W. Sławiński

A Dissertation Approved on

August 09, 2010-08-07

by the following Thesis Committee:

\footnotetext{
Thesis Director Dr. Francis P. Zamborini

Dr. Aleeta M. Powe

Dr. Marta C. Yappert

Dr. Christopher T. Burns

Dn. Gamini U. Sumanaşêkera

Dr. Richard P. Baldwin
} 


\section{DEDICATION}

This dissertation is dedicated to my parents

Teresa i Juliusz Sławińscy 


\section{ACKNOWLEDGEMENTS}

Here I would like to acknowledge the people that helped me during these years to complete my degree. First I would like to thank to my advisor, Dr. Francis P. Zamborini, for his guidance and support during my research.

I would like to thank Dr. Aneta Mieszawska for support and good advice. A special thanks to Olga Ivanova for suggestions and perceptive criticism during my work and research.

I would like to thank Dr. Robert Cohn from the Department of Electrical and Computer Engineering at the University of Louisville for allowing access to the Scanning Electron Microscope (SEM) and Joe Williams for assistance with SEM.

I am grateful to my parents Teresa and Juliusz Sławińscy, to whom this work is dedicated, for their patience, understanding, love and encouragement to follow my dreams. Without them this work would never have come to existence. 


\section{ABSTRACT \\ THE ELECTROCHEMICAL SYNTHESIS, CHEMICAL SYNTHESIS, AND GALVANIC EXCHANGE OF SILVER NANOSTRUCTURES DIRECTLY ON SURFACES}

\section{Grzegorz Slawiński}

August, 09, 2010

This dissertation describes galvanic exchange of silver $(\mathrm{Ag})$ nanostructures with $\mathrm{PdCl}_{4}{ }^{2-}$ in 1) various $\mathrm{PdCl}_{4}{ }^{2-}$ concentrations, 2) the presence of $0.1 \mathrm{M}$ cetyltrimethylammonium bromide (CTAB), and 3) the presence of $0.1 \mathrm{M}$ potassium bromide $(\mathrm{KBr})$. It also describes the electrochemical seed-mediated growth of $\mathrm{Ag}$ nanorods directly on indium tin oxide (ITO) coated glass electrodes, and the synthesis of Ag nanostructures directly on thin sheets of graphene and the Raman enhancement of the graphene.

Ag nanorods (NRs) and nanowires (NWs) synthesized directly on surfaces from surface-attached Au nanoparticles (NPs) by seed-mediated growth react spontaneously with $\mathrm{PdCl}_{4}{ }^{2-}$ solutions by galvanic exchange. The morphology of the resulting AgPd alloy nanostructures depends on the galvanic exchange rate when performed in aqueous solutions with no other additives. The rate increases with increasing $\mathrm{PdCl}_{4}{ }^{2-}$ 
concentration over a concentration range of $1.0 \times 10^{-5}$ to $1.0 \times 10^{-4} \mathrm{M}$. A concentrations of $7.5 \times 10^{-5} \mathrm{M}$ or higher lead to rapid galvanic exchange resulting in Pd deposition over the entire $\mathrm{Ag}$ nanostructure at the early stages of exchange. When the concentration of $\mathrm{PdCl}_{4}{ }^{2-}$ is in the range of $1.0 \times 10^{-5}$ to $5.0 \times 10^{-5} \mathrm{M}$, Pd deposition occurs preferentially at high energy twin plane defects in the form of well-spaced nanoparticles during the early stages of exchange. Composition analysis by linear sweep voltammetry shows that the UV-Vis data do not reflect the composition well. The rate at all concentrations is slower that the diffusion-limited rate and the reaction does not reach completion at any concentration studied $(\mathrm{Max}=70 \% \mathrm{Pd})$

The galvanic exchange in the presence of $0.1 \mathrm{M} \mathrm{CTAB}$ and concentrations of $\mathrm{PdCl}_{4}{ }^{2-}$ from $1.0 \times 10^{-5} \mathrm{M}$ to $1.0 \times 10^{-4} \mathrm{M}$ show several differences compared to exchange in water. First, the rate of exchange does not depend strongly on $\mathrm{PdCl}_{4}{ }^{2-}$ concentration. Second, the rate of exchange is slower overall and the morphology of the PdAg NWs is different. The galvanic exchange also occurs preferentially on twin -plane defect sites, but the Pd deposition is more continuous and the etching of the terraces more pronounced. Third, the extent of exchange is different. The $\mathrm{Ag}$ is fully exchanged in the presence of $\mathrm{CTAB}$ after $1 \mathrm{~h}$ in $5.0 \times 10^{-5} \mathrm{M} \mathrm{PdCl}_{4}{ }^{2-}$, while $25-30 \% \mathrm{Ag}$ remains on the surface for exchange in water only. The galvanic exchange rate is slower than the diffusion-limited rate at all $\mathrm{PdCl}_{4}{ }^{2-}$ concentrations.

In presence of $0.1 \mathrm{M} \mathrm{KBr}$, the rate of exchange is fastest out of all environments studied (water, $\mathrm{CTAB}, \mathrm{KBr}$ ). The resulting morphology is very different compared to morphologies obtained during exchange in water or CTAB. Exchange in $7.5 \times 10^{-5} \mathrm{M}$ 
$\mathrm{PdCl}_{4}{ }^{2-}$ in $0.1 \mathrm{M} \mathrm{KBr}$ leads to the destruction of the nanostructures and an evenly distributed rough morphology after exchange in $5.0 \times 10^{-5} \mathrm{M}$ and $2.5 \times 10^{-5} \mathrm{M} \mathrm{PdCl}_{4}{ }^{2-} \mathrm{M}$.

The electrodeposition of $\mathrm{Ag}$ in $\mathrm{pH} 10.6$ buffer occurs preferentially on $\mathrm{Au}$ nanoparticle seeds attached to glass/ITO electrodes over a potential range of -0.1 to -0.2 V vs. $\mathrm{Ag} / \mathrm{AgCl}$. $\mathrm{At}-150 \mathrm{mV}$ (vs. $\mathrm{Ag} / \mathrm{AgCl}$ ), the deposited nanostructures contain a small percentage of NRs and NWs, whereas other potentials produces mostly spherical or flower-like structures. This shows that the formation of NRs/NWs depends strongly on the reduction potential, which is an important finding for fundamental and applied studies.

$\mathrm{Ag}$ and $\mathrm{Au}$ nanostructures, including NRs/NWs, can be immobilized on thin sheets of graphene by attaching hydrophobic hexanethiolate Au seeds and growing them by seed-mediated growth. The presence of the $\mathrm{Au}$ and $\mathrm{Ag}$ nanostructures leads to the Raman enhancement of graphene by 50 and 150 fold, respectively. This shows that metal nanostructures are in intimate contact with graphene. These heterostructures could find use in catalysis, sensing, nanoelectronics, and optoelectronics applications. 


\section{TABLE OF CONTENTS}

\section{PAGE}

iv

$\mathrm{V}$

viii

$\mathrm{xi}$

$\mathrm{xV}$

CHAPTER

$\begin{array}{ll}\text { I. INTRODUCTION } & 1\end{array}$

1.1. Main goal/Summary 1

1.2. Motivation/Objective 2

1.3. Synthesis of one-dimensional (1D) metallic nanostructures 3

1.3.1. Solution based methods 3

1.3.2. Methods for growing $1 \mathrm{D}$ nanostructures directly on surface $\quad 9$

$\begin{array}{ll}\text { 1.4. Galvanic exchange } & 14\end{array}$

$\begin{array}{ll}\text { 1.5. Galvanic exchange mechanism } & 17\end{array}$

1.6. Application of 1D nanostructures $\quad 21$

1.7. Summary and Accomplishments 23

II. EXPERIMENTAL 25

2.1. Substrates 25

2.2. Solutions 28

2.3. Characterization and Instrumentation $\quad 35$

2.3.1. Scanning Electron Microscopy (SEM) 35

2.3.2. UV-Visible Spectroscopy and Localized Surface
Plasmon Resonance

2.3.3. Electrochemical methods $\quad 42$

III. UNIQUE STRUCTURES THROUGH TWIN PLANE

DECORATION OF Ag NANORODS DURING GALVANIC EXCHANGE WITH AQUEOUS PdCl ${ }_{4}^{2-} \quad 47$

3.1. Abstract 47

3.2. Introduction $\quad 48$

3.3. Experimental Section $\quad 51$

3.3.1. Chemicals and materials $\quad 51$ 
3.3.2. Synthesis of Ag nanostructures directly on surfaces

3.3.3. Galvanic exchange between $\mathrm{Ag} \mathrm{NRs} / \mathrm{NWs}$ and $\mathrm{PdCl}_{4}{ }^{2-} \quad 52$

3.3.4. Electrochemical characterization by Linear Sweep Voltammetry

3.3.5. Instrumentation

3.4. Results and Discussion

53

3.5. Conclusions

IV. EFFECT OF CTAB AND KBr ON THE GALVANIC

EXCHANGE REACTION BETWEEN SILVER NANOWIRES AND $\mathrm{PdCl}_{4}{ }^{2-}$ GROWN DIRECTLY ON SURFACES

70

4.1. Introduction

4.2. Experimental Section

4.2.1. Chemicals and materials

4.2.2. Synthesis of $A g$ nanostructures directly on surfaces

4.2.3. Galvanic exchange between $\mathrm{Ag} \mathrm{NRs} / \mathrm{NWs}$ and $\mathrm{PdCl}_{4}{ }^{2-}$ in $\mathrm{CTAB}$ and $\mathrm{KBr}$

4.2.4. Electrochemical characterization by Linear Sweep Voltammetry

4.2.5. Instrumentation

4.4. Conclusions

$\begin{array}{ll}\text { 5.1. Introduction } & 91 \\ \text { 5.2. Experimental Section } & 92\end{array}$

5.2.1. Chemicals and materials 92

5.2.2. Glass/ITO electrode functionalization 92

5.2.3. Electrochemical setup 93

5.2.4. Ag electrodeposition 93

5.3. Results and Discussion 93

5.4. Conclusions 99

VI. SURFACE-ENHANCED RAMAN SPECTROSCOPY STUDY OF THIN GRAPHENE SHEETS FUNCTIONALIZED WITH Au and Ag NRs BY SEED-MEDIATED GROWTH $\quad 100$ 6.1. Abstract 100 6.2. Introduction 101

6.3. Experimental Section 103

6.3.1. Chemicals and materials 103

6.3.2. Graphene deposition 103

6.3.3. Au monolayer-protected clusters (MPC) seeds $\quad 104$ 
6.3.4. Seed-mediated growth of $\mathrm{Au}$ and Ag nanorods on graphene

6.3.5. Characterization

106

6.4. Results and Discussion

6.5. Conclusions

VII. SUMMARY AND CONCLUSIONS

REFERENCES 


\section{LIST OF FIGURES}

FIGURE

PAGE

1.1. General procedure for nucleation and growth of metal nanostructures. 4

1.2. Methods for synthesizing 1D metal nanostructures. 6

1.3. (A) Preferable surfactant deposition on the crystal faces of Au seed nanoparticle and (B) structure of (100) and (111) crystal faces.

1.4. Reactions involved in the seed-mediated growth process.

1.5. Typical ways of synthesizing metallic or multi-metallic nanoparticles. 15

1.6. Schematic illustration of galvanic replacement reaction mechanism between $\mathrm{Ag}$ nanostructures and $\mathrm{HAuCl}_{4}$.

2.1. Schematic of procedure for growing gold and silver nanostructures

2.2. Functionalization of glass, $\mathrm{Si} / \mathrm{SiO}_{\mathrm{x}}$ or glass/ITO with MPTMS or APTES

2.3. Schematic of growth of Ag nanostructures.

2.4. Typical SEM image of $\mathrm{Si} / \mathrm{SiO}_{\mathrm{x}} / \mathrm{MPTMS} / \mathrm{Au}$ seed/Ag NRs/NWs sample. 34

2.5. Schematic of SEM (adapted from reference 69)

2.6. Electron beam/specimen interactions (adopted from reference 61)

2.7. Absorption spectrum of a nanorod sample (red spectrum) compared to spherical Ag nanoparticles (black spectrum) and spherical Au nanoparticles (brown spectrum).

2.8. $\mathrm{LSV}$ of ITO/MPTMS/Ag nanostructures in $0.5 \mathrm{M} \mathrm{H}_{2} \mathrm{SO}_{4}$. Scan rate $10 \mathrm{mV} / \mathrm{sec}$

2.9. $\mathrm{i}-\mathrm{V}$ curve of glass//TO in $2.5 \times 10^{-4} \mathrm{M} \mathrm{AgNO}_{3}$ in $0.1 \mathrm{M} \mathrm{CTAB}$ in 10.6 phosphate buffer solution. 
3.1. (A) UV-Vis spectra of an Ag sample exchanged with $5.0 \times 10^{-5} \mathrm{M}$ $\mathrm{PdCl}_{4}{ }^{2-}$. (B) Normalized absorbance as a function of time for exchange of $\mathrm{Ag}$ in $1.0 \times 10^{-5}, 2.5 \times 10^{-5}, 5.0 \times 10^{-5}, 7.5 \times 10^{-5}$, and $1.0 \times 10^{-4} \mathrm{PdCl}_{4}{ }^{2-}$ concentrations. (C) A zoom in of B from 1 to 900 seconds.

3.2. SEM images of galvanically exchanged nanostructures with different $\mathrm{PdCl}_{4}{ }^{2-}$ concentrations but matching value of absorbance (0.6).

3.3. SEM images of progressing galvanic exchange with time for $5.0 \times 10^{-5} \mathrm{M}$ $\mathrm{PdCl}_{4}{ }^{2-}$ in $\mathrm{H}_{2} \mathrm{O}$. A through $\mathrm{E}$ show $\mathrm{Ag} \mathrm{NR}$ during the galvanic exchange at $0,1,5,15$, and 60 minutes, respectively. F shows double defect at the twin plane along the entire length of $\mathrm{Ag} \mathrm{NW}$.

3.4. Model of galvanic exchange reaction with preferential decoration of twin-plane defects with time.

3.5. Linear sweep voltammograms of ITO/MPTMS/Auseed/AgNW after exchange with $5.0 \times 10^{-5} \mathrm{M} \mathrm{PdCl}_{4}{ }^{2-}$ for various times obtaines in A) $0.5 \mathrm{M}$ $\mathrm{H}_{2} \mathrm{SO}_{4}$ and $\mathrm{B}$ ) $0.01 \mathrm{M} \mathrm{KBr}$ in $0.1 \mathrm{M} \mathrm{HClO}_{4}$. Each time represents different sample where the $\mathrm{Ag}$ oxidation and $\mathrm{Pd}$ oxidation was performed in that order. C) shows a comparison between the experimental normalized absorbance (yellow circles), experimental \% Ag (red triangles), and theoretical (calculated) (blue diamonds) amount of $\mathrm{Ag}$ present on the sample after exchange with $5.0 \times 10^{-5} \mathrm{M} \mathrm{PdCl}_{4}{ }^{2-}$ for various times.

3.6. $\% \mathrm{Ag}$ vs. Pd concentration used for the galvanic exchange after 1 hour exchange.

4.1. (A) UV-Vis spectra of an Ag NW sample exchanged with $5.0 \times 10^{-5} \mathrm{M}$ $\mathrm{PdCl}_{4}{ }^{2-}$ in $0.1 \mathrm{M} \mathrm{CTAB}$ solution. (B) A plot of the normalized absorbance of the LSPR band as a function of time for galvanic exchange in $1.0 \times 10^{-5}$, $2.5 \times 10^{-5}, 5.0 \times 10^{-5}, 7.5 \times 10^{-5}$, and $1.0 \times 10^{-4} \mathrm{PdCl}_{4}{ }^{2-}$ concentrations in $0.1 \mathrm{M} \mathrm{CTAB}$.

4.2. (A) UV-Vis spectra of an $\mathrm{Ag} \mathrm{NW}$ sample exchanged with $5.0 \times 10^{-5} \mathrm{M}$ $\mathrm{PdCl}_{4}{ }^{2-}$ in $0.1 \mathrm{M} \mathrm{KBr}$ solution. (B) A plot of the normalized absorbance as a function of time for $1.0 \times 10^{-5}, 2.5 \times 10^{-5}, 5.0 \times 10^{-5}$, and $7.5 \times 10^{-5} \mathrm{M}$ $\mathrm{PdCl}_{4}{ }^{2-}$ concentrations plus $0.1 \mathrm{M} \mathrm{KBr}$.

4.3. SEM images of $\mathrm{Ag}$ nanostructures galvanically-exchanged with different concentrations of $\mathrm{PdCl}_{4}{ }^{2-}$ in $0.1 \mathrm{M} \mathrm{CTAB}(\mathrm{A}-\mathrm{C})$ and $0.1 \mathrm{M} \mathrm{KBr}(\mathrm{D}-\mathrm{F})$ until the normalized absorbance reaches $\sim 0.6$. 
4.4. SEM images of galvanically exchanged $\mathrm{Ag}$ nanostructures in different concentrations of $\mathrm{PdCl}_{4}{ }^{2-}$ and $0.1 \mathrm{M} \mathrm{CTAB}(\mathrm{A}-\mathrm{C})$ and $0.1 \mathrm{M} \mathrm{KBr}$ $(\mathrm{D}-\mathrm{F})$ until normalized absorbance reached of $\sim 0.4(\sim 70 \% \mathrm{Ag})$.

4.5. (A) Normalized absorbance with time for galvanic exchange of $\mathrm{Ag}$ with 5.0 $\times 10^{-5} \mathrm{M} \mathrm{PdCl}_{4}{ }^{2-}$ in water (red square, SEM B), $0.1 \mathrm{M} \mathrm{CTAB}$ (black diamond, SEM C), and $0.1 \mathrm{M} \mathrm{KBr}$ (blue triangle, SEM D) with corresponding SEM images at normalized absorbance of 0.6.

4.6. LSVs of ITO/MPTMS/Auseed/AgNW in (A) $0.5 \mathrm{M} \mathrm{H}_{2} \mathrm{SO}_{4}$ and (B) $0.01 \mathrm{M} \mathrm{KBr}$ and $0.1 \mathrm{M} \mathrm{HClO}_{4}$ after exchange with $5.0 \times 10^{-5} \mathrm{M}$ $\mathrm{PdCl}_{4}{ }^{2-}$ in $0.1 \mathrm{M} \mathrm{CTAB}$ for various times. (C) A comparison between the experimental normalized absorbance (yellow circles), \%Ag determined by LSV (red triangles), and theoretical (calculated) (blue diamonds) $\% \mathrm{Ag}$ based on a diffusion-limited reaction rate as a function of exchange time in $5.0 \times 10^{-5} \mathrm{M} \mathrm{PdCl}_{4}{ }^{2-}$ plus $0.1 \mathrm{M} \mathrm{CTAB} . \quad 86$

5.1. Electrochemical setup for Ag electrodeposition

5.2. Cyclic voltammograms of glass/ITO (A), glass/ITO/MPTMS (B), and glass/ITO/MPTMS/Au seed (C) in $2.5 \times 10^{-4} \mathrm{M} \mathrm{AgNO}_{3}$ and $0.1 \mathrm{M}$ $\mathrm{CTAB}$ in $\mathrm{pH} 10.6$ phosphate buffer. (D) An overlay of the plots A, B, and $\mathrm{C}$ in the potential range from 0 to $-0.4 \mathrm{~V}$.

5.3. SEM images of ITO/MPTMS/Au seed Ag nanostructures deposited at $0 \mathrm{mV}$ (A), $-150 \mathrm{mV}$ (B), $-200 \mathrm{mV}$ (C), $-300 \mathrm{mV}$ (D), $-400 \mathrm{mV}$ (E), $-500 \mathrm{mV}(\mathrm{F})$, and $-600 \mathrm{mV}(\mathrm{G})$. A clean glass/1TO surface is shown in $(\mathrm{H})$.

6.1. Schematic of the experimental set-up for the electrostatic deposition of graphene sheets onto an APTES-functionalized $\mathrm{Si} / \mathrm{SiO}_{2}$ substrate. (Schematic adapted from Anton Sidorov's unpublished results).

6.2. Procedure for the synthesis of $\mathrm{Au}$ and $\mathrm{Ag}$ nanorods on graphene, involving (1) modification of the $\mathrm{Si} / \mathrm{SiO}_{2}$ surface with APTES, (2) electrostatic deposition of the graphene on of the $\mathrm{Si} / \mathrm{SiO}_{2} / \mathrm{APTES}$ substrate, (3) chemisorption of the C6S Au MPCs ("seeds"), and (4) decoration of the graphene with $\mathrm{Au}$ or $\mathrm{Ag}$ nanostructures by seed-mediated growth of the Au MPC seeds. (Adapted from Anton Sidorov's unpublished results).

6.3. SEM images of (A) $\mathrm{Si} / \mathrm{SiO}_{2} / \mathrm{APTES} /$ graphene, (B) $\mathrm{Si} / \mathrm{SiO}_{2} / \mathrm{APTES} /$ graphene/Au nanostructures, and (C) $\mathrm{Si} / \mathrm{SiO}_{2} / \mathrm{APTES} /$ graphene/Ag nanostructures. 
6.4. SEM images of a sample of Au nanoparticles and nanorods grown on few layer graphene sheets. We regularly observed wrinkles and the formation of scroll-like structures for these graphene structures.

6.5. SEM images of graphene exposed to $\mathrm{pH} 2.8 \mathrm{Au}$ growth solution without exposure to Au MPCs first.

6.6. $\mathrm{SEM}$ images of a $\mathrm{Si} / \mathrm{SiO}_{2} / \mathrm{APTES} /$ graphene substrate coated with $\mathrm{Ag}$ nanostructures by seed-mediated growth. In contrast to those coated with $\mathrm{Au}$, these graphene sheets usually appeared intact and smooth.

6.7. $\mathrm{SEM}$ images of an $\mathrm{Si} / \mathrm{SiO}_{2} / \mathrm{APTES} /$ graphene substrate exposed to the $\mathrm{pH} \mathrm{Ag}$ growth solution without any exposure to C6S Au MPC seeds. No nanostructures grow in the absence of seed and the graphene sheets are stable at high $\mathrm{pH}$.

6.8. Raman spectra of the graphene monolayer with and without $\mathrm{Au}$ nanostructures.

6.9. Raman spectra of the graphene monolayer with and without attached Ag nanostructures. 


\section{LIST OF TABLES}

TABLE

PAGE

1.1. Numbers of structures synthesized by galvanic exchange reported in the literature. 


\section{CHAPTER I \\ INTRODUCTION}

\subsection{Main goal/Summary.}

This research involved the following three different reactions involving silver nanostructures grown directly on surfaces: 1) galvanic exchange, 2) electrochemical seed-mediated growth, and 3) seed-mediated growth on graphene. The main goals were to better understand the effect of reaction rate and additives on galvanic exchange reactions, better understand the effect of reduction potential on the seed-mediated growth of Ag nanostructures, and fabricate heterojunctions between graphene and onedimensional (1D) metal nanostructures. This follows up on our previous work, where we synthesized and aligned $\mathrm{Ag}$ nanorods/nanowires (NRs/NWs) directly on surfaces, and demonstrated galvanic exchange with $\mathrm{PdCl}_{4}{ }^{2-}$ and $\mathrm{PtCl}_{4}{ }^{2-}$. This chapter (Chapter I) provides background information on the synthesis of metallic, and more specifically $\mathrm{Ag}$, nanostructures (structures that are defined as having at lease one dimension within the range from 1 to $100 \mathrm{~nm}$ ) and their properties. It also provides background information on galvanic exchange, electrodeposition, and graphene. Chapter II describes the experimental procedures and instrumentation used in this study. Chapter III describes our research on the synthesis of Ag NRs/NWs and effect of rate on the galvanic exchange with aqueous $\mathrm{PdCl}_{4}{ }^{2-}$. Chapter IV continues the research on galvanic exchange describing the differences in the exchange in aqueous $\mathrm{PdCl}_{4}{ }^{2-}$ solutions and those 
containing stabilizers (Cetyltrimethylammonium bromide (CTAB) and potassium bromide salt)). Chapter V describes the potential-controlled electrochemical seedmediated growth of Ag nanostructures directly on indium tin oxide (ITO) electrode surfaces and Chapter VI describes a surface enhanced Raman spectroscopy (SERS) study of thin graphene sheets functionalized with $\mathrm{Au}$ and $\mathrm{Ag}$ nanostructures by chemical seedmediated growth. Chapter VII provides a summary and future directions of this research.

\subsection{Motivation/Objective.}

One objective of this research was to better understand the galvanic exchange process between $\mathrm{PdCl}_{4}{ }^{2-}$ and $\mathrm{Ag}$ nanoscale metals. We focused our experiments on studying the rate of the galvanic exchange between $\mathrm{Ag} \mathrm{NRs} / \mathrm{NWs}$ and $\mathrm{PdCl}_{4}{ }^{2-}$ in different environments and the effect of these variables on the morphology of the final nanostructures. Studying the effect of diverse environments may improve our understanding of galvanic exchange on the nanoscale and lead to formation of structures with unique optical properties that could find use for possible applications in the areas of catalysis, sensing, biosensing or photovoltaics. A second objective was to better understand the seed-mediated growth of 1D NRs and NWs. Specifically, we explored the effect of reduction potential using electrochemical methods. This could leaf to improved control over the dimensions and yields of these fascinating structures, which is an important goal in nanotechnology. Finally, our third objective was to utilize our chemical seed-mediated growth on surfaces to synthesize interesting nanoscale heterostructures. We focused on $\mathrm{Au}$ and $\mathrm{Ag}$ with graphene due to the recent excitement about graphene in various applications and studued the heterostructures by Raman Spectroscopy. 


\subsection{The synthesis of one-dimensional (1D) metallic nanostructures.}

One-dimensional (1D) nanostructures ${ }^{1}$ have recently gained a tremendous amount of attention due to their fascinating chemistry, properties, and potential use in a wide range of electronic, ${ }^{2}$ analytical, ${ }^{3-5}$ and biomedical applications. ${ }^{6}$ Single- or multicomponent nanoscale materials comprised of semiconductors, carbon, polymers, and metals show unique electronic, optical, and magnetic properties that vary with composition, size, and shape of the nanostructure. Our group recently described the synthesis, ${ }^{7-9}$ assembling, ${ }^{8}$ patterning, ${ }^{1}$ and alignment ${ }^{10}$ of $1 \mathrm{D} \mathrm{Au}$ and $\mathrm{Ag}$ and hetero nanostructures $^{11,12}$ directly on surfaces. Fundamental research in nanomaterials synthesis will lead to a better fundamental understanding of structure-function relationships of 1D materials and potential applications in electronics, sensing, catalysis, and electrochemistry.

\subsubsection{Solution based methods.}

Most methods for synthesizing metal nanostructures involve the reduction of a metal salt to metallic form in the presence of a stabilizer. The general procedure for the formation of metal nanostructures is shown in Figure 1.1. The formation of metal occurs in two steps, which are nucleation and growth. The reducing agent reduces the $\mathrm{M}^{\mathrm{n}+}$ to $\mathrm{M}^{0}$ to form $\mathrm{M}^{0}{ }_{\mathrm{x}}$ clusters (nucleation sites). The small clusters then act as seeds for growth into bigger structures by continuous addition of the metal ions (Figure 1.1 A). The energy required to reduce $\mathrm{M}^{\mathrm{n}+}$ to $\mathrm{M}^{0}$ during the nucleation step is larger than that for the growth step. Several groups synthesized metal nanostructures in this way, using stabilizers, such as thiols, surfactants, polymers or ions, to prevent nanoparticle aggregation. 

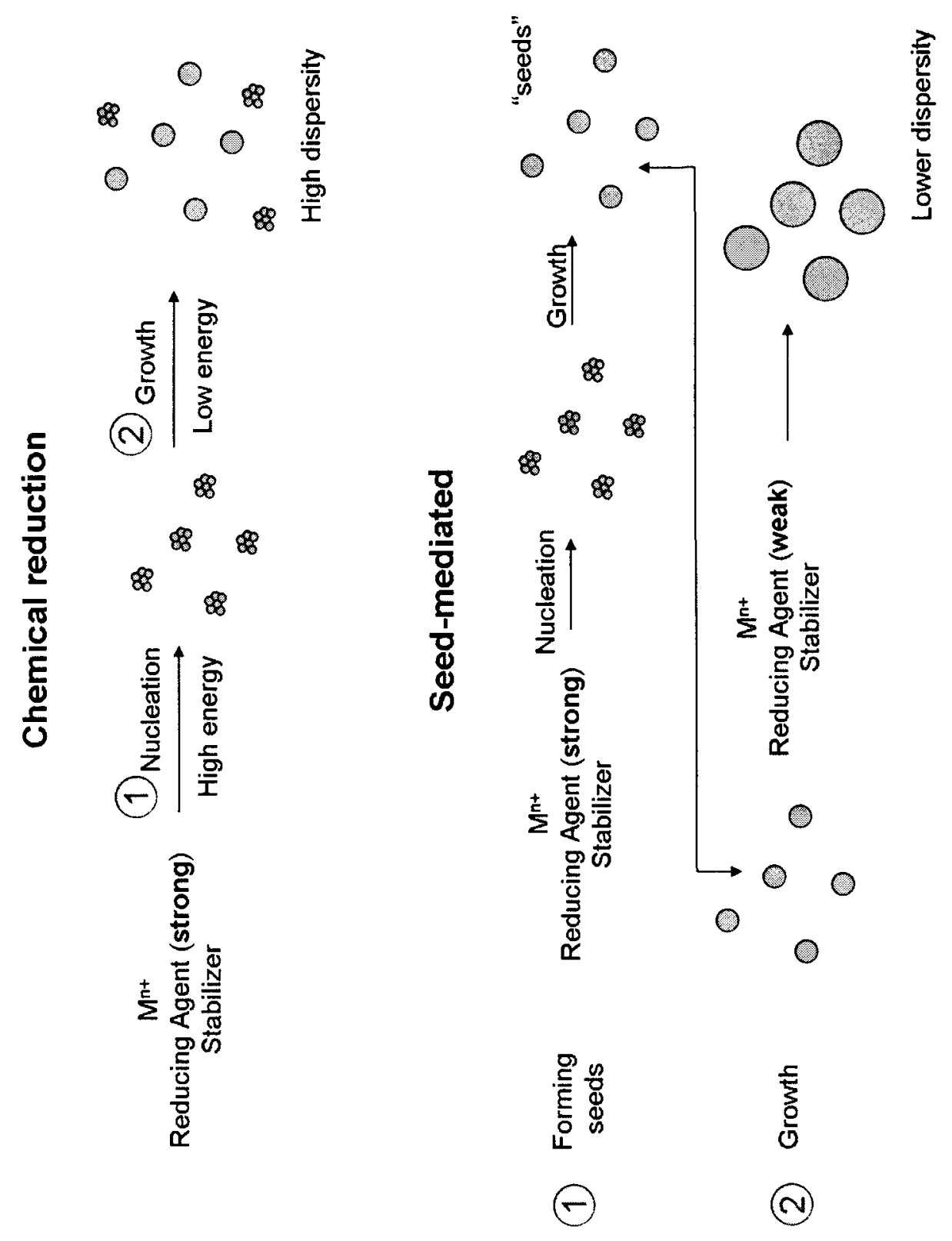
Murphy and coworkers recently developed a solution method for synthesizing 1D metals (nanorods and nanowires) from pre-synthesized metal nanoparticle "seeds", which act as catalysts in the process known as seed-mediated growth. ${ }^{13}$ Seed-mediated growth works on the principal, described in Figure 1.1B, where nucleation and growth are separated into two steps. First, small metal nanoparticle "seeds" are synthesized with a strong reducing agent, such as borohydride (high energy nucleation step). Then, the growth of these "seeds" is controlled by combining the "seeds" with more metal salt and a weak reducing agent, such as citrate (low energy growth step)(Figure 1.1B). Since the seedmediated synthesis occurs by preferential metal reduction on a catalyst "seed" particle, the procedure is ideal for synthesizing metal 1D structures directly on surfaces from surface-attached "seeds". The presynthesized seeds (3-5 nm diameter Au nanoparticles) are added to the growth solution, which contains cetyltrimethylammonium bromide (CTAB), ascorbic acid, and $\mathrm{AuCl}_{4}{ }^{-}$or $\mathrm{AgNO}_{3}$ for the formation of $\mathrm{Au}$ or $\mathrm{Ag}$ nanostructures, respectively. Ascorbic acid is a weak reducing agent and CTAB is a surfactant that aids in the formation of nanorods (NRs)/nanowires (NWs) from the seeds directly on the surface. The seed-mediated growth process was used in my research for the synthesis of $\mathrm{Au}$ and $\mathrm{Ag} \mathrm{NRs} / \mathrm{NWs}$ directly on surfaces. Figure 1.2A describes general methods for the chemical synthesis of 1D nanostructures with "seed" particles while Figure $1.2 \mathrm{~B}$ shows some template procedures.

Another popular solution-phase approach to synthesize $\mathrm{Ag} 1 \mathrm{D}$ nanostructures was developed by Xia and co-workers. ${ }^{14-18}$ The synthesis of silver nanorods involves two steps similar to the seed-mediated growth. The first step is the formation of $\mathrm{Pt}$ or $\mathrm{Ag}$ seeds by reducing $\mathrm{PtCl}_{2}$ or $\mathrm{AgNO}_{3}$, respectively, with ethylene glycol (EG) at 

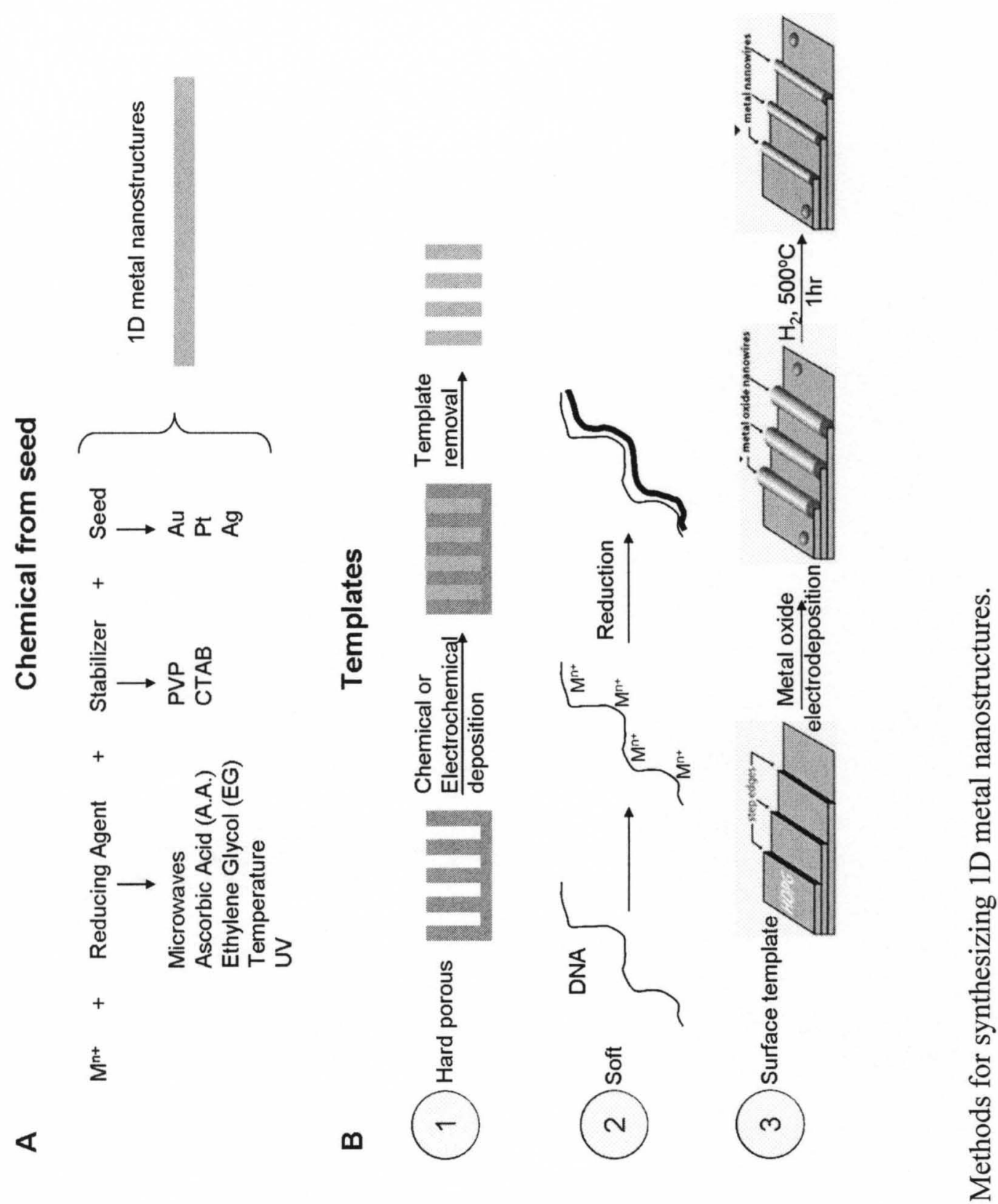

ํㅣㄹ 
approximately $160^{\circ} \mathrm{C}$. Next, solutions of ethylene glycol, polyvinyl pyrrolidone (PVP), and $\mathrm{AgNO}_{3}$ are added and $\mathrm{Ag}$ nanowires grow on the previously formed seeds. The simultaneous and drop wise addition of both solutions of PVP and $\mathrm{AgNO}_{3}$ was key to the formation of wire shaped $\mathrm{Ag}$ structures. The exact role of PVP in this process is not fully understood yet. Probably it controls growth rates of different crystalline faces by adsorbing and desorbing on them at different rates. A similar synthesis was used by Silvert and co-workers. ${ }^{19}$

Another technique for the preparation of $\mathrm{Ag}$ nanorods is the ultraviolet irradiation photoreduction technique, introduced by Zhou and co-workers, using polyvinylalcohol (PVA) as a protecting agent. ${ }^{20}$ Here, at room temperature, solutions of PVA and $\mathrm{AgNO}_{3}$ are irradiated with an ultraviolet source for a desired period of time. Similarly to Xia's study, the concentration of PVA and $\mathrm{AgNO}_{3}$ in this study was a key feature in obtaining 1D nanostructures. Also, as seen in previous work, the exact role of the protecting agent is not fully understood.

Microwave heating was used by Liu and co-workers to form Ag nanorods in a two step experiment. ${ }^{21}$ The first step is the formation of Au seed particles by reduction of $\mathrm{HAuCl}_{4}$ with citrate. In the second step citrate acts as a reducing agent for $\mathrm{Ag}^{+}$ions while the Au seed particles act as nucleation sites. The formation of $\mathrm{Ag}$ nanostructures is immediate after adding $\mathrm{AgNO}_{3}$ and citrate to microwave irradiated solution of $\mathrm{Au}$ seeds.

The formation of Ag nanowires can be accomplished by combining microwave heating and the polyol method. ${ }^{17}$ This combination yields improved results in obtaining both $\mathrm{Ag}$ nanorods and nanowires, reducing the time needed to form $\mathrm{Ag}$ nanostructures to 
only a few minutes. Also, centrifugation is used to increase the yield of formed $1 \mathrm{D}$ nanostructures to $79 \%$.

Another widely used technique for the formation of 1D nanostructures is the use of various templates. Chakravoty and co-workers grew $\mathrm{Ag}$ nanowires in the pores of silica gel. ${ }^{22}$ The silica gel was heat treated at various temperatures to control the pore sizes. Next, the template was immersed into the $\mathrm{AgNO}_{3}$ solution so that it could partially fill the pores. In the last step of the experiment the electrodes were placed on opposite sides of the pores with a dc voltage applied across them. Ag nanowires formed after 30 min of the experiment. A similar approach was used by Yang, who formed Ag NWs in mesoporous silica SBS-15. ${ }^{23}$ Stucky and co-workers extended the procedure with SBS15 silica to other metals including $\mathrm{Au}$ and $\mathrm{Pt}^{24}$

$\mathrm{Ag}$ nanowires were also electrochemically grown into nanoporous anodic alumina and polycarbonate templates, and on the surface of highly oriented pyrolityc graphite (HOPG). ${ }^{25,26}$ For alumina templates the prepared $\mathrm{Ag}$ nanowires had diameter and length of approximately $170 \mathrm{~nm}$ and $58 \mu \mathrm{m}$, respectively, with the sizes corresponding to the dimension of the pores in the NANOPORE aluminum membrane (180nm, $58 \mu \mathrm{m})$. The dimensions of $\mathrm{Ag}$ nanowires fabricated with use of polycarbonate templates were $80 \mathrm{~nm}$ and $5 \mu \mathrm{m}$ respectively. The use of templates allows better control over the dimensions and density of formed nanostructures and eliminates the formation of other shapes. The drawback of this method are the templates. In order to apply the resulting nanowires into nanoelectronic devices, one has to extract them from the template and assemble them into a workable device. The Ag mesowires grown on HOPG are rough and discontinuous, 
and for future use in nanoelectonic devices they have to be transferred to another substrate.

We choose the seed-mediated growth procedure for synthesizing 1D nanostructures directly on surfaces for the following reasons:

1) It is a simple chemical procedure.

2) The synthesis occurs at room temperature.

3) There is no need for external energy (heat, light, microwaves).

4) There is no need for templates.

5) No instrumentation is needed during the synthesis steps.

6) The procedure can be performed directly on surfaces.

\subsubsection{Methods for growing 1D nanostructures directly on surfaces.}

Our group and others have used the seed-mediated growth procedure to grow $\mathrm{Au}$ and Ag nanostructures directly on surfaces. ${ }^{1,7,8,27}$ The general procedure involves attaching pre-synthesized 3-5 nm diameter Au seed nanoparticles to a desired substrate and then growing the seeds into larger structures by reducing $\mathrm{AuCl}_{4}{ }^{-}$or $\mathrm{AgNO}_{3}$ preferentially onto the Au seeds with ascorbic acid in the presence of cetyltrimethylammonium bromide (CTAB), which is the same method as that described by Murphy and co-workers for seed-mediated growth in solution except that the seed particles are surface-bound instead of in solution. ${ }^{13,28-32}$ Taub and co-workers first described the synthesis of Au nanorods (NRs) directly on surfaces from such surfacebound Au nanoparticle seeds. ${ }^{27}$ Our group recently described the synthesis, assembling, patterning, and alignment of 1D Au and $\mathrm{Ag}$ and hetero nanostructures directly on surfaces. ${ }^{1,7-12}$ Aslan and co-workers ${ }^{33,34}$ and Lee and co-workers ${ }^{35,36}$ later extended the 
work to Ag nanostructures. These seed particles were attached to amine-coated and thiolcoated substrates, respectively. Previously, we described the effect of $\mathrm{pH}$ on the seedmediated growth of $\mathrm{Ag}$ NRs/NWs directly on surfaces. ${ }^{7} \mathrm{Ag}$ NRs/NWs grow optimally at pH 10.6 under our conditions which was confirmed by UV-Vis spectroscopy and SEM. We showed that the yield of NRs/NWs is low $(\sim 3 \%)$ but can be improved significantly ( $36 \%$ ) by using adhesive tape to remove other shapes.

Other related approaches for $\mathrm{Ag} \mathrm{NW}$ synthesis directly on surfaces in the literature include electroless deposition of Ag onto a surface-bound DNA network or DNA template assembled across an electrode gap. ${ }^{37} \mathrm{~A}$ uniform layer of nanoporous DNA network was formed on an amine-coated surface. After immersing such a substrate into $\mathrm{AgNO}_{3}$ solution, the silver ions were attracted to the DNA by electrostatic interactions and adsorbed to its surface. $\mathrm{The}^{+} \mathrm{g}^{+}$ions were then chemically-reduced to metallic silver. The size of the pores in the DNA network, which is determined by the concentration of DNA, dictates the morphology of the Ag structures.

\section{Seed-mediated growth mechanism.}

The formation of 1D nanostructures by seed-mediated growth occurs by adding presynthesized 3-5 nm gold nanoparticle (Au NPs) seeds into a growth solution containing cetyltrimethylammonium bromide (CTAB), $\mathrm{AuCl}_{4}^{-}$, and ascorbic acid. Although the exact growth mechanism is not fully understood, the following mechanism proposed by Murphy and co-workers is generally accepted. The growth procedure is related to the crystallographic structure of the seed particles. Recent studies showed that single crystalline Au seed particles grow into decahedral particles that are twinned with five-fold symmetry as shown in Figure 1.3. Elongation of the decahedral particle lead to 

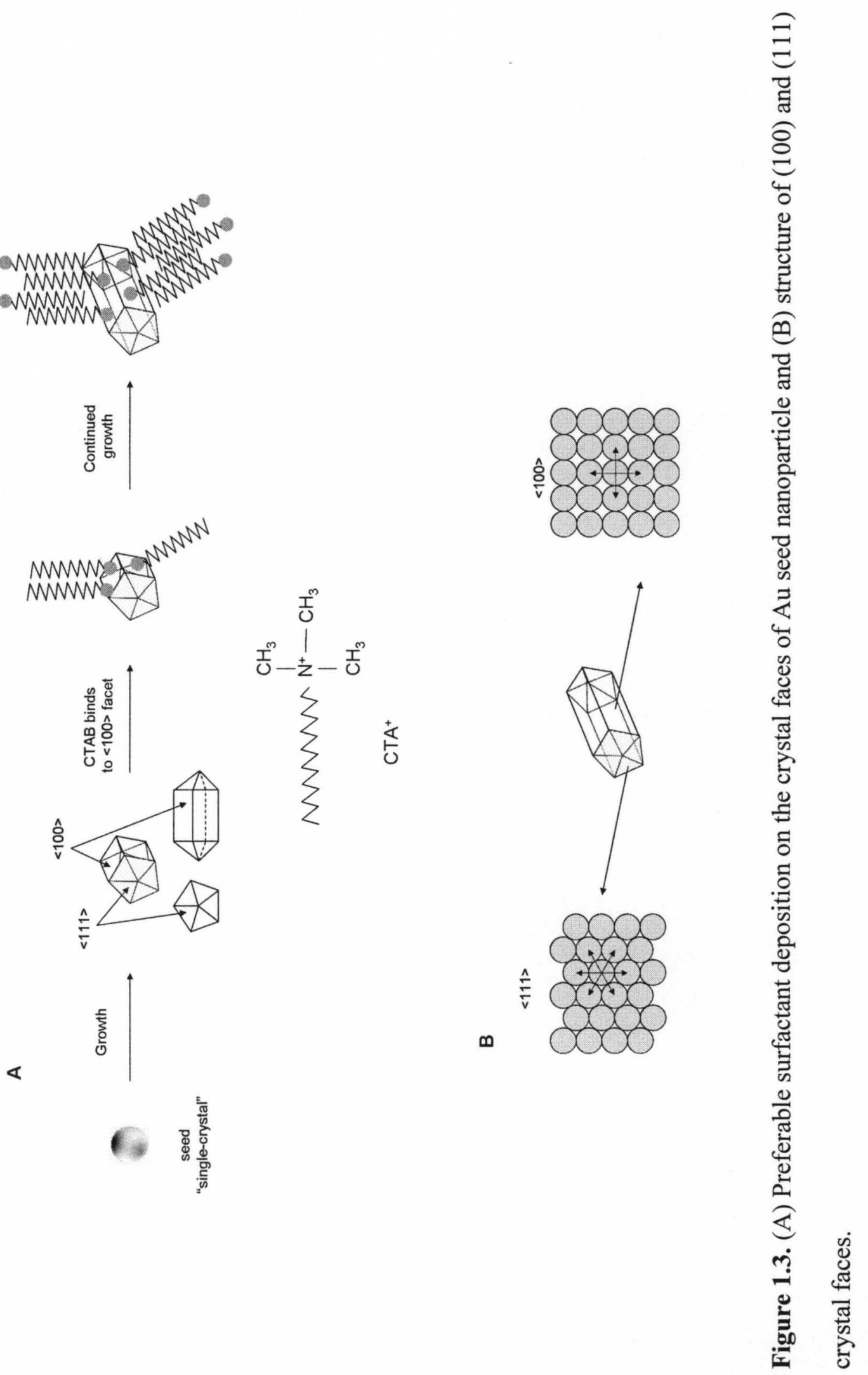
$\mathrm{Au}$ (111) faces on the ends and $\mathrm{Au}(100)$ on the sides. Further growth of the multiplytwinned decahedral particles leads to the NR or NW structure. Thus, the final structure is a multiply-twinned NR with five-fold symmetry and a pentagonal shaped cross-section. The ends of NRs/NWs contain 5 (111) facets and the sides (long axis) contains 5 (100) facets. The formation of nanorod (NR) or nanowire (NW) structures is thought to occur by the preferential blocking of the $\mathrm{Au}(100)$ faces by the CTAB, leading to preferential growth on the (111) ends. Figure 1.3B shows the structure of crystal faces (100) and (111). The growth of seed into rods is based on the high affinity of surfactant (cetyltrimethylammonium bromide (CTAB)) to the (100) crystal face and lower affinity to the (111) face. Thus, CTAB blocks the side (long axis in future rods) crystal faces and promotes growth of the seed on the (111) faces.

Figure 1.4 shows the chemical equations involved in the reduction of Au onto the seed nanoparticle. ${ }^{I}$ The process described here is reduction of $\mathrm{Au}(\mathrm{III})$ via seed-mediated reduction. The first reaction that occurs when $\mathrm{HAuCl}_{4}$ is combined with $\mathrm{CTAB}$ is the exchange of $\mathrm{Cl}^{-}$from $\mathrm{Au}^{\mathrm{III}} \mathrm{Cl}_{4}{ }^{-}$with the excess $\mathrm{Br}^{-}$from solution, resulting in the formation of $\mathrm{Au}^{\mathrm{III}} \mathrm{Br}_{4}{ }^{-}$. Next, the $\mathrm{Au}^{\mathrm{III}} \mathrm{Br}_{4}{ }^{-}$is reduced (by $2 \mathrm{e}^{-}$) by ascorbic acid (AA) to form $\mathrm{Au}^{l} \mathrm{Br}_{2}^{-}$. Excess ascorbic acid in solution also gives two electrons to $\mathrm{Au}$ seed nanoparticles, which are used to further reduce two $\mathrm{Au}^{\mathrm{I}} \mathrm{Br}_{2}{ }^{-}$ions into two metallic $\mathrm{Au}^{0}$ atoms directly on the surface of the Au seed nanoparticle. The process continues until the $\mathrm{Au}$ seed particle grows further into larger nanostructures, including rods, particles, triangles, squares, and hexagons. The growth of silver nanostructures is based on a similar mechanism. Ascorbic acid reduces $\mathrm{Ag}^{+}$(from $\mathrm{AgNO}_{3}$ ) to metallic $\mathrm{Ag}^{0}$ 


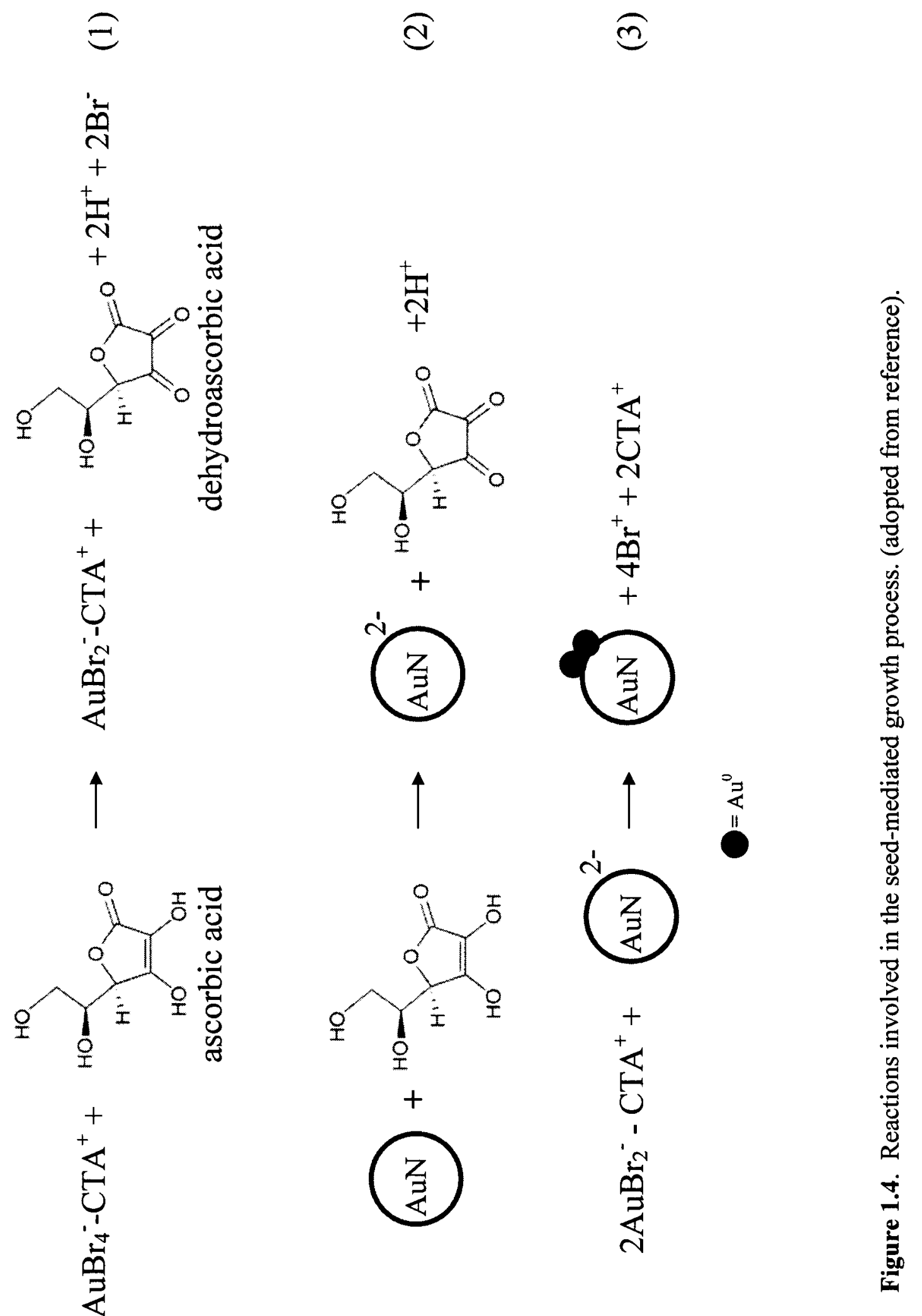


nanostructures. The same mechanism presumably occurs for seed-mediated growth on surfaces dye to the similarity in reaction products formed.

\subsection{Galvanic exchange.}

While monometallic nanostructures have several useful properties and applications, there are many cases where bimetallic or multimetal nanostructures are desirable. There are several methods for synthesizing bi- or multi-metal nanostructures, including seeded growth of one metal onto another, co-reduction of two metal salts in the presence of a stabilizer, or the galvanic exchange method. Schematic representation of these typical methods is shown in Figure 1.5.

Galvanic exchange is a reaction involving exchange between a zero-valent metal and an oxidized metal ion or complex in solution. This occurs spontaneously when the zero-valent metal has a lower oxidation potential than the oxidized metal ion/complex. The zero-valent metal becomes oxidized and dissolves into solution while the oxidized metal ions in the solution are reduced. The galvanic exchange reaction is a well-known oxidation-reduction reaction commonly shown in most general chemistry textbooks. An example is the reaction between metallic $\mathrm{Zn}$ and $\mathrm{Cu}^{2+}$. If one places zinc metal into a solution of $\mathrm{Cu}^{2+}$ ion, the blue color of the solution fades away and a black crust of $\mathrm{Cu}$ metal forms on the $\mathrm{Zn}$ surface as $\mathrm{Zn}$ also oxidizes to $\mathrm{Zn}^{2+}$. The $\mathrm{Cu}$ appears black because it is very finely divided. The overall reaction consists of the two following half-reactions:

$$
\begin{array}{lll}
\text { Reduction (cathode): } & \mathrm{Cu}^{2+}+2 \mathrm{e}^{-} \rightarrow \mathrm{Cu}^{0} \quad\left(\mathrm{E}^{0}=+0.34 \mathrm{~V}\right) \\
\text { Oxidation (anode): } & \mathrm{Zn}^{0} \rightarrow \mathrm{Zn}^{2+}+2 \mathrm{e}^{-} \quad\left(\mathrm{E}^{0}=-0.76 \mathrm{~V}\right) \\
\hline \text { Overall: } & \mathrm{Zn}^{0}+\mathrm{Cu}^{2+} \rightarrow \mathrm{Zn}^{2+}+\mathbf{C u}^{0}
\end{array}
$$


Pure metals:

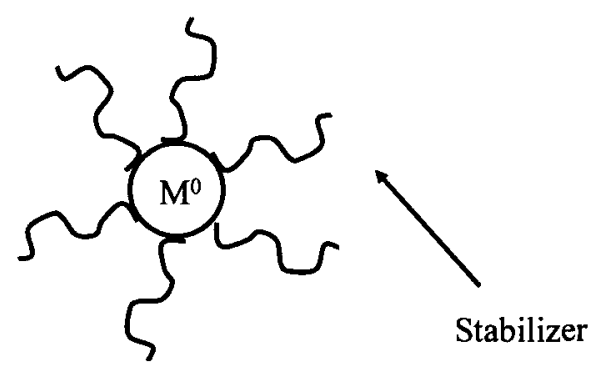

Alloys:

$$
\mathrm{M}^{\mathrm{n}^{+}} \frac{\text { Reduction }}{\text { Stabilizer }}
$$

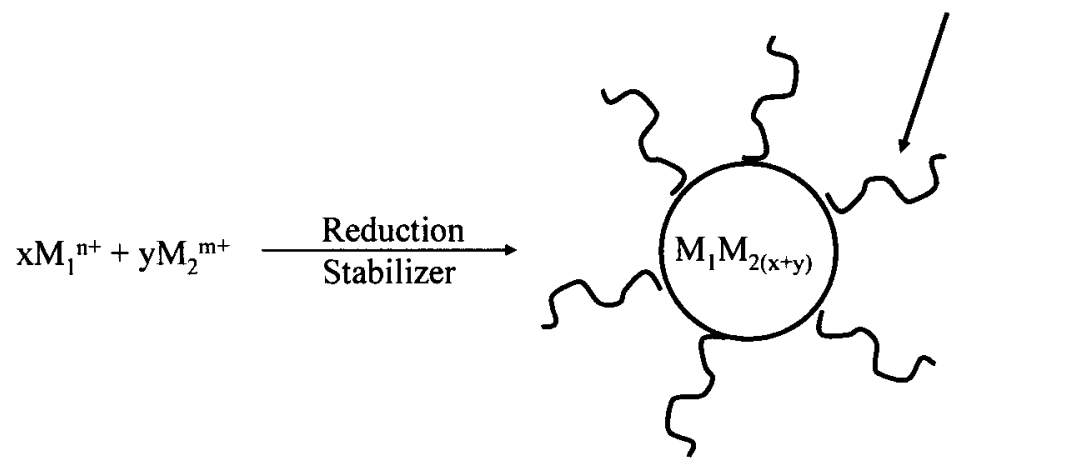

Galvanic exchange:

$$
\begin{aligned}
& M_{1} \text { red }+M_{2} \text { ox } \leftrightarrow \quad M_{1} \text { ox }+M_{1} M_{2} \text { alloy (alloying) } \\
& \mathrm{M}_{1} \mathrm{M}_{2} \text { alloy }+\mathrm{M}_{2} \text { ox } \leftrightarrow \mathrm{M}_{1} \text { ox }+\mathrm{M}_{2} \text { red (dealloying) } \\
& \text { M1 red }+ \text { M2 ox } \leftrightarrow \text { M1 ox }+ \text { M2 red } \\
& \text { (complete } \\
& \text { oxidation/reduction } \\
& \text { reaction) }
\end{aligned}
$$

Figure 1.5. Typical ways of synthesizing metallic or multi-metallic nanoparticles. 
where $\mathrm{E}_{\text {cell }}^{0}=\mathrm{E}_{\text {cathode }}^{0}-\mathrm{E}_{\text {anode }}^{0}=0.34-(-0.76)=1.10 \mathrm{~V}$. A positive value indicates that the reaction will happen spontaneously and the voltage which would be generated if all species were at standard conditions. The equilibrium constant of the reaction is given by

$$
K=K_{e q}=\frac{\left[\mathrm{Zn}^{2+}\right]}{\left[\mathrm{Cu}^{2+}\right]}
$$

$\mathrm{K}_{\mathrm{eq}}$ can be calculated from the standard cell potential, $\mathrm{E}_{\text {cell, }}^{0}$ as follows:

$$
E_{\text {cell }}^{0}=\frac{0.0592 \times \log K_{e q}}{n}
$$

where $\mathrm{n}$ is number of electrons, $\mathrm{K}_{\mathrm{eq}}$ is $1.4 \times 10^{37}$ in this case, showing that it is highly favored and should occur spontaneously. The process of galvanic exchange can be controlled and stopped at a desired time or the metals can be combined in a certain ratio to obtain a desired composition of the final metallic alloy nanostructure. In the case of nanostructures, the morphology of the final exchanged product is often unique and not easily synthesized by direct metal ion reduction methods.

Xia and co-workers titrated previously silver nanowires with gold salt solution to obtain unique metal nanotubes with two or three coaxial walls made of AuAg alloy. ${ }^{38}$ The reaction of cubic $\mathrm{Ag}$ nanostructures with $\mathrm{HAuCl}_{4}$ led to the formation of cubic $\mathrm{Au}$ nanocages. ${ }^{39}$ In similar fashion, $\mathrm{Ag}$ or $\mathrm{AgAu}$ alloys treated with $\mathrm{AuCl}_{4}{ }^{-}, \mathrm{PtCl}_{4}{ }^{2-}$, or $\mathrm{PdCl}_{4}{ }^{2-}$ salts led to the formation of nanorattles, nanoshells, nanocubes, nanocages, nanoboxes, and nanoframes. ${ }^{38-42}$ Galvanic exchange of Pd nanowires with Au salt lead to the formation of tadpole-like structures consisting of a Au head and Pd tail formed. ${ }^{40}$ Our group previously synthesized Ag NRs/NWs and formed hollow Pd nanotubes and $\mathrm{Au} / \mathrm{Pd}$ 
core/shell nanostructures using galvanic replacement reactions directly on surfaces. ${ }^{7}$ Others used galvanic replacement reactions to form nanoporous $\mathrm{Cu}-\mathrm{Ni}$ films, ${ }^{43}$ hollow metallic or bimetallic urchin-like Pt or Pd nanostructures, ${ }^{44,45}$ Pt nanofibers and nanotubes, ${ }^{44} \mathrm{Pt}$ coated nanoporous Au nanorods, ${ }^{46} \mathrm{Pd}$-Au nanostructures, ${ }^{47} \mathrm{Ag}$-Au bimetals, ${ }^{42,48}$ hollow $\mathrm{Pt}$ and $\mathrm{Au}$ nanoshells, ${ }^{49,50}$ nanotaper- $\mathrm{ZnO}^{51}$ tubes or superhydrophobic Ag-coated films on a copper surface. ${ }^{52,53}$ Table 1.1 lists a number of nanostructures synthesized by galvanic exchange reported in the literature.

By using galvanic exchange, many of the structures mentioned above and in Table 1.1 exhibit unique and tunable properties ${ }^{54,55}$ not accessible by other synthesis methods. This can lead to new applications. For example, during the galvanic exchange process with the addition of $\mathrm{HAuCl}_{4}$, the composition of $\mathrm{Ag}$ nanoboxes changed and the resulting nanocages showed very different optical properties. ${ }^{39}$ Also, Xia and co-workers showed that galvanically-exchanged metal nanostructures can be used to tune the metal optical properties in the near-IR region where human tissue has the highest transmission for applications in tumor treatment. ${ }^{56}$ Other nanostructures obtained through galvanic exchange showed applications in surface-enhanced Raman spectroscopy (SERS), 38, 39, 42, ${ }^{57,58}$ possible use as catalysts, ${ }^{59-61}$ or as hydrogen sensors. ${ }^{40,41}$

\subsection{Galvanic exchange mechanism.}

The mechanism of the galvanic replacement reaction between $\mathrm{Ag}$ and $\mathrm{HAuCl}_{4}$ was studied by Xia and co-workers on Ag NRs, nanoboxes and twinned nanoparticles. Silver nanostructures suspended in solution can be oxidized according to the following replacement reaction:

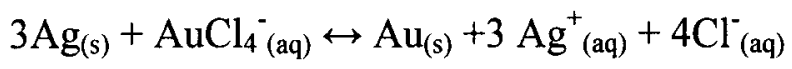




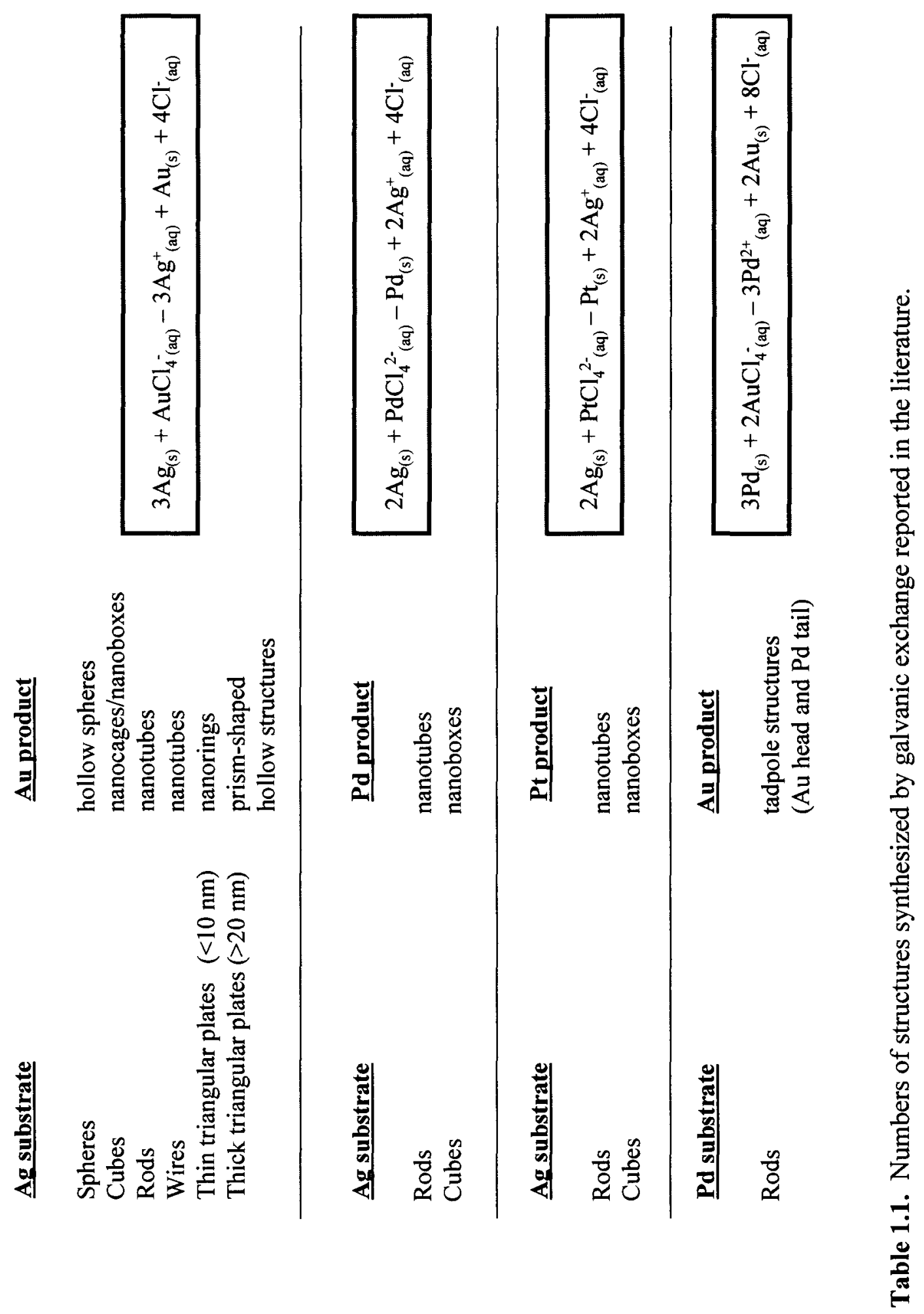


There is also a secondary equilibrium reaction associated with the solubility of $\mathrm{AgCl}_{(\mathrm{s})}$

$$
3 \mathrm{Ag}_{(\mathrm{aq})}^{+}+4 \mathrm{Cl}_{(\mathrm{aq})}^{-} \leftrightarrow \mathrm{AgCl}_{(\mathrm{s})}+\mathrm{Cl}^{-}
$$

The elemental Au produced in this reaction is confined to the $\mathrm{Ag}$ (template) surface. It nucleates and grows into very small particles and eventually evolves into a thin shell around the silver template. At room temperature the surface of the shell is rough showing cracks and openings. Increasing the reaction temperature to $100^{\circ} \mathrm{C} \mathrm{Xia} \mathrm{and} \mathrm{co-workers}$ showed that the shell becomes highly crystalline and smoother compared to the room temperature results. ${ }^{62}$ The roughness of the Au shell over the silver template is partly because of $\mathrm{AgCl}$ contamination. Increasing the temperature to $100^{\circ} \mathrm{C}$, and thus improving the solubility of $\mathrm{AgCl}$, prevents $\mathrm{Au}$ shells from being contaminated by $\mathrm{AgCl}$. A higher temperature also leads to greater metal atom mobility, resulting in a smoothing of the surface.

Figure 1.6 shows a schematic illustration of the mechanism of galvanic exchange between $\mathrm{Ag}$ nanoparticles and $\mathrm{Au}$. The Au nucleates on the surface of the $\mathrm{Ag}$ nanostructure. This reaction is believed to initiate at high energy surface defect sites and expand/proceed to ones with lower energy. Facets are flat faces on geometric shapes. As the reaction proceeds, $\mathrm{Au}$ forms a pinhole-free shell of $\mathrm{Ag} / \mathrm{Au}$ alloy through galvanic replacement, alloying, and Ostwald ripening. Ostwald ripening is a spontaneous process between smaller and bigger particles. Large particles grow at the expense of small ones. Larger particles, with lower surface to volume ratio, have lower energy than the small particles. As the whole system tends to obtain lowest possible energy, atoms on the surface of small particles (energetically unfavorable) will diffuse and add to the big 


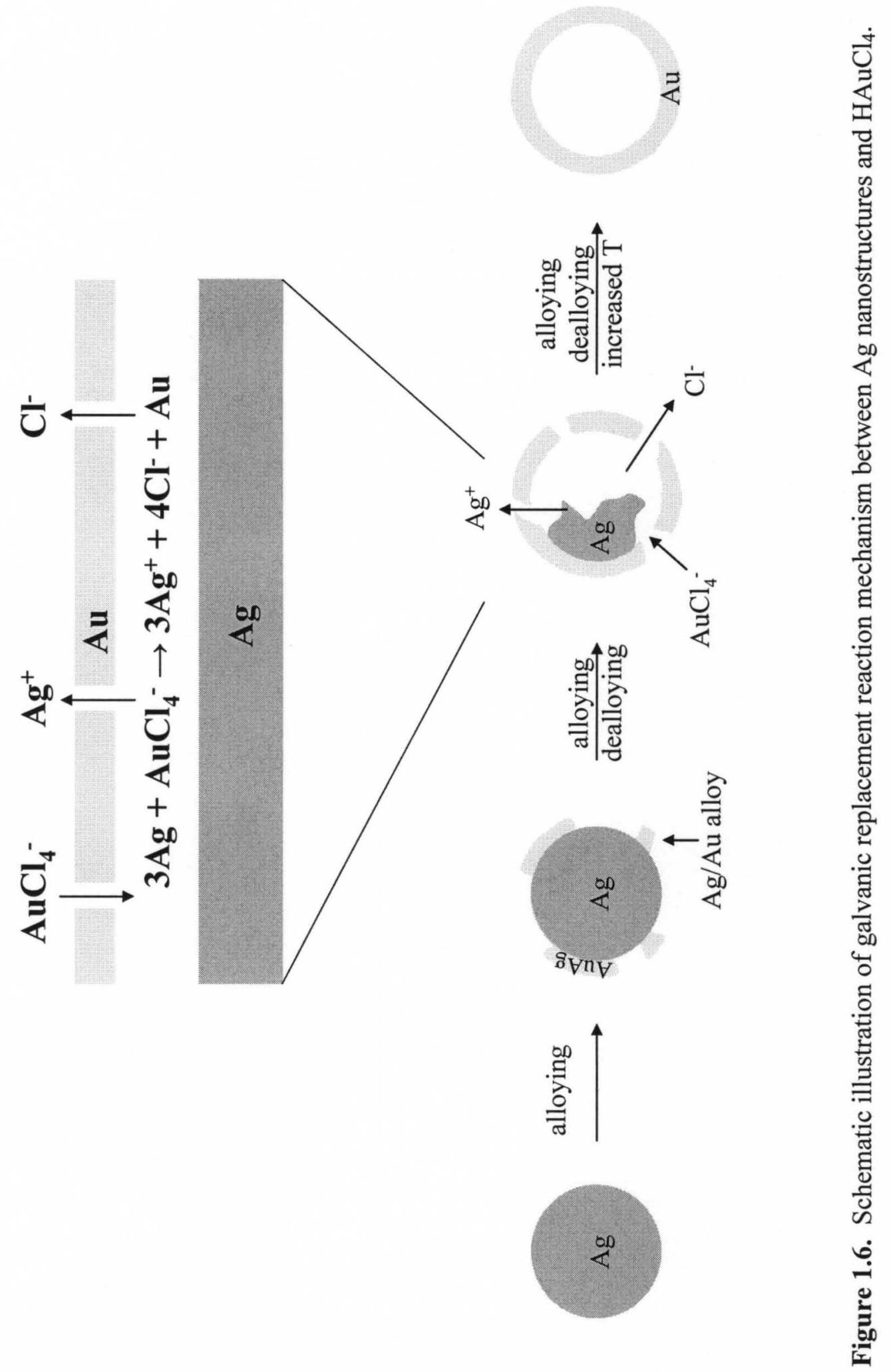


particles making bigger particles grow and smaller ones shrink. In the second step, cavities or holes in the shell start to form through a dealloying process in which $\mathrm{Ag}$ atoms are extracted from the alloyed walls. Both processes continue (alloying and dealloying) at high temperatures to allow the Au shell to restructure into a highly crystalline structure with the shape resembling the shape of the original $\mathrm{Ag}$ nanoparticle or nanowire, although it is a hollow Au nanoshell or nanotube. The mechanism described in Figure 1.6 was performed by Tunneling Electron Microscopy (TEM) imaging for different samples at various stages of the reaction. This study was limited to $\mathrm{Ag}$ and $\mathrm{Au}$ and the galvanic exchange process occurred in the presence of polyvinylpyrrolidone (PVP).

\subsection{Applications of $1 D$ nanostructures.}

The fact that properties drastically change for materials in the nanosize regime in comparison to bulk materials has attracted the interest of researchers. The "new" properties of nanostructures give many opportunities for the use of nanostructures in new applications. These properties are connected with reduced size and higher surface area, as well as with material behavior on the nanoscale. Also, the study of 1D nanostructures is important because of their possible future use in nanodevices. Some potential applications of metal NRs/NWs are discussed below.

One use for ID nanostructures is metal enhanced fluorescence. This topic has gained the interest of many research groups. For instance, Geddes and co-workers applied the simple seed-mediated growth on glass surfaces to receive 50 -fold enhancement in emission intensity for protein-immobilized indocyanine green. ${ }^{34}$ Similar research by Goldys and co-workers showed that $\mathrm{Au} / \mathrm{Ag}$ core/shell nanostructures can also enhance fluorescence. ${ }^{63}$ Other methods for metal induced fluorescence enhancement are based on nanostructures deposited on surfaces, 
forming random $\mathrm{Ag}$ island films ( $\mathrm{SiFs}$ ). The main disadvantage of films is the big dispersity in size and distance between structures which leads to different enhancement factors. The method proposed by Geddes and Goldys gives better uniformity in nanostructures on the surface and thus better fluorescence enhancement.

Surface enhanced Raman spectroscopy (SERS) is another major application for $\mathrm{Au}$ and $\mathrm{Ag}$ nanostructures. In this technique, the Raman effect (inelastic scattering of photons) is enhanced due to it close proximity to a rough, or highlycurved, metal surface. The molecules near metals like Au or Ag exhibit Raman scattering signals enhanced typically $10^{4}-10^{6}$ fold, but as large as $10^{14}$ enhancement. The enhancement of the Raman signal is from the electromagnetic field of an optically active nanostructure. The chemical enhancement of the Raman signal comes from charge transfer between nanostructures and adsorbed molecules. The other type of enhancement is electromagnetic enhancement (EME) which depends mainly on the roughness, shape, and geometry of the metal surface of the nanostructure that the molecules are adsorbed to. Yang and co-workers used the Langmuir-Blodget technique to assemble monolayers of aligned $\mathrm{Ag}$ nanorods and nanowires, and showed $10^{5}$ enhancement for thiol and dinitrotoluene, and $10^{9}$ for Rhodamine $6 \mathrm{G}^{64}$ Another application of 1D nanostructures is for sensing applications. For example, Penner's group showed that electrochemically prepared Ag NWs have a reversible resistance-change upon exposure to ammonia vapors. ${ }^{65}$ During the exposure to ammonia vapor, the resistance of $\mathrm{Ag}$ wires increased in a reversible process. On the other hand, during exposure to vapors of strong acids, such as $\mathrm{HCl}$ or $\mathrm{HNO}_{3}$, the resistance dropped irreversibly.

Pd NWs grown by electrodeposition have been used as a hydrogen sensor and hydrogen-actuated switches. ${ }^{4}$ The Pd structures were deposited on highly oriented 
pyrolityc graphite and then transferred to a glass surface. These wires exhibit nanoscale cracks and gaps called "break junctions", leading to an open circuit (little current flow) with a total resistance of $>30 \mathrm{M} \Omega$. The wires were exposed to hydrogen, which led to an increase in current. The resistance of the circuit drops due to formation of $\mathrm{PdH}_{\mathrm{x}}$ which expands in volume and connects the "break junctions". The process is fully reversible and in the absence of hydrogen the resistance of the circuit increases again. ${ }^{26}$

\subsection{Summary and Accomplishments.}

Chapter III describes the exchange of surface-grown Ag NRs/NWs with aqueous $\mathrm{PdCl}_{4}{ }^{2-}$ solutions as a function of $\mathrm{PdCl}_{4}{ }^{2-}$ concentration. This provides information on the effect of exchange rate on the morphology of the exchanged structures and we also describe an electrochemical method to determine the AgPd composition as a function of exchange time. Chapter IV focuses on the effect of additives ( $\mathrm{CTAB}$ and $\mathrm{KBr}$ ) on the galvanic replacement reaction. The following systems were studied:

- Growth of Ag nanostructures directly on surfaces.

- Galvanic exchange of $\mathrm{Ag} \mathrm{NRs/NWs} \mathrm{in} \mathrm{aqueous} \mathrm{PdCl}_{4}{ }^{2-}$ solutions.

- Galvanic exchange of $\mathrm{Ag} \mathrm{NRs/NWs} \mathrm{in} \mathrm{PdCl}_{4}{ }^{2-}$ plus $0.1 \mathrm{M} \mathrm{CTAB}$ or $0.1 \mathrm{M}$ $\mathrm{KBr}$.

This work shows that the galvanic exchange rate and the presence of additives have an effect on the nanostructure morphology.

Chapter V describes electrochemical seed-mediated growth on electrode surfaces. In this chapter we compare the morphology of Ag nanostructures electrodeposited from a solution containing $2.5 \times 10^{-4} \mathrm{M} \mathrm{AgNO}_{3}$ and $0.08 \mathrm{M}$ cetyltrimethylammonium 
bromide (CTAB) onto Au-nanoparticle (NP)-seeded mercaptopropyltrimethoxysilane (MPTMS)-functionalized glass/indium tin oxide (glass/ITO) electrodes as a function of the electrode potential. This work shows that by varying applied potential we can change the morphology of nanostructures.

Chapter VI describes the synthesis of heterostructures of graphene and Au and $\mathrm{Ag}$ nanostructures and the surface enhanced Raman scattering properties. Thin graphene sheets are attached to amine-functionalized $\mathrm{Si} / \mathrm{SiO}_{\mathrm{x}}$ substrates, and $\mathrm{Au}$ monolayer protected clusters (MPCs) are attached to the graphene surface through hyfrophobic interactions. Seed-mediated growth procedure leads to the growth of larger nanostructures directly on graphene sheets. Thin graphene sheets decorated with $\mathrm{Au}$ or Ag nanostructures show 50 to 150 fold enhancements of Raman spectra, respectively. 


\section{CHAPTER II}

\section{EXPERIMENTAL}

Figure 2.1 shows our procedures for synthesizing various metal nanostructures directly on surfaces, including $\mathrm{Ag}$ NRs/NWs followed by galvanic exchange, $\mathrm{Ag}$ nanostructures by electrochemical seeded growth and grapheme/Au or grapheme/Ag heterostructures. This chapter describes the substrates, substrate functionalization, seed synthesis and deposition, $\mathrm{Ag}$ growth, and galvanic exchange of $\mathrm{Ag}$ NRs/NWs with $\mathrm{PdCl}_{4}{ }^{2-}$ at various concentrations and in various environments. In this work we focus on the synthesis of Ag NRs/ NWs structures and galvanic exchange reaction as a function of rate and additives (CTAB, $\mathrm{KBr}$ ). All these steps will be described in details in the following sections.

\subsection{Substrates}

\section{Glass microscope slides}

Corning plain micro slides (Corning Glass Works, Scientific Glassware Dept.) were used to grow metal nanostructures for UV-Vis characterization. Micro Slides were cut with a diamond pen into $25 \times 10 \mathrm{~mm}$ slices to fit the UV-Vis instrument. After cutting, the slides were cleaned with piranha solution, rinsed with nanopure $\mathrm{H}_{2} \mathrm{O}$, and dried under a stream of $\mathrm{N}_{2}$ and used in experiments. The piranha solution is a mixture of $30 \% \mathrm{H}_{2} \mathrm{O}_{2}$ and sulfuric acid in 1:3 ratio and is very effective at removing organic impurities from the glass substrates used in our experiments. The glass slides were used to grow silver nanostructures directly on surfaces using the seed-mediated 


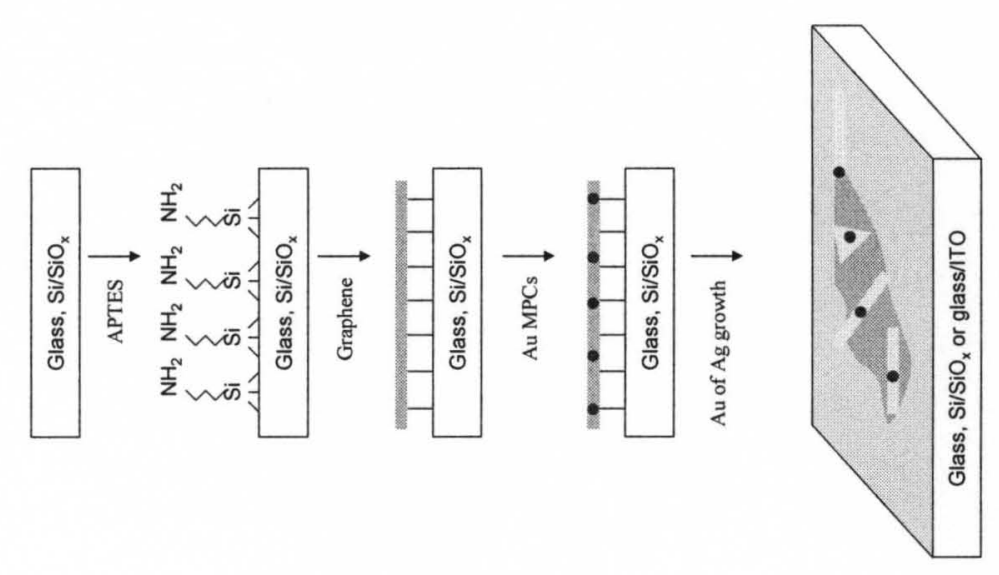

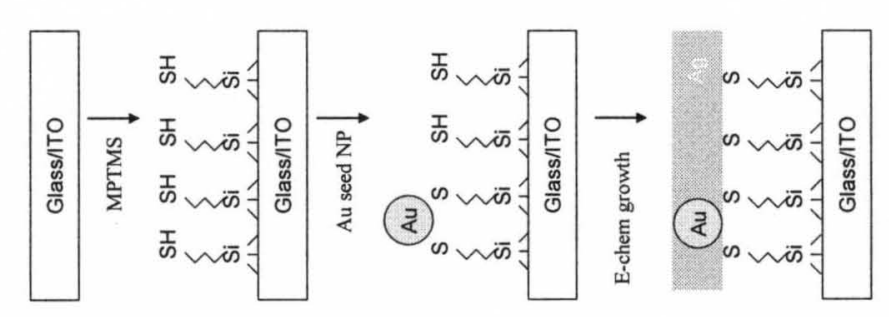



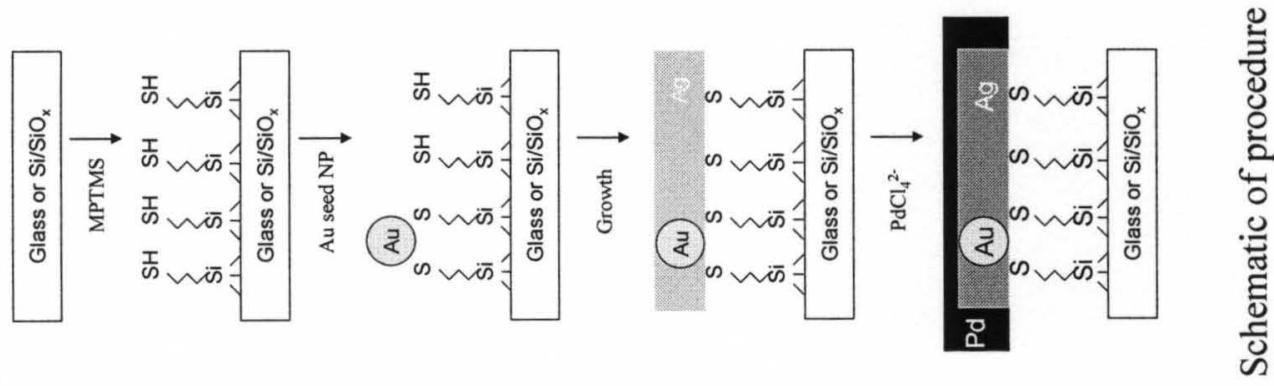

范 
growth procedure, which is explained in later sections. After this growth procedure, the Ag coated glass slides were place exchanged with other metals and analyzed by UV-Vis spectroscopy. All of these techniques are described in later sections.

\section{Silicon}

Silicon with a native oxide layer $\left(\mathrm{Si} / \mathrm{SiO}_{\mathrm{x}}\right)$ was used for characterization by Scanning Electron Microscopy (SEM) and Raman Spectroscopy. A p-type $<100>$ silicon wafer (purchased from Silicon Quest International, CA) was cut with a diamond pen into smaller, approximately, $5 \times 5 \mathrm{~mm}$ pieces. Next, every piece was cleaned with piranha solution, rinsed with nanopure $\mathrm{H}_{2} \mathrm{O}$, and dried under a stream of $\mathrm{N}_{2}$ prior to use. The clean silicon slides were used as substrates to 1) grow $\mathrm{Ag}$ nanostructures and study galvanic exchange, and 2) deposit graphene and grow $\mathrm{Au}$ and $\mathrm{Ag}$ nanostructures on the graphene.

\section{Indium Tin Oxide (ITO)}

Indium tin oxide coated glass electrodes (Glass/ITO) with resistivity of $8-12 \Omega$ were cut into approximately $7 \times 25 \mathrm{~mm}$ pieces. These pieces were then cleaned by sonication in acetone, isopropanol, ethanol, and water for 15 minutes in each solvent. Next, each piece was rinsed with nanopure $\mathrm{H}_{2} \mathrm{O}$ and dried under a stream of $\mathrm{N}_{2}$. Glass/ITO slides were used as substrates to grow metal nanostructures, perform exchange, analyze by electrochemical stripping Voltammetry and for electrochemical seed-mediated growth of $\mathrm{Ag}$ nanostructures.

Preparation of glass, silicon or ITO surface for growth procedure.

The glass, silicon or ITO substrates were functionalized by heating for $30 \mathrm{~min}$ in a solution containing $10 \mathrm{~mL}$ of 2-propanol, $100 \mu \mathrm{L}$ of mercaptopropyltrimethoxysilane 
(MPTMS) and 4 to 5 drops of nanopure water. In this step, the surface hydroxyl $(-\mathrm{OH})$ groups of glass or silicon react with the methoxy $\left(-\mathrm{O}-\mathrm{CH}_{3}\right)$ groups of MPTMS covalently to form a monolayer. Glass/MPTMS, $\mathrm{Si}_{\mathrm{SiO}} / \mathrm{MPTMS}$ or ITO/MPTMS substrates were then placed directly in an aqueous solution of 3-5 nm Au NP seed for 20 min. Au NP seeds strongly attach to the SH- groups of MPTMS. The functionalized glass, $\mathrm{Si} / \mathrm{SiO}_{\mathrm{x}}$ or ITO/MPTMS/Au NP slide was removed, rinsed with water, dried with $\mathrm{N}_{2}$ and placed in the $\mathrm{Ag}$ growth solution at $28{ }^{\circ} \mathrm{C}$ for 30 minutes. The substrate surface was functionalized with aminopropyltriethoxysilane (APTES) similarly, which produces an amine terminated surface, for studies involving graphene deposition, $\mathrm{C}_{6} \mathrm{~S}$ Au MPC seed attachment to graphene, and growth of $\mathrm{Au}$ and $\mathrm{Ag}$ nanostructures. The chemically functionalized glass or $\mathrm{Si} / \mathrm{SiO}_{\mathrm{x}}$ substrates are schematically illustrated in Figure 2.2.

\subsection{Solutions}

\section{Piranha solution}

Piranha solution is commonly used for removing organic residues from substrates, particularly in microfabrication laboratories. The regularly prepared piranha solution is a 3:1 mixture of sulfuric acid and $30 \%$ hydrogen peroxide $\left(\mathrm{H}_{2} \mathrm{O}_{2}\right)$. The solution may be prepared before place the sample into it or by placing the sample in a beaker and then adding piranha by adding hydrogen peroxide first followed by sulfuric acid. During the cleaning procedure and disposal one should be cautious about keeping organic solvents out of piranha solution since it reacts violently with organics. Piranha solution was used to clean glass and silicon substrates. All operations were performed under a hood. Substrates were kept in piranha solution for 10-15 min. Next, substrates were rinsed with 

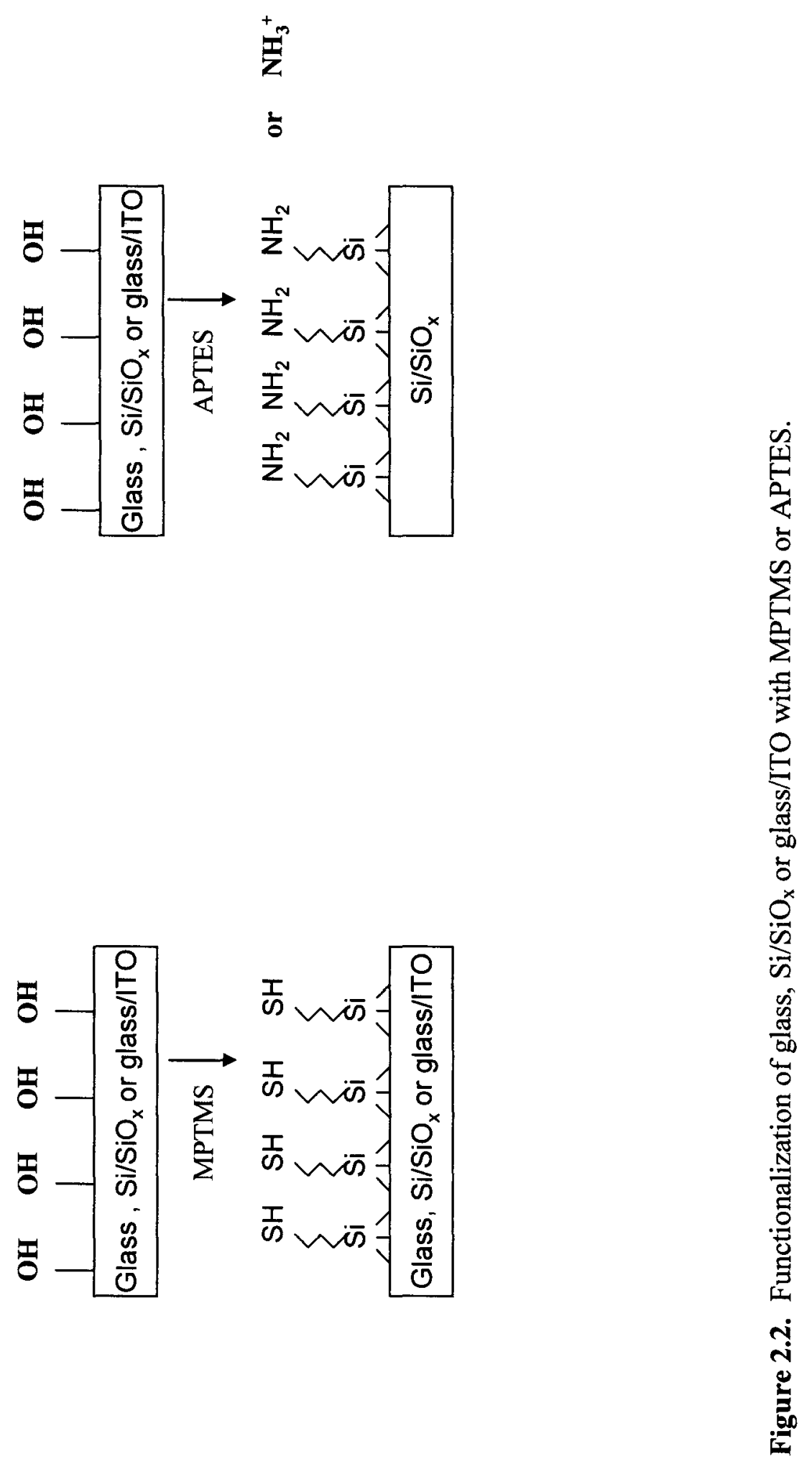

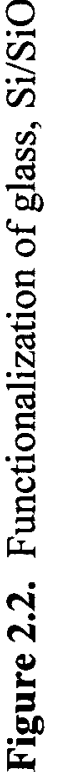


nanopure $\mathrm{H}_{2} \mathrm{O}$ for several minutes, rinsed with isopropyl alcohol (IPA) and dried under a stream of $\mathrm{N}_{2}$.

\section{Gold nanoparticle (Au NP) seed synthesis}

We used the procedure of Murphy and co-workers to prepare 3-5 nm diameter Au seed particles. ${ }^{13}$ Au seeds were used in our experiments as a nucleation point for the growth of several metals such as Au or Ag. The preparation of seed solution involves preparing $0.01 \mathrm{M}$ trisodium citrate salt and $\mathrm{HAuCl}_{4}$ solutions, and $0.1 \mathrm{M}$ sodium borohydride solution. Hydrogen tetrachloroaurate trihydrate $\left(\mathrm{HAuCl}_{4} \cdot 3 \mathrm{H}_{2} \mathrm{O}\right)$ was synthesized in lab according to a literature procedure. ${ }^{66}$ Trisodium citrate was used as received from Fisher Scientific Company. To $18.4 \mathrm{~mL}$ of nanopure $\mathrm{H}_{2} \mathrm{O}$, $0.5 \mathrm{~mL}$ of trisodium citrate and $0.5 \mathrm{~mL}$ of $\mathrm{HAuCl}_{4}$ were added in that order, making the solution turns pale yellow. The solution was vigorously stirred throughout the whole process. Next, $0.6 \mathrm{~mL}$ of ice cold $\mathrm{BH}_{4}{ }^{-}$solution was added, during which time the whole solution immediately turned red, indicating the formation of Au seed particles. The final concentration in a $20 \mathrm{~mL}$ vial was $2.5 \times 10^{-4} \mathrm{M} \mathrm{HAuCl}_{4}$ and $2.5 \times 10^{-4} \mathrm{M}$ trisodium citrate. Citrate serves as a capping agent to stabilize the particles by electrostatic repulsion, which prevents aggregation. The particles in this solution were used as the Au seed solution in the following section within $2-5$ hours after preparation. The average particle size was $3-5 \mathrm{~nm}$ according to literature ${ }^{13}$ and our previous work. ${ }^{9}$

\section{Au monolayer - protected cluster (MPC) Seeds}

Hexanethiolate (C6S)-coated Au MPCs were synthesized according to the Brust reaction. ${ }^{67}$ Briefly, $2.40 \mathrm{~g}$ of $\mathrm{HAuCl}_{4}$ were dissolved in $25 \mathrm{~mL}$ of water. To $\mathrm{HAuCl}_{4}$ solution, $4.89 \mathrm{~g}$ of tetra-n-octylammonium bromide dissolved in $150 \mathrm{~mL}$ of toluene was 
added. The solutions were mixed under constant stirring until all of the $\mathrm{AuCl}_{4}{ }^{-}$ transferred into the toluene phase. Organic phase was then separated from aqueous and $2.60 \mathrm{~mL}$ of hexanethiolate were added to the toluene phase and stirred until the solution became colorless. Ratio of hexanethiolate to Au was 3:1. The solution was then cooled to $\sim 0^{\circ} \mathrm{C}$, and a 10 -fold excess of $\mathrm{NaBH}_{4}(2.30 \mathrm{~g}$ in $10 \mathrm{~mL}$ of water $)$ was added to the solution and stirred. The solution turned black indicating the formation of Au MPCs. An additional $10 \mathrm{~mL}$ of water was added and the solution was stirred overnight. The toluene was removed by rotary evaporation and the solid powder was collected on a Buchner funnel and washed thoroughly with acetonitrille to remove side products and other impurities. These Au MPCs have an average diameter of $1.6 \mathrm{~nm}$ according to literature. ${ }^{67}$ The Au MPCs were used as seeds for the synthesis of $\mathrm{Au}$ and $\mathrm{Ag}$ NRs/NWs on graphene.

\section{Ag growth solution}

For the synthesis of $\mathrm{Ag}$ nanostructures on glass, silicon or graphene, $0.29 \mathrm{~g}$ $\left(8 \times 10^{-4} \mathrm{~mol}\right)$ of CTAB was first dissolved by sonication (Branson, Connecticut, Model 8510 ) in $10 \mathrm{~mL}$ of $\mathrm{pH} 10.6$ phosphate buffer leading to a $\sim 0.08 \mathrm{M}$ CTAB solution. The composition of phosphate buffer solutions was adapted from G .D. Christian and W. C. Purdy. ${ }^{68}$ The buffer solution has an ionic strength of $0.2 \mathrm{M}$. Next, $0.25 \mathrm{~mL}$ of $0.01 \mathrm{M}$ $\mathrm{AgNO}_{3}$, and $0.50 \mathrm{~mL}$ of freshly prepared $0.1 \mathrm{M}$ ascorbic acid solutions were added in that order. Seed-coated glass, $\mathrm{Si} / \mathrm{SiO}_{\mathrm{x}}$ or graphene were placed in this solution to grow $\mathrm{Ag}$ nanostructures.

The growth solution remained colorless through the entire growth procedure indicating that reduction of $\mathrm{Ag}^{+}$to metallic $\mathrm{Ag}^{0}$ did not occur in solution to a significant extent. The time and temperature the substrate (containing Au seed particles) was 
immersed in growth solution was set to $30 \mathrm{~min}$ and $28^{\circ} \mathrm{C}$ in all experiments. The scheme of $\mathrm{Ag}$ nanostructures growth is shown in Figure 2.3. Figure 2.3 shows the steps needed during synthesis of silver nanostructures. The glass, silicon or ITO electrode substrate was functionalized with MPTMS (Figure 2.2), leaving the surface terminated with thiols. Because of the high affinity of sulfur to $\mathrm{Au}$ or $\mathrm{Ag}$, Au NP seeds bound well with thiol groups. The attached Au NP seed particles act as a nucleation site for growth of silver nanostructures. Figure 2.3 also shows that a variety of shapes form, including triangles, hexagons, rods, wires, and spheres. Figure 2.4 shows the typical SEM image of $\mathrm{Si} / \mathrm{SiO}_{\mathrm{x}} / \mathrm{MPTMS} / \mathrm{Au}$ seed/Ag NRs/NWs. Average coverage was calculated to be $26 \pm 17$ nanostructures per square micrometer. The length of $\mathrm{Ag}$ NRs/NWs varied from tens of $\mathrm{nm}$ to more than $10 \mu \mathrm{m}$ with a yield of $\sim 4 \%$. Average diameter is $35 \pm 4 \mathrm{~nm}$.

\section{Au growth solution}

For the synthesis of $\mathrm{Au}$ nanostructures appropriate seed-coated substrates were placed into a growth solution containing $4.5 \times 10^{-4} \mathrm{M} \mathrm{HAuCl}_{4}, 0.1 \mathrm{M} \mathrm{CTAB}$, and $5.0 \mathrm{x}$ $10^{-4} \mathrm{M}$ ascorbic acid for one hour at $25^{\circ} \mathrm{C}$. The $\mathrm{pH}$ measured for the Au growth solution was 2.8. This led to the seed-mediated growth of the graphene-bound Au MPCs into Au nanoparticles (NPs), nanorods (NRs), and other shapes

\section{Galvanic exchange between $\mathrm{Ag}$ and Pd}

The surface-attached (glass or Si/SiOx or ITO)/MPTMS/Ag NWs were placed into aqueous $0.01,0.001,0.0001,0.000075,0.000050,0.000025$, or $0.000010 \mathrm{M} \mathrm{K}_{2} \mathrm{PdCl}_{4}$ solutions for time ranging from 0 to $3600 \mathrm{sec}$. After the desired time, samples were removed, rinsed with nanopure $\mathrm{H}_{2} \mathrm{O}$, dried under $\mathrm{N}_{2}$ and characterized by UV-Vis, SEM, and electrochemical stripping voltammetry. In a similar fashion, the surface-attached 


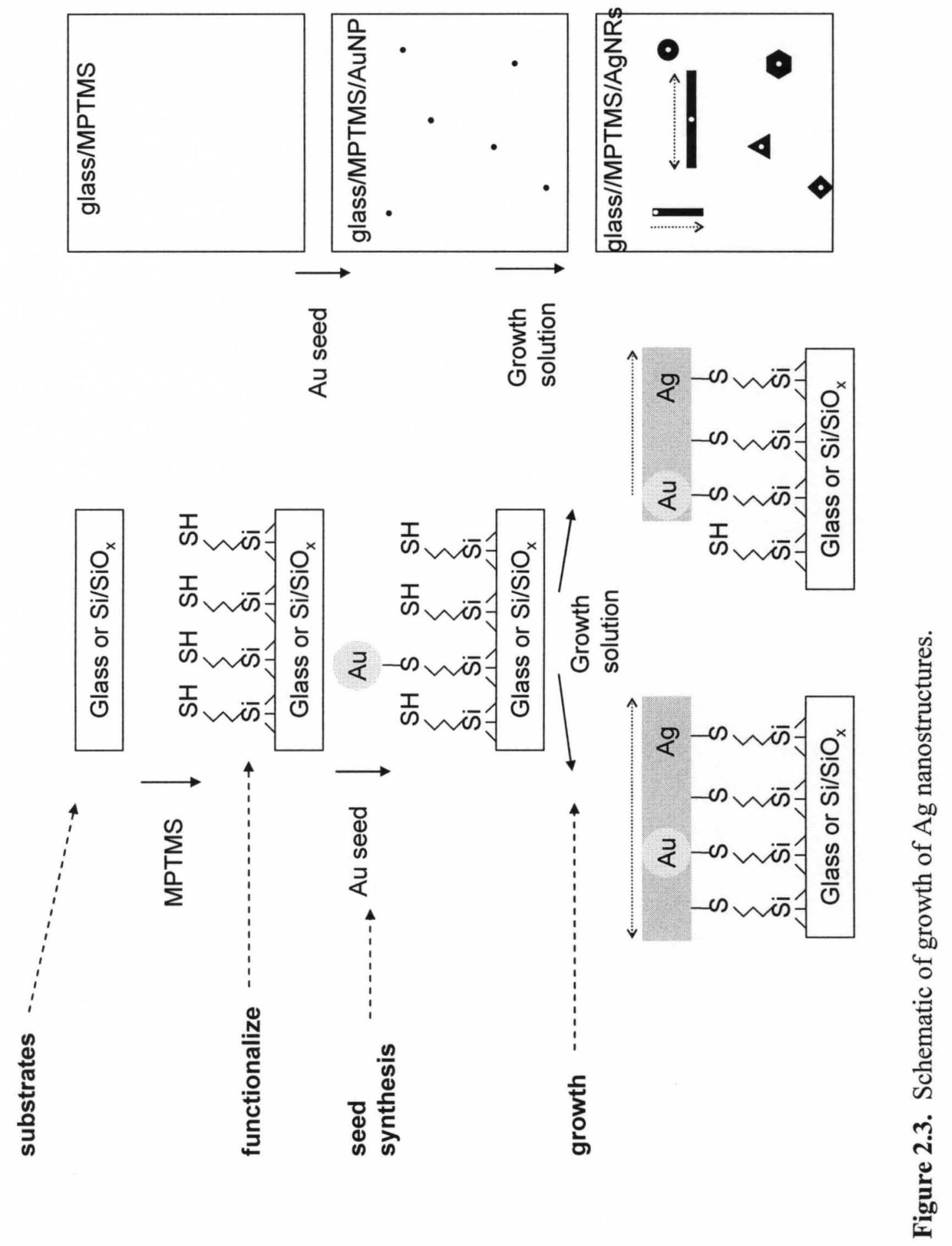




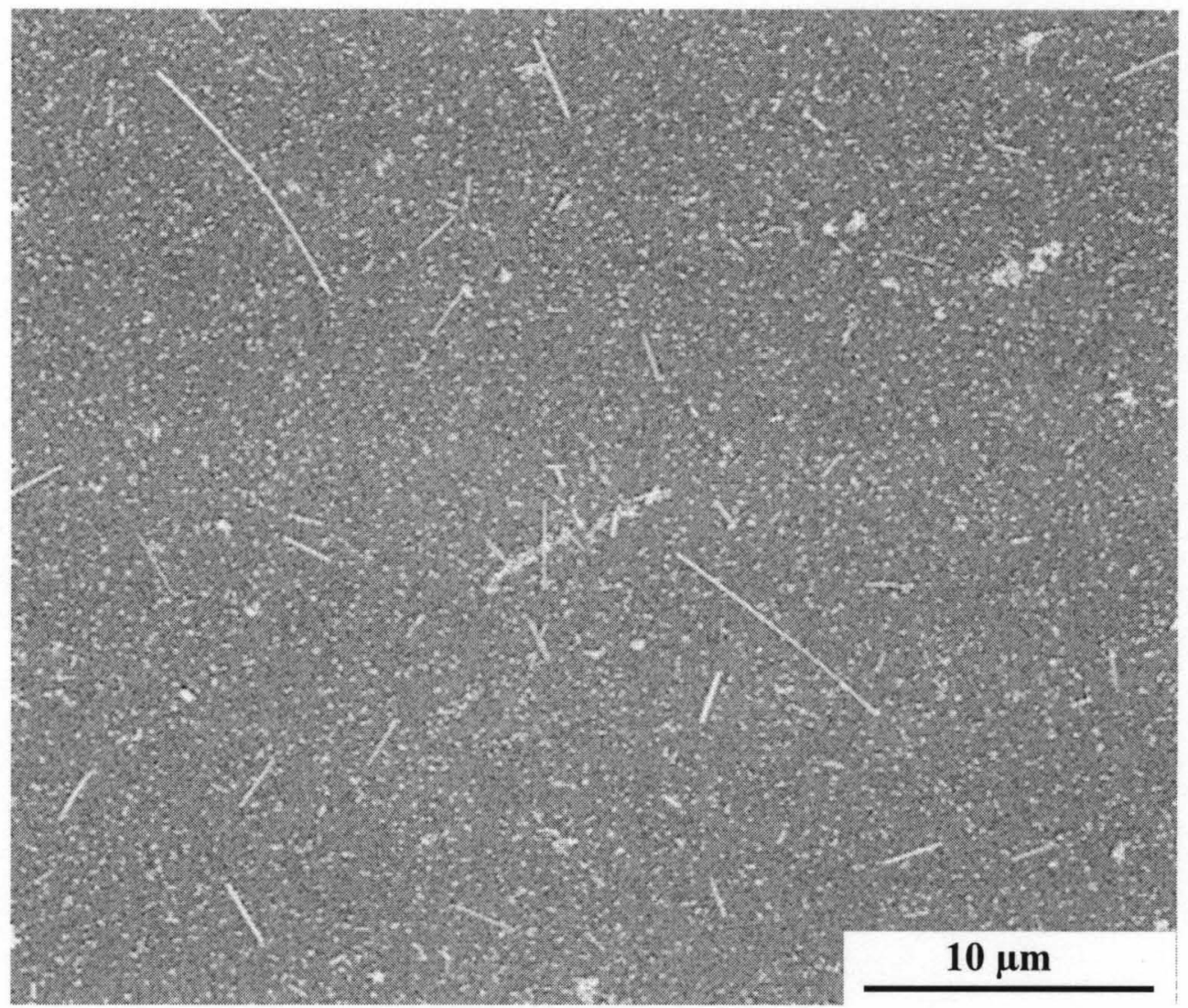

Figure 2.4. Typical SEM image of $\mathrm{Si}_{\mathrm{SiO}} / \mathrm{MPTMS} / \mathrm{Au}$ seed/Ag NRs/NWs sample. 
(glass or $\mathrm{Si} / \mathrm{SiOx}$ or ITO)/MPTMS/Ag NWs were placed into 0.01, 0.001, 0.0001, $0.000075,0.000050,0.000025$, or $0.000010 \mathrm{M} \mathrm{K}_{2} \mathrm{PdCl}_{4}$ solutions plus $0.1 \mathrm{M} \mathrm{CTAB}$ or $0.1 \mathrm{M} \mathrm{KBr}$ for times ranging from 0 to $3600 \mathrm{sec}$. At the desired time, samples were removed, rinsed with nanopure $\mathrm{H}_{2} \mathrm{O}$, dried under a stream of $\mathrm{N}_{2}$ and characterized by UV-Vis, SEM, and electrochemical stripping voltammetry.

\subsection{Characterization and Instrumentation}

\subsubsection{Scanning Electron Microscopy (SEM)}

Electron microscopy images were obtained at different magnifications using a Carl Zeiss SMT AG SUPRA 35VP field emission scanning electron microscope (FESEM) operating at an accelerating voltage of $20.00 \mathrm{kV}$ and using an in-lens ion annular secondary electron detector. Electron microscopes are scientific instruments that use a beam of highly energetic electrons to image and analyze objects with nanometerscale resolution. This can give information about topography, morphology, composition, and crystallographic information. Electron microscopes were developed due to the limitations of light microscopes which are limited by the wavelength which is typically $\sim 0.2$ micrometers. The first Scanning Electron Microscope (SEM) was developed in 1942 and commercially available around 1965.

The SEM uses electrons instead of light to create an image. The electron beam comes from a filament (electron gun), made of various types of materials (shown on Figure 2.5). The most common are the tungsten and lanthanum hexaboride filaments. The filament functions as the cathode. After applying a voltage to the filament it heats up. The anode, which in this case is positive with respect to the filament, forms powerful attractive forces for electrons. This causes electrons to accelerate toward the anode. 


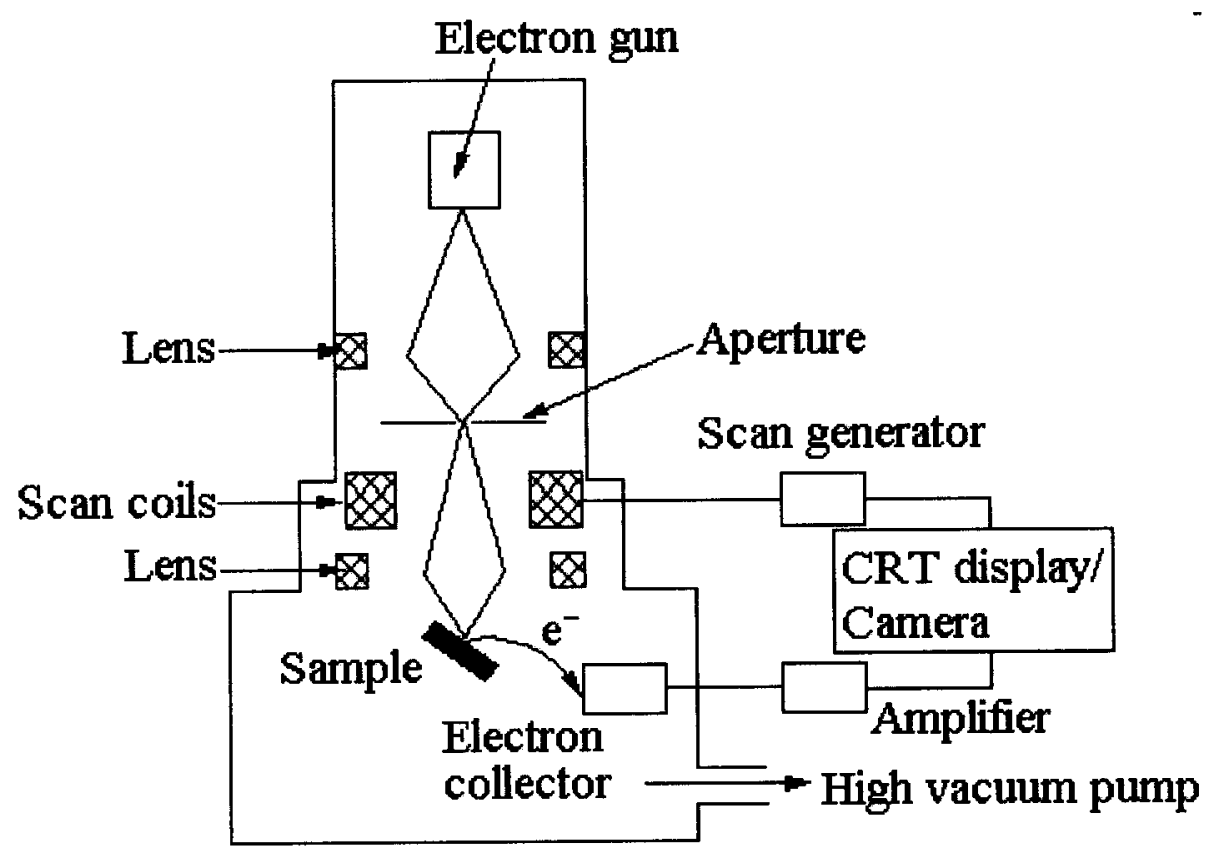

Figure 2.5. Schematic of SEM. (Adapted from reference 69) 
Some accelerate right by the anode and on down the column, to the sample. The energy of the beam of the electrons can be controlled within the range from few hundreds of electronvolts, [eV], to $\sim 100 \mathrm{keV}$. The beam that reaches the sample has a specific diameter. The diameter is controlled by the condenser lenses to give a beam with a focal spot from 1 to $5 \mathrm{~nm}$ depending on the instrument. The size of this beam determines the resolution of the SEM. After obtaining the desired beam size, the beam passes through pairs of scanning coils in the objective lens. Scanning coils deflect the beam horizontally and vertically so that it scans in a raster fashion over a rectangular area of the sample surface. The most common types of electrons used to obtain topographical information about the sample are secondary electrons (SE) and backscattered electrons(BSE) (as shown in Figure 2.6)

The secondary electrons (SE) with energies of $50 \mathrm{eV}$ or less are emitted from the sample after the sample is hit with the electron beam. Due to their low energy, these electrons originate within a few nanometers from the surface (50 to $500 \AA)$. The number of SEs is much smaller than the number of backscattered electrons. The backscattered electrons (BSE) consist of high-energy electrons originating from the electron beam. These electrons are called backscattered electrons because they come back out of the sample. When the electron beam strikes the sample some of the electrons will interact with the nucleus of the atom. The negatively-charged electron is attracted to the positive nucleus. With the correct angle, instead of being captured by the "gravitational pull" of the nucleus the electron will circle the nucleus and come back out of the sample without slowing down. The backscattered electrons move in straight lines because of their speed. With increasing size of the nuclei the number of BSE increases. This can be used to 


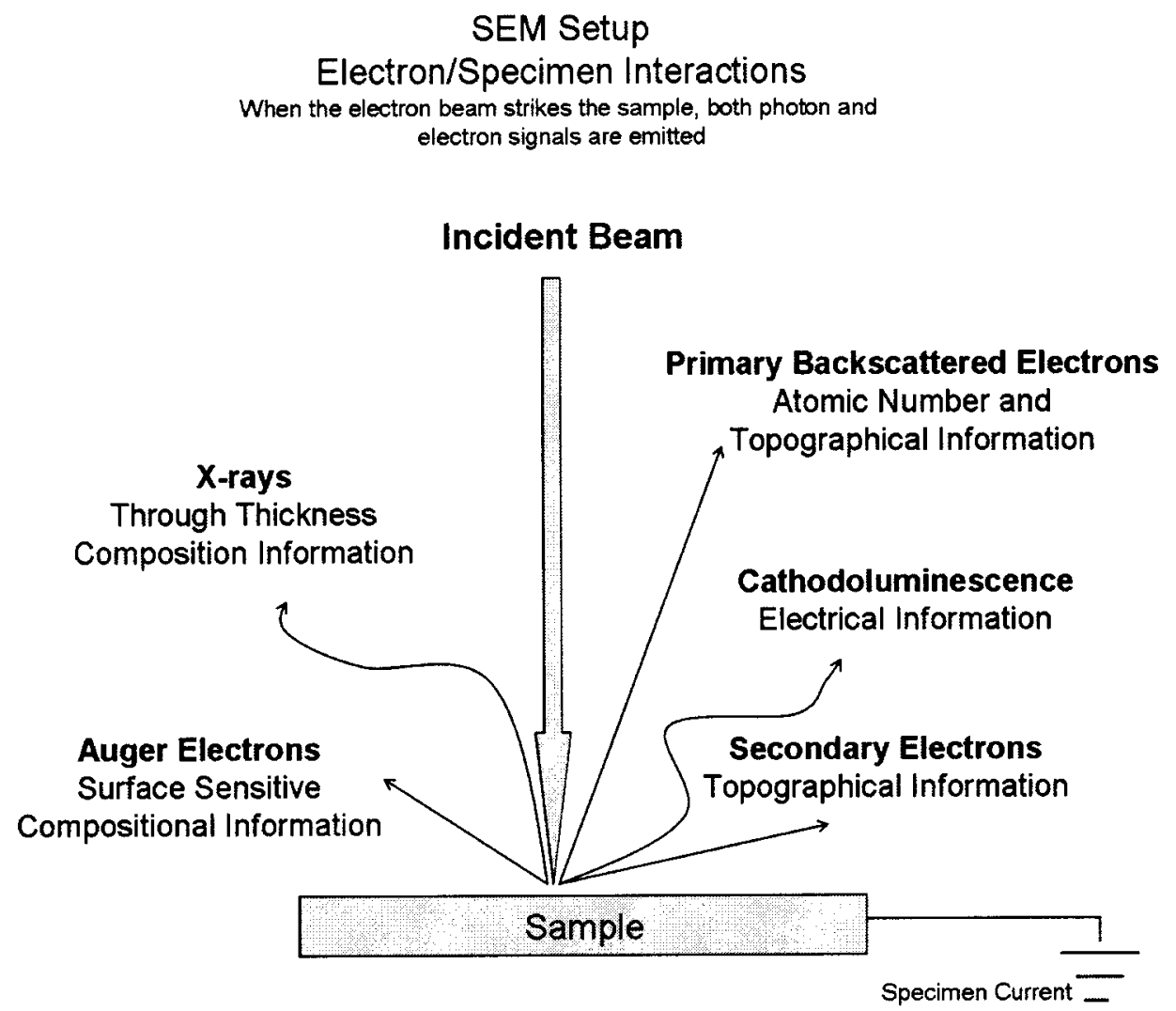

Figure 2.6. Electron beam/specimen interactions. (Adapted from reference 70) 
obtain an image that shows samples composed of different elements. The SEs are detected by a scintillator-photomultiplier device. The resulting signal is transformed into a two-dimensional intensity distribution that can be viewed on a TV screen. This process is based on a raster scan of the incident beam. The brightness of the signal depends on the number of secondary electrons reaching the detector. The BSE are usually detected with the Everhart-Thornley detector. The main component of the detector is a scintillator that emits photons when hit by high-energy electrons. The emitted photons are collected by a light guide and transported to a photomultiplier for detection. Two small drawbacks of SEM are that the scanning electron microscopy is limited to conductive or semiconductive samples and most of the instruments work under vacuum conditions.

\subsubsection{UV-Visible Spectroscopy and Localized Surface Plasmon Resonance}

UV-Vis spectroscopy data were obtained using a Varian Cary 50 Bio UV-Visible Spectrophotometer. Instruments for measuring the absorption of UV or visible radiation consist of a light source (UV and visible), wavelength selector (monochromator), sample container, detector, and signal processor and readout. For molecules, the absorbance of light in the ultraviolet-visible region corresponds to the excitation of electrons to higher energy electronic levels. Ultraviolet and visible light are energetic enough to promote outer electrons to higher energy levels.

$\mathrm{Au}$ or $\mathrm{Ag}$ nanostructures absorb strongly in the visible region due to the wellknown localized surface plasmon absorption. The excitation of conducting electrons of a metal by light is denoted as a surface plasmon for planar surfaces or localized surface plasmon for nanometer-sized metallic structures. Localized surface plasmon resonance (LSPR) occurs when the conduction band electron oscillation in the metallic 
nanoparticles is in resonance with the frequency of light. The electric field induces polarization of the electrons and creates a net charge difference on the nanostructure surface creating a dipolar oscillation of the electrons. If the frequency of the electromagnetic field is in resonance with the electron oscillation, strong absorption and scattering by the metal nanostructures occurs.

The LSPR band depends on the nanostructure shape and size and red shifts for larger structures. In the case of nanostructures for which one dimension is greater than the other, such as high aspect ratio NRs and NWs, the LSPR band splits into two peaks. The shorter wavelength band is called the transverse plasmon absorption band while the longer wavelength one is called the longitudinal band. The wavelength of the longitudinal band depends on the aspect ratio (AR, length divided by width) of nanostructures. The greater the AR, the greater the $\lambda_{\max }$ of the longitudinal band. The transverse band is produced by the oscillation of the electrons perpendicular to the major axis of the rods while the longitudinal band is caused by the oscillation of the electrons along the major axis of the NRs or NWs. Figure 2.7 shows the UV-Vis spectra of Au and Ag NPs and Au NRs attached to the glass substrate surface. Au NR sample shows two plasmon bands, transverse and longitudinal. Au NP sample shows only transverse band which is located at approximately $520 \mathrm{~nm}$. Ag NP sample also shows transverse band only which is located at approximately $400 \mathrm{~nm}$. The absence of longitudinal band in $\mathrm{Au}$ $\mathrm{NP}$ and Ag NP samples is due to low yield of NRs in those samples, $\sim 8 \%$ and $\sim 4 \%$ respectively. 


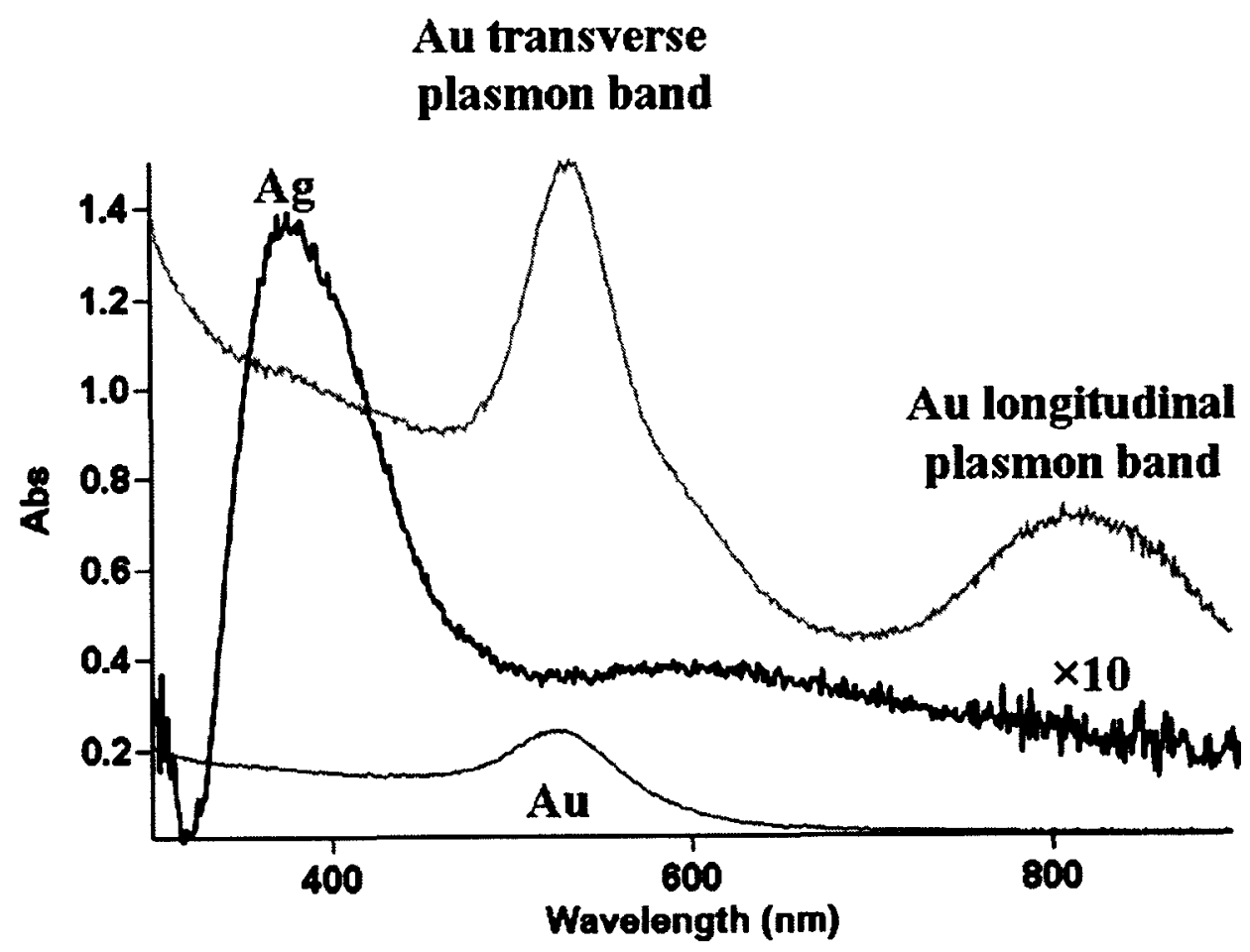

Figure 2.7. Absorption spectrum of a nanorod sample (red spectrum) compared to spherical Ag nanoparticles (black spectrum) and spherical Au nanoparticles (brown spectrum). 


\subsubsection{Electrochemical Methods}

\section{Linear Sweep Voltammetry (LSV) - Stripping voltammetry}

Stripping voltammetry is a widely used electroanalytical tool. It is usually used to determine the composition of species present on the electrode surface and their amount in terms of moles. A typical stripping voltammetry experiment involves changing the applied voltage with time and recording the current. An electrochemical cell for stripping analysis consists of three electrodes: 1) working electrode - an electrode on which the electrochemical reaction occurs, 2) reference electrode - an electrode with known constant potential versus which the potential of the working electrode is measured, and 3) counter electrode - an electrode used to close the circuit and allow the flow of electrons.

A characteristic stripping voltammograms of ITO/MPTMS/Ag nanostructures is shown in Figure 2.8. The scan begins at $0.0 \mathrm{~V}$ and ends at $1.0 \mathrm{~V}$. The negative flow of current with a maximum at $\sim 0.42 \mathrm{~V}$ corresponds to the oxidation of $\mathrm{Ag}$ as follows:

$$
\mathrm{Ag}^{0} \rightarrow \mathrm{Ag}^{+}+1 \mathrm{e}^{-}
$$

The current reaches a maximum and then drops back to the baseline once all of the $\mathrm{Ag}$ is oxidized. This $\mathrm{i}-\mathrm{V}$ curve can be used to determine the amount of Ag oxidized. The area under the oxidation peak gives the amount of charge passed during the oxidation reaction. Charge is expressed in units of Coulombs. The following equation gives the moles of metal from the measured Coulombs of charge $(Q)$ under the LSV peak in figure 2.8, where $F$ is Faraday Constant, and $n$ is the number of electrons involved in the oxidation:

$$
m o l=\frac{Q}{n F}
$$




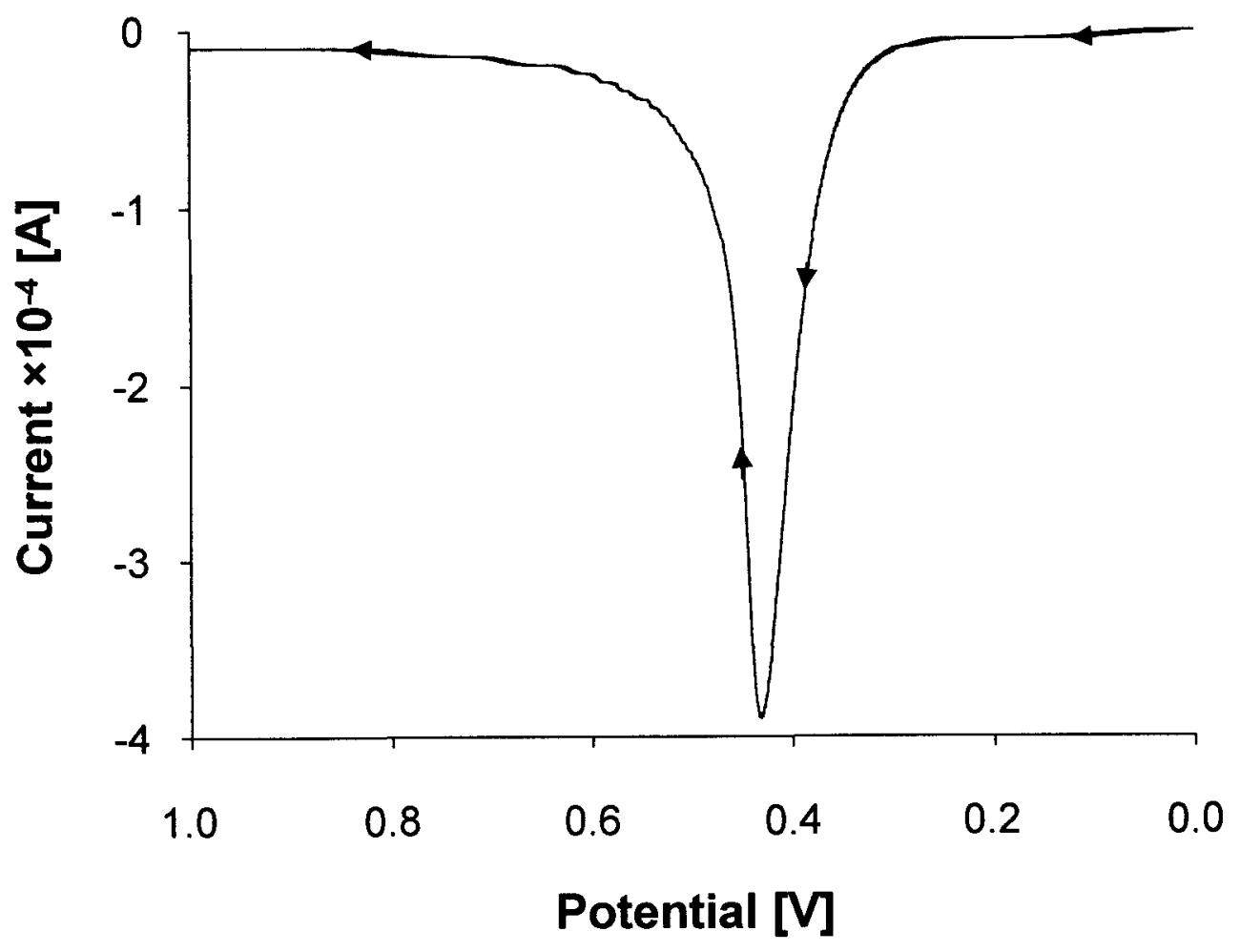

Figure 2.8. $\mathrm{LSV}$ of ITO/MPTMS/Ag nanostructures in $0.5 \mathrm{M} \mathrm{H}_{2} \mathrm{SO}_{4}$. Scan rate 10 $\mathrm{mV} / \mathrm{sec}$. 


\section{Electrochemical characterization by Linear Sweep Voltammetry}

We developed a compositional analysis by linear sweep stripping voltammetry in order to obtain the approximate metal composition of the galvanically-exchanged nanostructures. We used a three electrode setup where glass/ITO/MPTMS/Au seed/Ag nanostructures (before and after galvanic exchange with $\mathrm{PdCl}_{4}{ }^{2-}$ ) served as the working electrode, $\mathrm{Ag} / \mathrm{AgCl}(3 \mathrm{M} \mathrm{KCl})$ as a reference, and $\mathrm{Pt}$ wire as a counter electrode. We ran the $1^{\text {st }} \mathrm{LSV}$ in $0.5 \mathrm{M} \mathrm{H}_{2} \mathrm{SO}_{4}$ from 0.0 to $0.6 \mathrm{~V}$ at $10 \mathrm{mV} / \mathrm{sec}$ in order to obtain an $\mathrm{Ag}$ oxidation (or stripping) peak. Next, the sample was gently rinsed in nanopure $\mathrm{H}_{2} \mathrm{O}$ and a

$2^{\text {nd }} \mathrm{LSV}$ scan was obtained in $0.01 \mathrm{M} \mathrm{KBr}$ plus $0.1 \mathrm{M} \mathrm{HClO}_{4}$ from 0.0 to $0.8 \mathrm{~V}$ at 10 $\mathrm{mV} / \mathrm{sec}$ in order to monitor the Pd striping peak. Linear sweep voltammograms were analyzed and the composition of the nanostructures was determined by integrating the areas under the oxidation peaks.

\section{Electrochemical deposition}

Electrochemical deposition is the process by which a solid metal is deposited from a solution of ions onto an electrically conductive surface. The process is opposite to that described earlier for stripping voltammetry. During the electrochemical deposition the potential is scanned from a positive potential towards negative potentials.

Figure 2.9 represents a typical i-V curve for Ag deposition on a glass/ITO electrode. While scanning the potential from $0.2 \mathrm{~V}$ to $-1.0 \mathrm{~V}$, the energy level of the electrons on the electrode surface increases. When the applied potential approaches the reduction potential of $\mathrm{Ag}^{+}$, the energy level of the electrons on the electrode surface is high enough to transfer electrons to the positively charged $\mathrm{Ag}^{+}$ions in the electrolyte 


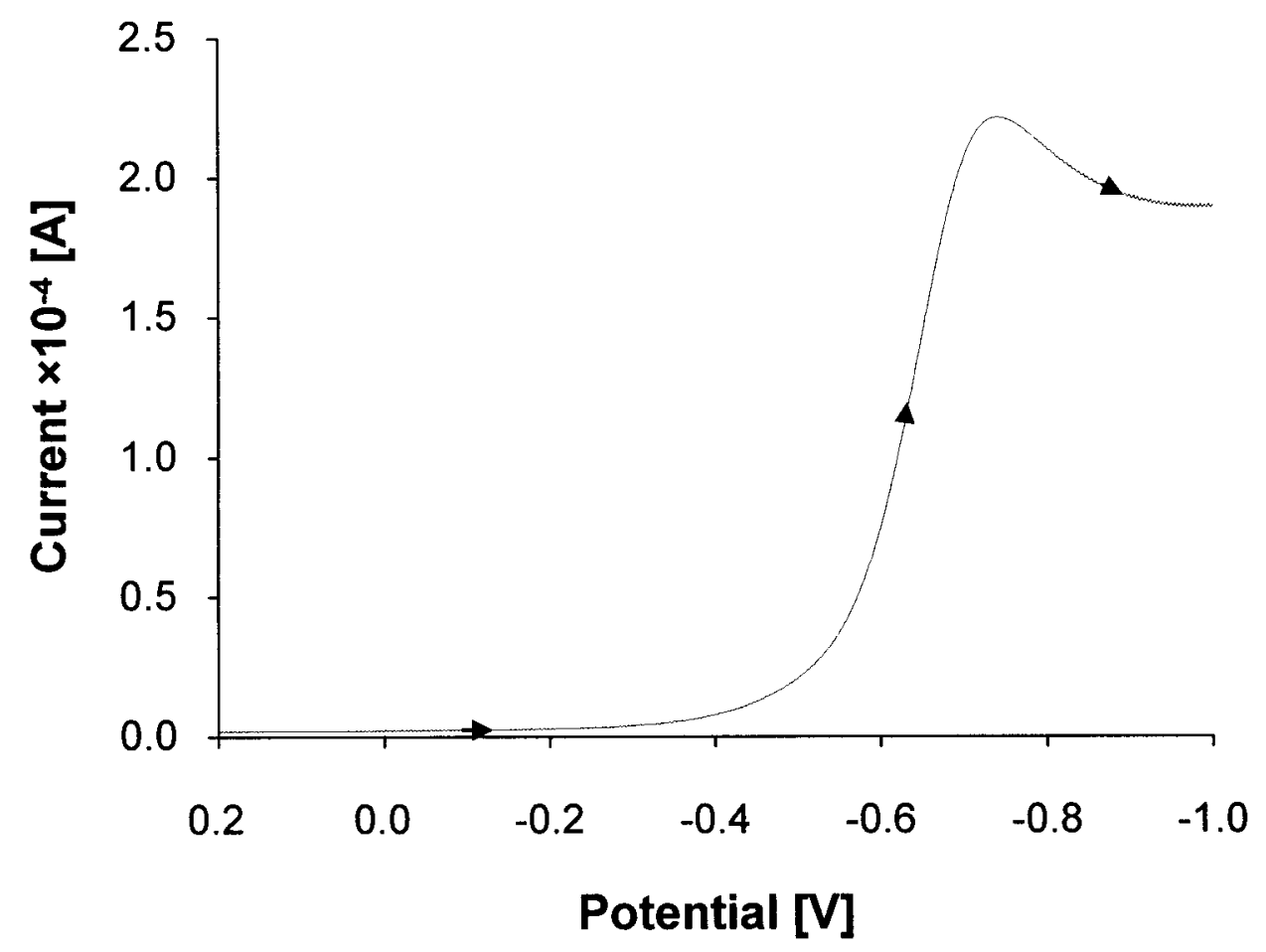

Figure 2.9. $\mathrm{i}-\mathrm{V}$ curve of glass/ITO in $2.5 \times 10^{-4} \mathrm{M} \mathrm{AgNO}_{3}$ in $0.1 \mathrm{M} \mathrm{CTAB}$ in 10.6 phosphate buffer solution. 
solution in close vicinity of the electrode, leading to the reduction of $\mathrm{Ag}^{+}$ions and deposition in the form of $\mathrm{Ag}^{0}$ metal on the electrode surface by the following reaction:

$$
\mathrm{Ag}^{+}+1 \mathrm{e}^{-} \rightarrow \mathrm{Ag}^{0}
$$

As the potential reaches more negative values, the current initially increases due to an increase in the rate of $\mathrm{Ag}^{+}$reduction as the potential becomes more negative. Eventually, the current decreases due to the depletion of $\mathrm{Ag}^{+}$ions at the electrode surface. The current is diffusion limited in this region (less than $-0.7 \mathrm{~V}$ ). 


\section{CHAPTER III}

\section{UNIQUE STRUCTURES THROUGH TWIN PLANE DECORATION OF Ag NANORODS DURING GALVANIC EXCHANGE WITH AQUEOUS PdCl ${ }_{4}^{2-}$}

\subsection{ABSTRACT}

Here we describe the galvanic exchange of surface-grown Ag nanorods (NRs) and nanowires (NWs) with $\mathrm{PdCl}_{4}{ }^{2-}$ as a function of $\mathrm{PdCl}_{4}{ }^{2-}$ concentration. The morphology of the resulting AgPd alloy nanostructures depends on the galvanic exchange rate, which increases with increasing $\mathrm{PdCl}_{4}{ }^{2-}$ concentration over a specific concentration range. When the concentration of $\mathrm{PdCl}_{4}{ }^{2-}$ exceeds $7.5 \times 10^{-5} \mathrm{M}$ (or mol $\mathrm{PdCl}_{4}{ }^{2-}$ in solution to mol Ag on surface ratio > 542), rapid galvanic exchange results in Pd deposition over the entire Ag nanostructure at the early stages of exchange. When the concentration of $\mathrm{PdCl}_{4}{ }^{2-}$ is in the range of $1.0 \times 10^{-5}$ to $5.0 \times 10^{-5} \mathrm{M}\left(\mathrm{mol} \mathrm{PdCl}_{4}{ }^{2-}\right.$ in solution to mol $\mathrm{Ag}$ on the surface $=13-54)$, Pd deposition occurs preferentially at high energy twin plane defects in the form of well-spaced nanoparticles during the early stages of exchange. At later stages, the Pd deposits grow and coalescence into a rough shell and etching of the $\mathrm{Ag}$ leads to a presumably hollow nanostructure. Composition analysis by linear sweep voltammetry as a function of time shows that the galvanic exchange rate is much slower than the diffusion-limited rate and, when correlated with UV-Vis spectroscopy, shows that less than $10 \% \mathrm{Pd}$ in the nanostructure completely dampens the Ag localized surface plasmon band. 


\subsection{INTRODUCTION}

Metallic nanostructures have gained attention in recent years due to their interesting size, shape, and composition dependent properties and potential use in photonics, ${ }^{71}$ catalysis, ${ }^{72}$ nanoelectronics, ${ }^{73}$ chemical sensing, ${ }^{74}$ and other nanoscale device

applications. ${ }^{75,76}$ One-dimensional (1D) metal nanostructures are of interest to our group because of their possible use in sensing and catalysis applications. Several methods exist for the chemical synthesis of 1D nanometals, including UV-irradiation, seed-mediated growth, and the polyol process. ${ }^{14,15,17,20-24,37,77-88}$

While monometallic nanostructures have several useful properties and applications, there are also cases where bimetallic or multimetal nanostructures are desirable. There are several methods for synthesizing bi- or multi-metal nanostructures, including seeded growth of one metal onto another, co-reduction of two metal salts in the presence of a stabilizer, or the galvanic exchange method. In galvanic exchange, a metal in the reduced form becomes replaced by a metal in the oxidized form by a simple oxidation-reduction reaction. The requirement is that the metal initially in the reduced form has a more negative reduction potential than the metal initially in the oxidized form. Since the metal in the reduced form requires more energy to be reduced than the metal in the oxidized form, this will lead to spontaneous replacement via oxidation of the reduced metal and reduction of the oxidized metal.

Several processes occur during galvanic exchange reactions. The solid metal structure becomes oxidized (dissolved) while metal ions from solution become reduced (deposited) onto the original template structure. At an intermediate point before the reaction is complete, the metal undergoing reduction may alloy with the second metal. 
As the second metal dissolves, this may also involve a dealloying process. Reactions 1-3 show the possible reactions that occur where M1 represents a metal initially in the reduced form and M2 represents a metal in the oxidized form. Reaction 1 is the combined full reaction comprised of the oxidation and reduction reactions. Reactions 2 and 3 represent alloying and dealloying processes.

$$
\begin{aligned}
& \mathrm{M} 1_{\text {red }}+\mathrm{M} 2_{\mathrm{ox}} \leftrightarrow \mathrm{M} 1_{\mathrm{ox}}+\mathrm{M} 2_{\text {red }} \text { (complete oxidation/reduction reaction) (R. 3.1) } \\
& \mathrm{M} 1_{\text {red }}+\mathrm{M} 2_{\mathrm{ox}} \quad \leftrightarrow \quad \mathrm{M} 1_{\mathrm{ox}}+\mathrm{M} 1 \mathrm{M} 2_{\text {alloy }} \quad \text { (alloying) } \\
& \mathrm{M} 1 \mathrm{M} 2_{\text {alloy }}+\mathrm{M} 2_{\mathrm{ox}} \leftrightarrow \mathrm{M} 1_{\mathrm{ox}}+\mathrm{M} 2_{\text {red }} \quad \text { (dealloying) }
\end{aligned}
$$

While many groups use the galvanic exchange method to synthesize novel metallic structures with interesting properties, there are very few detailed mechanistic studies revealing the factors that control the final morphology of the galvanicallyexchanged metal. Xia and co-workers recently studied the mechanism of the galvanic exchange reaction between $\mathrm{Ag}$ and $\mathrm{HAuCl}_{4}$ in aqueous medium on $\mathrm{Ag} \mathrm{NRs,} \mathrm{nanoboxes,}$ and twinned nanoparticles. ${ }^{87}$ The metallic Au formed in this reaction acquires the shape of the Ag template to some degree. Due to instant access to more Au salt, metallic Au nucleates and grows into a layer around the template via an alloying and dealloying process. ${ }^{89}$ The final AuAg alloy structure is generally similar to the original Ag structures but hollow or caged. Xia and co-workers also studied the effect of temperature, showing that it played a key role in the final morphology of $\mathrm{Au}$ nanostructures formed from $\mathrm{Ag}$ due to the increased solubility of $\mathrm{AgCl}$ and enhanced mobility of metal atoms at higher temperature. ${ }^{62}$ There are few studies of other metal pairs or the effect of other variables, such as the reaction rate, presence of stabilizers 
(surfactants, polymers), and the effect of various ions in solution. The goal of our research is to better understand the effect of these variables on the morphology of galvanic-exchanged metal nanostructures and to use the knowledge gained to create unique structures with useful properties for sensing and catalysis applications.

Recently, we synthesized Au and Ag NRs/NWs directly on surfaces through seedmediated synthesis. We also recently synthesized Pt and Pd 1D nanostructures by galvanic-exchange of the $\mathrm{Ag} \mathrm{NRs} / \mathrm{NWs}$ with $\mathrm{PtCl}_{4}{ }^{2-}$ and $\mathrm{PdCl}_{4}{ }^{2-}$, respectively, and deposited $\mathrm{Ag}$ onto $\mathrm{Au}$ NRs and galvanically-exchanged the $\mathrm{Ag}$ with $\mathrm{PdCl}_{4}{ }^{2-}$ to form hollow $\mathrm{Au} / \mathrm{Pd}$ or $\mathrm{Au} / \mathrm{PdAg}$ core/shell structures. ${ }^{89}$ The exchange occurred in relatively large $\mathrm{PdCl}_{4}{ }^{2-}$ concentration with fast rates and no stabilizers in solution. Chen and co-workers formed $\mathrm{Pd}$-Ag nanoboxes during galvanic exchange of $\mathrm{Ag}$ nanocubes with $\mathrm{PdCl}_{4}{ }^{2-}$ in solution as another example of the $\mathrm{Ag} / \mathrm{PdCl}_{4}{ }^{2-}$ system.

Here we describe the galvanic exchange of $\mathrm{Ag} \mathrm{NRs} / \mathrm{NWs}$ with $\mathrm{PdCl}_{4}{ }^{2-}$ as a function of exchange rate. We first synthesized the $\mathrm{Ag} \mathrm{NRs} / \mathrm{NWs}$ directly on glass or $\mathrm{Si} / \mathrm{SiO}_{\mathrm{x}}$ surfaces and performed the exchange reaction on the surface-attached nanostructures in aqueous solutions. We varied the bulk $\mathrm{PdCl}_{4}{ }^{2-}$ concentration to control the flux of $\mathrm{PdCl}_{4}{ }^{2-}$ to the surface, which controls the reaction rate. The benefit of surfaceattached $1 \mathrm{D} \mathrm{Ag}$ nanostructures is that the solution is surfactant free or we can intentionally add surfactants, polymers, or other additives in the future to examine their effect on the galvanic exchange process. In this work we show that the morphology of the galvanically-exchanged $\mathrm{Ag}$ nanostructures depends on the reaction rate and additionally developed an electrochemical stripping voltammetry method to approximate 
the $\mathrm{Ag}$ and $\mathrm{Pd}$ composition at various times of exchange, which we then correlate to the optical properties of the metallic nanostructures.

\subsection{EXPERIMENTAL SECTION}

\subsubsection{Chemicals and materials.}

Silver nitrate $\left(\mathrm{AgNO}_{3}, 99+\%\right)$, sodium borohydride $\left(\mathrm{NaBH}_{4}, 98 \%\right)$, potassium tetrachloropalladate (II) $\left(\mathrm{K}_{2} \mathrm{PdCl}_{4}, 98 \%\right)$, and L-ascorbic acid $(99.9 \%)$ were purchased from Sigma-Aldrich. Hydrogen tetrachloroaurate trihydrate $\left(\mathrm{HAuCl}_{4} \cdot 3 \mathrm{H}_{2} \mathrm{O}\right)$ was synthesized according to a literature procedure. ${ }^{66}$ Citric acid trisodium salt was purchased from Bio-Rad Laboratories. Sodium phosphate dibasic and sodium phosphate tribasic was purchased from Fisher Scientific Company. Potassium bromide (min $99.0 \%)$, perchloric acid (60\%), hydrogen peroxide $\left(\mathrm{H}_{2} \mathrm{O}_{2} 30 \%\right.$ solution), and 2-propanol (HPLC grade, 99.99\%) were purchased from EMD. Sulfuric acid was purchased from BDH Aristar (distributed by VWR). Cetyltrimethylammonium bromide (CTAB) was purchased from Fluka (Assay $\geq 99.0 \%$ ). NANOpure ultrapure water (Barnstead Nanopure Deionization System, resistivity of $18 \mathrm{M} \Omega-\mathrm{cm}$ ) was used for all aqueous solutions. Indium-tin-oxide (ITO) - coated glass (Glass/ITO, $\mathrm{R}_{s}=8-12 \Omega$ ) substrates were purchased from Delta Technologies Limited (Stillwater, MN).

\subsubsection{Synthesis of Ag nanostructures directly on surfaces.}

We synthesized Ag nanostructures directly on surfaces as described previously. First, glass or $\mathrm{Si} / \mathrm{SiO}_{\mathrm{x}}$ substrates were cleaned and functionalized with mercaptopropyltrimethoxysilane (MPTMS). (Glass or $\mathrm{Si} / \mathrm{SiO}_{\mathrm{x}}$ )/MPTMS substrates were

were then placed in an aqueous solution of 3-5 $\mathrm{nm}$ Au seed nanoparticles (Au NPs) for 20 minutes. Finally, (glass or $\mathrm{Si} / \mathrm{SiO}_{\mathrm{x}}$ )/MPTMS/Au NP substrates were placed in an $\mathrm{Ag}$ 
growth solution, containing $10 \mathrm{~mL}$ of $\mathrm{pH} 10.6$ phosphate buffered $0.08 \mathrm{M} \mathrm{CTAB}, 250 \mu \mathrm{L}$ of $0.01 \mathrm{M} \mathrm{AgNO}_{3}$, and $500 \mu \mathrm{L}$ of $0.1 \mathrm{M}$ ascorbic acid, for 30 minutes in a $28^{\circ} \mathrm{C}$ temperature bath. This procedure leads to Ag nanostructures on the surface with a density of $26 \pm 14 \mu \mathrm{m}^{-2}$ and a $\sim 3 \%$ yield of $1 \mathrm{D}$ Ag nanorods (NRs) and nanowires (NWs) on the surface with a diameter of $34 \pm 14 \mathrm{~nm}$ and lengths ranging from tens of $\mathrm{nm}$ to more than $10 \mu \mathrm{m}$. Since most of the structures have an aspect ratio (AR) greater than 20 , we will refer to all 1D nanostructures as NWs in the text, even though some may technically be NRs $(A R<20)$.

\subsubsection{Galvanic exchange between $\mathrm{Ag} \mathrm{NRs} / \mathrm{NWs}$ and $\mathrm{PdCl}_{4}{ }^{2-}$.}

The surface-attached (glass or $\mathrm{Si} / \mathrm{SiO}_{\mathrm{x}}$ )/MPTMS/Ag NWs were placed into aqueous $0.01,0.001,0.0001,0.000075,0.000050,0.000025$, or $0.000010 \mathrm{M} \mathrm{K}_{2} \mathrm{PdCl}_{4}$ solutions for times ranging from 0 to $3600 \mathrm{sec}$. Galvanic exchange occurred extremely fast for concentrations of 0.01 and $0.001 \mathrm{M}$, therefore the results shown focus on the range from $1.0 \times 10^{-4} \mathrm{M}$ to $1 \times 10^{-5} \mathrm{M}$. Glass samples were placed in the appropriate aqueous $\mathrm{PdCl}_{4}{ }^{2-}$ solution for a desired period of time, removed, rinsed with nanopure $\mathrm{H}_{2} \mathrm{O}$, and dried under a stream of nitrogen prior to UV-Vis analysis. Si/SiO $\mathrm{S}_{\mathrm{x}}$ samples were placed in the $\mathrm{PdCl}_{4}{ }^{2-}$ solution, removed at a desired time, rinsed with nanopure $\mathrm{H}_{2} \mathrm{O}$, dried under $\mathrm{N}_{2}$, and characterized by scanning electron microscopy (SEM).

\subsubsection{Electrochemical characterization by Linear Sweep Voltammetry.}

We developed a compositional analysis by linear sweep stripping voltammetry in order to obtain the approximate metal composition of the galvanically-exchanged nanostructures. We used a three electrode setup where glass/ITO/MPTMS/Au seed/Ag nanostructures (before and after galvanic exchange with $\mathrm{PdCl}_{4}{ }_{4}^{2-}$ ) served as the working 
electrode, $\mathrm{Ag} / \mathrm{AgCl}(3 \mathrm{M} \mathrm{KCl})$ as a reference, and $\mathrm{Pt}$ wire as a counter electrode. We ran the $1^{\text {st }} \mathrm{LSV}$ in $0.5 \mathrm{M} \mathrm{H}_{2} \mathrm{SO}_{4}$ from 0.0 to $0.6 \mathrm{~V}$ at $10 \mathrm{mV} / \mathrm{sec}$ in order to obtain an $\mathrm{Ag}$ oxidation (or stripping) peak. Next, the sample was gently rinsed in nanopure $\mathrm{H}_{2} \mathrm{O}$ and a $2^{\text {nd }} \mathrm{LSV}$ scan was obtained in $0.01 \mathrm{M} \mathrm{KBr}$ plus $0.1 \mathrm{M} \mathrm{HClO}_{4}$ from 0.0 to $0.8 \mathrm{~V}$ at 10 $\mathrm{mV} / \mathrm{sec}$ in order to monitor the Pd striping peak. Linear sweep voltammograms were analyzed and the composition of the nanostructures was determined by integrating the areas under the oxidation peaks.

\subsubsection{Instrumentation.}

Scanning Electron Microscopy images were obtained at different magnifications using a Carl Zeiss SMT AG SUPRA 35VP field emission scanning electron microscope (FESEM) operating at an accelerating voltage of 5.00 to $20.00 \mathrm{kV}$ and using an in-lens ion annular secondary electron detector. UV-Vis spectra were obtained using a Varian Cary 50 Bio UV-Visible Spectrophotometer. A CH Instruments (Austin, TX) 630C electrochemical analyzer/workstation was used for electrochemical stripping analysis of $\mathrm{Ag}$ and galvanically exchanged $\mathrm{AgPd}$ alloy nanostructures.

\subsection{RESULTS AND DISCUSSION}

Most of the studies reported on the galvanic exchange of metallic nanostructures to date occurred in solutions containing a stabilizer (polymer or surfactant) with the final metal composition controlled by the ratio of the reduced metal and the oxidized metal in solution, where the reaction went to completion. ${ }^{66,89}$ While the morphology of the final product can be obtained as a function of the final composition, the effect of exchange rate and the effect of the stabilizer could not be determined and was not the focus. We are interested in studying the effect of these variables on the morphology of galvanically- 
exchanged metal nanostructures. Here we describe our findings for the galvanic exchange of $\mathrm{Ag}$ with $\mathrm{PdCl}_{4}{ }^{2-}$. Bulk optical and electrochemical measurements reflect the entire surface, containing mostly nanoparticles with $\sim 3 \%$ Ag NWs. We focus our SEM imaging on the $\mathrm{Ag}$ NWs because of our interest in 1D nanostructures. Since we synthesized the Ag nanostructures directly on surfaces, we are able to study the exchange in stabilizer-free aqueous solutions and control the rate of exchange by varying the $\mathrm{PdCl}_{4}{ }^{2-}$ concentration, which alters the flux of $\mathrm{PdCl}_{4}{ }^{2-}$ to the surface.

The reaction between $\mathrm{Ag}^{0}$ and $\mathrm{PdCl}_{4}{ }^{2-}$ occurs as follows:

$$
\mathrm{Ag}^{0}+\mathrm{PdCl}_{4}^{2-} \rightarrow \mathrm{Pd}^{0}+2 \mathrm{Ag}^{+}+4 \mathrm{Cl}^{-}
$$

A second possible reaction is the precipitation of $\mathrm{AgCl}_{(\mathrm{S})}$ as follows:

$$
\mathrm{Ag}^{+}+\mathrm{Cl}^{-} \rightarrow \mathrm{AgCl}_{(\mathrm{S})} \quad \mathrm{K}_{\mathrm{sp}}=1.8 \times 10^{-10}
$$

For an unlimited amount of $\mathrm{Ag}$, calculations of equilibrium concentrations show that all of the $\mathrm{PdCl}_{4}{ }^{2-}$ would be converted to $\mathrm{Pd}^{0}$, showing the reaction goes to completion, at all concentration of $\mathrm{PdCl}_{4}{ }^{2-}$ used in this study. Since our samples contain $3.7 \times 10^{-8} \mathrm{~mol} \mathrm{Ag}$ on average, there will actually be $\mathrm{PdCl}_{4}{ }^{2-}$ left in solution and all of the $\mathrm{Ag}$ oxidized to $\mathrm{Ag}^{+}$. There is still the question of $\mathrm{AgCl}_{(\mathrm{S})}$ precipitate formation. If all of the $\mathrm{Ag}^{0}$ becomes oxidized to $\mathrm{Ag}^{+}$, that would give $3.7 \times 10^{-8}$ mole $\mathrm{Ag}^{+}$and $7.4 \times 10^{-8} \mathrm{~mol} \mathrm{Cl}^{-}$in solution. The diffusion layer thickness is $0.38 \mathrm{~cm}$ after 1 hour and the electrode area is $3.5 \mathrm{~cm}^{2}$. For two sides of the glass slide, this $\mathrm{Ag}^{+}$and $\mathrm{Cl}^{-}$will be contained in $\sim 2.9 \mathrm{~mL}$ of solution, giving a $\left[\mathrm{Ag}^{+}\right]$of $1.4 \times 10^{-5}$ and $\left[\mathrm{Cl}^{-}\right]$of $2.8 \times 10^{-5}$. The product of these $\left(3.92 \times 10^{-10}\right)$ is slightly above the $\mathrm{K}_{\mathrm{sp}}$ of the $1.8 \times 10^{-10} \mathrm{M}^{2}$, therefore we expect some $\mathrm{AgCl}_{(\mathrm{S})}$ precipitate to form. 
This $\mathrm{AgCl}_{(\mathrm{S})}$ would likely dissolve during the subsequent rinsing in water, so would not likely appear in the SEM images, but it could affect the exchange rates.

Figure 3.1A shows the UV-Vis spectra of a sample of Ag nanostructures grown on glass before and at various times during galvanic exchange for $3600 \mathrm{~s}$ with an aqueous $5.0 \times 10^{-5} \mathrm{M} \mathrm{PdCl}_{4}{ }^{2-}$ solution. At $0 \mathrm{~s}$ of exchange, the pure $\mathrm{Ag}$ nanostructures exhibit a prominent, well-known localized surface plasmon (LSPR) band at about $420 \mathrm{~nm}$. As the exchange with $\mathrm{PdCl}_{4}{ }^{2-}$ proceeds, the $\mathrm{Ag} \mathrm{LSPR}$ band decreases in intensity and red shifts as shown previously. ${ }^{7}$ This is consistent with PdAg alloy formation as the exchange process occurs. ${ }^{89}$

Figure 3.1B shows the normalized peak absorbance of the LSPR band as a function of exchange time for exchange with the $5.0 \times 10^{-5} \mathrm{M} \mathrm{PdCl}_{4}{ }^{2-}$ and the four other concentrations of $\mathrm{PdCl}_{4}{ }^{2-}$ ranging from $1.0 \times 10^{-5} \mathrm{M}$ to $1.0 \times 10^{-4} \mathrm{M}$ as shown. The values of absorbance were measured at the peak maxima. Later, when the peaks are getting broader and flatter the absorbance was extrapolated to a line, reflecting the trend at the changing peak maxima with time. For the experimental reaction of galvanic exchange between $\mathrm{Ag}$ and $\mathrm{PdCl}_{4}{ }^{2-}$ we performed theoretical calculations to determine how much Ag we should have on the electrode surface in order to reach equilibrium for all concentrations of $\mathrm{PdCl}_{4}{ }^{2-}$ based on the following equation:

$$
E_{\text {cell }}=E^{0}{ }_{P d / P d C l_{4}{ }^{2-}}-E^{0}{ }_{A g / A g^{+}}-\frac{0.0592}{n} \log \frac{\left[\mathrm{Cl}^{-}\right]^{4}\left[\mathrm{Ag}^{+}\right]^{2}}{\left[\mathrm{PdCl}_{4}{ }^{2-}\right]}
$$

where $E^{0}{ }_{P d / P d C l}{ }^{2-}$ and $E^{0}{ }_{A g / A g}$ are standard reduction potentials and $\mathrm{n}$ is the number of electrons involved in the reaction $(\mathrm{n}=2)$. Results of the calculations showed that $\mathrm{Ag}^{0}$ will 

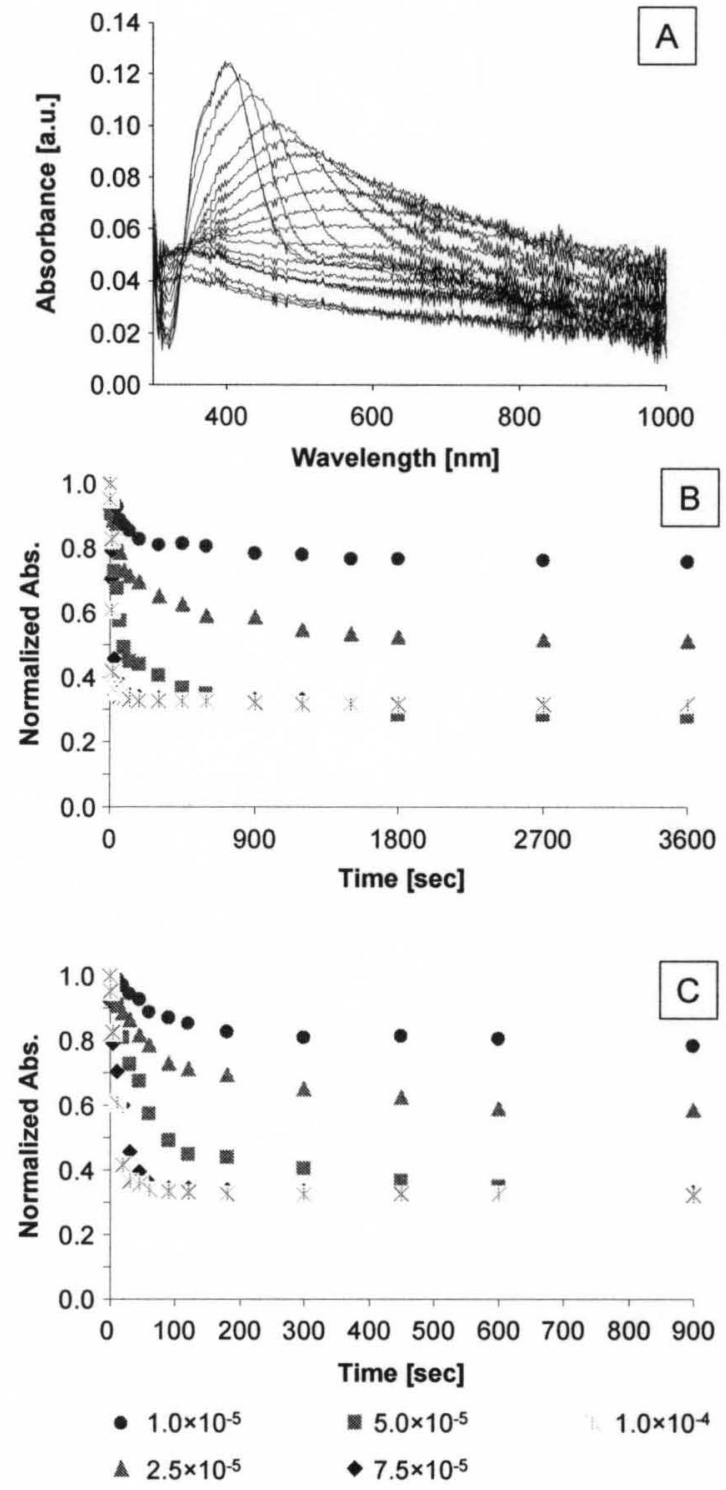

Figure 3.1. (A) UV-Vis spectra of an Ag sample exchanged with $5.0 \times 10^{-5} \mathrm{M} \mathrm{PdCl}_{4}^{2-}$.

(B) Normalized absorbance as a function of time for exchange of $\mathrm{Ag}$ in $1.0 \times 10^{-5}$, $2.5 \times 10^{-5}, 5.0 \times 10^{-5}, 7.5 \times 10^{-5}$, and $1.0 \times 10^{-4} \mathrm{PdCl}_{4}{ }^{2-}$ concentrations. (C) A zoom in of B from 1 to 900 seconds. 
be completely oxidized to $\mathrm{Ag}^{+}$for all concentrations based on the fact that there is $3.7 \times 10^{-8}$ mole based on the average of 16 samples as determined by linear stripping voltammetry performed on double-sided glass/ITO/Ag. The plots clearly show an increasing rate of exchange with increasing $\mathrm{PdCl}_{4}{ }^{2-}$ concentration in Figure 3.1B. Frame $\mathrm{C}$ shows a blow-up of the plot from frame B from 0 to $900 \mathrm{~s}$. The initial slope of the curve over the first 30 seconds provides an estimate rate of exchange at early stages. The slope of the plots for $1.0 \times 10^{-4} \mathrm{M}, 7.5 \times 10^{-5} \mathrm{M}, 5.0 \times 10^{-5} \mathrm{M}, 2.5 \times 10^{-5} \mathrm{M}$, and $1.0 \times 10^{-5} \mathrm{M}$ $\mathrm{PdCl}_{4}{ }^{2-}$ concentrations were $0.0211,0.0181,0.0092,0.0045$, and 0.0019 , respectively. From this data, the rate appears to be first order in $\mathrm{PdCl}_{4}{ }^{2-}$ concentrations.

In addition, Figure 3.1B shows that the $\mathrm{Ag}$ nanostructures exchanged with the two lowest $\mathrm{PdCl}_{4}{ }^{2-}$ concentrations do not reach the same level of completion after $3600 \mathrm{~s}$ when compared to those exchanged with $5.0 \times 10^{-5} \mathrm{M} \mathrm{PdCl}_{4}{ }^{2-}$ or higher, which all have the same final normalized absorbance value. Based on the calculated $3.7 \times 10^{-8} \mathrm{~mol} \mathrm{Ag}$ on the surface, the ratio of total mol $\mathrm{PdCl}_{4}{ }^{2-}$ to total mol Ag ranges from 13 to 542 for the range of $1.0 \times 10^{-5}$ to $1.0 \times 10^{-4} \mathrm{M} \mathrm{PdCl}_{4}{ }^{2-}$ solutions. There is clearly enough total mol $\mathrm{PdCl}_{4}{ }^{2-}$ in the solution to exchange all of the $\mathrm{Ag}$ on the surface. After $3600 \mathrm{~s}, 9.64 \times 10^{-9}$ to $9.64 \times 10^{-8}$ total mol of $\mathrm{PdCl}_{4}{ }^{2-}$ reaches the substrate surface for the $1.0 \times 10^{-5} \mathrm{M}$ to $1.0 \times 10^{-4} \mathrm{M} \mathrm{PdCl}_{4}{ }^{2-}$ concentrations. This would lead to $1.93 \times 10^{-9}$ to $1.93 \times 10^{-8} \mathrm{~mol} \mathrm{Ag}$ reacted during that time considering that $2 \mathrm{Ag}^{+}$form from $1 \mathrm{PdCl}_{4}{ }^{22-}$. Calculations therefore show that after $3600 \mathrm{~s}$ there is not enough Pd to reach and exchange all of the $\mathrm{Ag}$ present on the surface in the case of $1.0 \times 10^{-5} \mathrm{M} \mathrm{PdCl}_{4}{ }^{2-}$.

In order to determine how the rate of galvanic exchange affects the morphology of the exchanged structure, we conducted the exchange reactions at three different 
concentrations and stopped them at the same level of exchange as judged by the normalized UV-Vis absorbance value. Figure 3.2 shows SEM images of Ag NWs galvanically exchanged with $2.5 \times 10^{-5} \mathrm{M}, 5.0 \times 10^{-5} \mathrm{M}$, and $7.5 \times 10^{-5} \mathrm{M} \mathrm{PdCl}_{4}{ }^{2-}$ until the normalized absorbance reached $\sim 0.6$. Assuming that the absorbance is related closely to the composition, these $\mathrm{AgPd}$ NWs should have a similar composition that was reached at different rates. In fact, it took 600,60 , and $20 \mathrm{~s}$, respectively, with increasing $\mathrm{PdCl}_{4}{ }^{2-}$ concentration, to reach the normalized value of 0.6 . This again shows that the higher concentration $\mathrm{PdCl}_{4}{ }^{2-}$ reacts at a faster rate. Based on the electrochemical composition analysis shown later, these samples contain $\sim 90 \% \mathrm{Ag}$, indicating that this is very early in the exchange. The main conclusion from the images is that the morphology of the nanostructures varies when the composition is constant, but the galvanic exchange occurred at different rates. For the lowest rate of exchange $\left(2.5 \times 10^{-5} \mathrm{M} \mathrm{PdCl}_{4}{ }^{2-}\right)$, the twin-plane defects of the Ag NWs become decorated with a high density of fairly small Pd nanoparticle deposits. Exchange with $5.0 \times 10^{-5} \mathrm{M} \mathrm{PdCl}_{4}{ }^{2-}$ also leads to twin plane decoration with Pd nanoparticles, but the density is lower and the particles are larger. At the fastest rate $\left(7.5 \times 10^{-5} \mathrm{M}\right)$, Pd deposits grow in the form of nanoparticles more or less evenly all over the Ag NW. From these images it is not clear exactly where the $\mathrm{Ag}$ oxidation occurs. This is the first demonstration to our knowledge of different morphologies of $1 \mathrm{D}$ exchanged metal as a function of exchange rate.

We found the twin-plane decorated Ag NWs to be fascinating, unique structures and decided to study the exchange process on these NWs in more detail. Figure 3.3 shows SEM images of different samples of Ag NWs at different stages of exchange with 

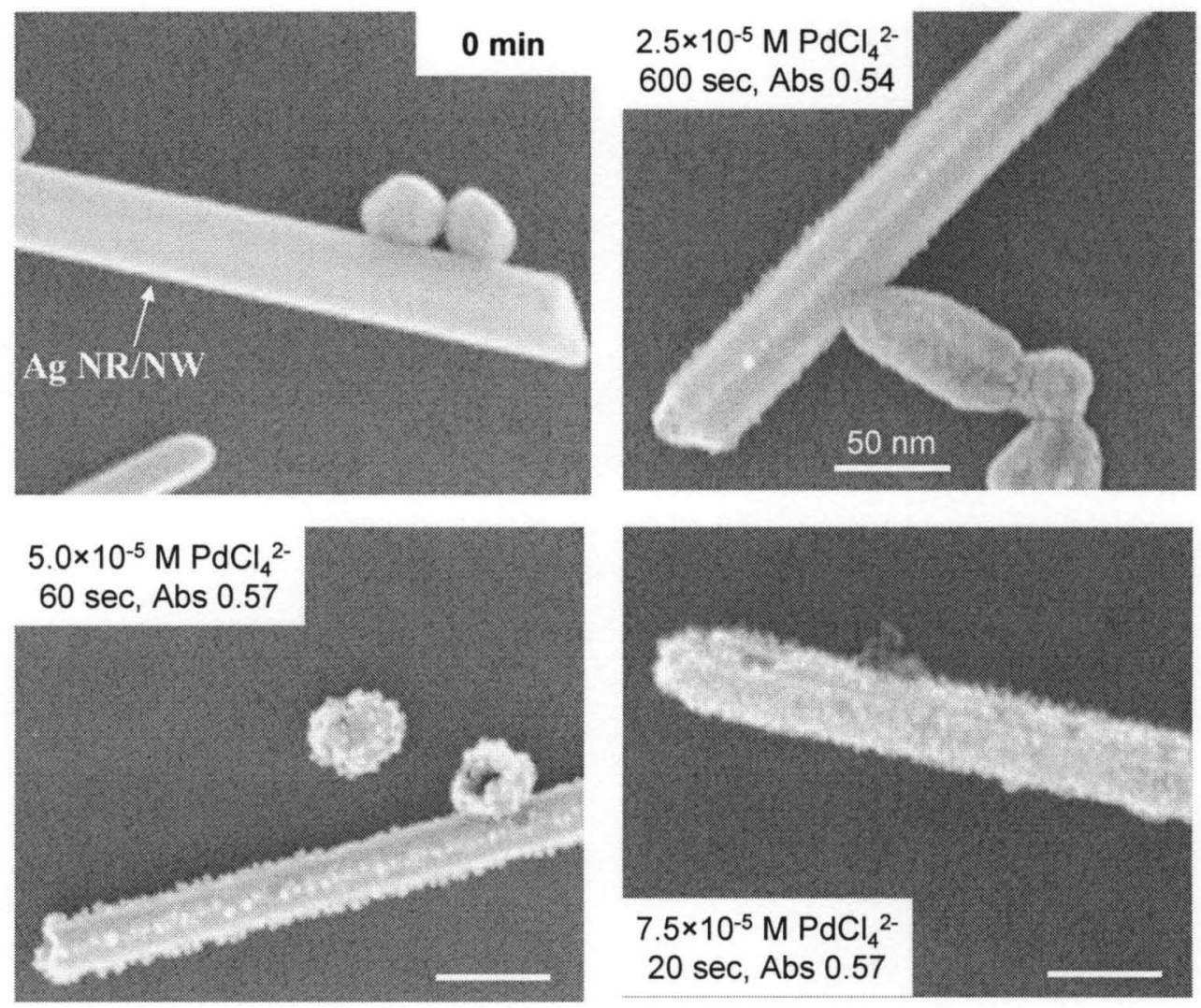

Figure 3.2. SEM images of galvanically exchanged nanostructures with different $\mathrm{PdCl}_{4}{ }^{2-}$ concentrations but matching value of absorbance (0.6). 

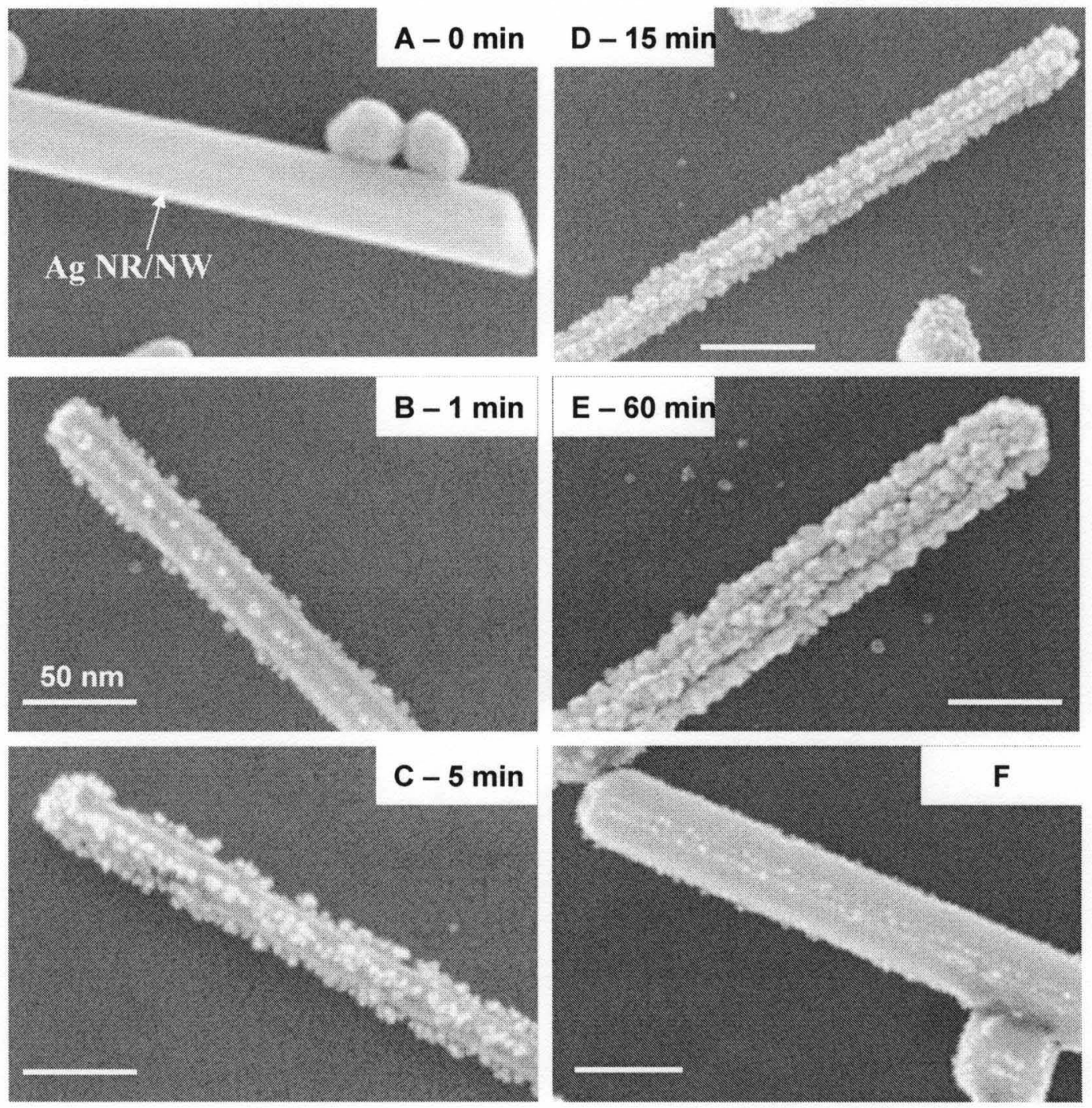

Figure 3.3. SEM images of progressing galvanic exchange with time for $5.0 \times 10^{-5} \mathrm{M}$ $\mathrm{PdCl}_{4}{ }^{2-}$ in $\mathrm{H}_{2} \mathrm{O}$. A through $\mathrm{E}$ show Ag NR during the galvanic exchange at $0,1,5,15$, and 60 minutes, respectively. F shows double defect at the twin plane along the entire length of $\mathrm{Ag} \mathrm{NW}$. 
$5.0 \times 10^{-5} \mathrm{M} \mathrm{PdCl}_{4}^{2-}$, where twin plane decoration occurs at the early stages. Frame $\mathrm{A}$ of Figure 3 shows a representative structure of an $\mathrm{Ag} \mathrm{NW}$ grown directly on $\mathrm{Si} / \mathrm{SiO}_{\mathrm{x}}$ before the galvanic exchange. The NW has smooth terraces and a uniform diameter along the entire length. The NW structure is known to be multiply twinned with 5-fold symmetry and a pentagonal cross-section. One of the twin-planes is faint, but observable along the center of the NW. Frames B through $\mathrm{E}$ show different Ag NWs following galvanic exchange with a $5.0 \times 10^{-5} \mathrm{M} \mathrm{PdCl}_{4}{ }^{2-}$ solution for $1,5,15$, and 60 minutes as indicated. Frame B shows that the reduction of Pd again occurs favorably at the Ag NW twin-plane defect and Pd presents itself on the surface of $\mathrm{Ag}$ as well separated nanoparticles. With an increasing exchange time the Pd particles grow in size while $\mathrm{Ag}$ dissolves and after approximately 15 minutes (frame D), the Pd NPs coalesce with neighboring particles and form a continuous 'wire' structure along all of the twin-planes of the original Ag NW. After 60 minutes of the reaction, the nanostructure is significantly roughened, but it is clear the Pd deposition during exchange emanated from the twin-planes.

The original Ag NWs are multiply twinned structures with 5-fold symmetry where the cross section is a pentagonal shape, the ends of the NRs/NWs contains five (111) facets, and the long axis contains five (100) facets. These 1D structures grow from multiply twinned decahedral particles. The theoretical angle between two (111) planes is $70.52^{\circ}$. Since $5 \cdot 70.52^{\circ}=352.60^{\circ}$, there is a misfit angle of $7.4^{\circ}$ to complete $360^{\circ}$ as described by Chen and Gao. ${ }^{88,90}$ We believe this is the reason for the double parallel lines of Pd that we often observe at the twin-plane defects during exchange, such as those shown in frame $\mathrm{F}$. We note that $\mathrm{Bi}$ and co-workers also observed twin-plane decoration 
of Ag NWs, but with Pt, during galvanic exchange in surfactant containing solutions, where their goal was to synthesize a high yield of platinum nanowires. ${ }^{44}$

Figure 3.4 shows a proposed scheme for the galvanic exchange reaction. The twin plane of the $\mathrm{Ag} \mathrm{NW}$ is a defect site of the crystal lattice. It is well-known that defect sites are more reactive compared to defect free crystallographic terraces. Step A in Scheme 1 shows the pentagonal cross section of the Ag NW structure. In most cases, based on SEM images, the Ag NWs grow on the surface showing only three twin planes while the other two are bound to the surface. Step B shows the deposition of Pd on the defect sites (twin planes) of an Ag NW. Steps C through F, show more deposition of Pd on the $\mathrm{Ag}$ while the $\mathrm{Ag}$ is removed as $\mathrm{Ag}^{+}$, presumably from the terraces and interior of the Ag NW. Continuation of this process leads to the structures shown in Figure 3.3 E or Figure 3.4 F. Based on previous work, we believe that the final structures are hollow, although this has not been confirmed by our SEM images.

An important question that arose in this work was how the normalized intensity of the LSPR band correlates with the Ag and Pd composition in the nanostructures. We used linear sweep voltammetry (LSV) to very roughly estimate the Ag and Pd composition on glass/ITO electrodes during the galvanic exchange process in order to correlate the composition to the normalized absorbance. First we acquired an $\mathrm{Ag}$ oxidation peak by running $\mathrm{LSV}$ in $0.5 \mathrm{M} \mathrm{H}_{2} \mathrm{SO}_{4}$ of Glass/LTO/Ag-Pd electrodes from 0 to $0.6 \mathrm{~V}$. Next, we obtained LSVs of the same electrode from 0 to $0.8 \mathrm{~V}$ in $10 \mathrm{mM} \mathrm{KBr}$ plus $0.1 \mathrm{M} \mathrm{HClO}_{4}$ to acquire the $\mathrm{Pd}$ oxidation peak. 

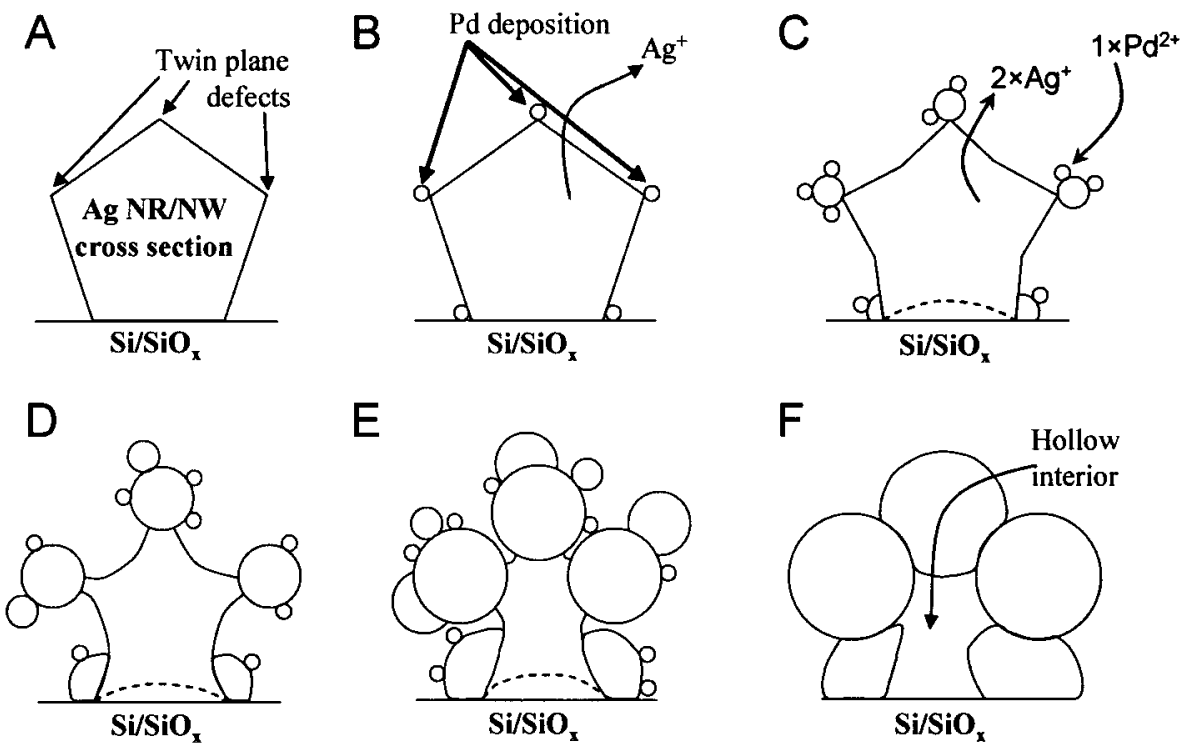

Figure 3.4. Model of galvanic exchange reaction with preferential decoration of twinplane defects with time. 
Figure 3.5 A and B shows LSVs of galvanically exchanged $\mathrm{Ag}$ nanostructures after different exchange time with $5.0 \times 10^{-5} \mathrm{M} \mathrm{PdCl}_{4}{ }^{2-}$, which correlates to the SEM images in Figure 3.3 and UV-Vis data in Figure 1A. Figure 3.5 A shows that the amount of $\mathrm{Ag}$ in the sample decreases with time during the exchange, as determined from the decreasing area under the $\mathrm{Ag}$ oxidation peak with increasing exchange time. This is expected since the Pd replaces $\mathrm{Ag}$ during exchange. After 60 min of exchange, the $\mathrm{Ag}$ peak is still visible, however, showing that not all of the $\mathrm{Ag}$ became oxidized during the reaction. Figure $3.5 \mathrm{~B}$ shows that the Pd oxidation peak increases as a function of exchange time, as expected since Pd deposited on the surface and replaced the Ag. The peak at $\sim 0.1 \mathrm{~V}$ is due to oxidation of leftover $\mathrm{Ag}$ in $\mathrm{Br}^{-}$(to form $\mathrm{AgBr}$ ). The amount of leftover $\mathrm{Ag}$ during the $\mathrm{Pd}$ oxidation is less than $10 \%$ of the $\mathrm{Ag}$ oxidation in $\mathrm{H}_{2} \mathrm{SO}_{4}$, but does represent a small error in the measured amount of Ag. We used the LSV data to calculate the ratio of the mol of $\mathrm{Ag}$ and $\mathrm{Pd}$ present in the sample to roughly estimate the composition of the nanostructures. The following equation gives the mol of metal from the measured Coulombs of charge (Q) under the LSV peaks in Figure 3.5 A and 3.5 B, Faradays constant (F), and the number of electrons involved in the oxidation (n):

$$
\mathrm{mol}=\mathrm{Q} / \mathrm{nF}
$$

Figure 3.5 $\mathrm{C}$ shows a comparison of the normalized absorbance (yellow circles) and the actual Ag composition determined by LSV (red triangles) as a function of exchange time. Figure $3.5 \mathrm{C}$ also shows a theoretical plot of the $\% \mathrm{Ag}$ as a function of time based on the assumption that all of the $\mathrm{PdCl}_{4}{ }^{2-}$ molecules reacted with $\mathrm{Ag}$ on the surface at a diffusion-controlled rate. The mol of $\mathrm{PdCl}_{4}{ }^{2-}$ to reach the surface with time, assuming 

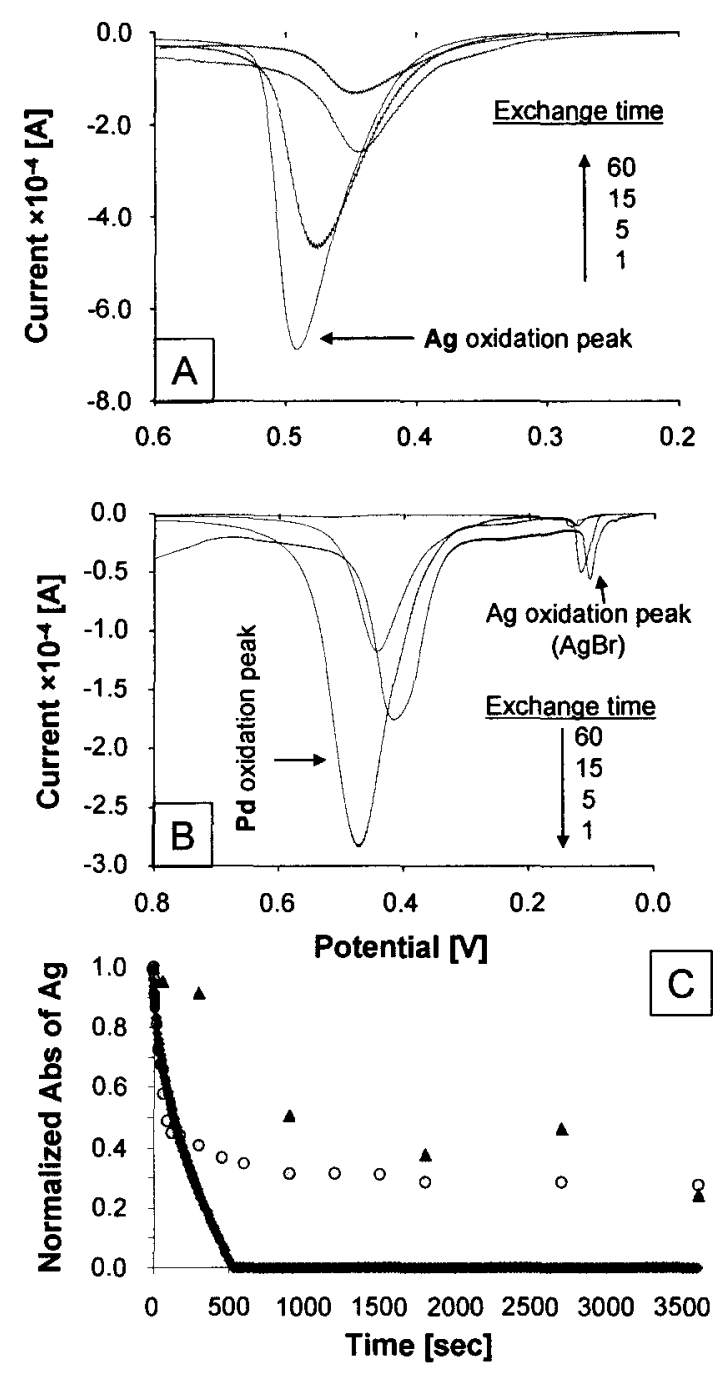

Figure 3.5. Linear sweep voltammograms of ITO/MPTMS/Auseed/AgNW after exchange with $5.0 \times 10^{-5} \mathrm{M} \mathrm{PdCl}_{4}{ }^{2-}$ for various times obtaines in A) $0.5 \mathrm{M} \mathrm{H}_{2} \mathrm{SO}_{4}$ and B) $0.01 \mathrm{M} \mathrm{KBr}$ in $0.1 \mathrm{M} \mathrm{HClO}_{4}$. Each time represents different sample where the $\mathrm{Ag}$ oxidation and Pd oxidation was performed in that order. C) shows a comparison between the experimental normalized absorbance (yellow circles), experimental \% Ag (red triangles), and theoretical (calculated) (blue diamonds) amount of Ag present on the sample after exchange with $5.0 \times 10^{-5} \mathrm{M} \mathrm{PdCl}_{4}{ }^{2-}$ for various times. 
linear diffusion, is given by:

$$
m o l=\frac{2 \cdot A \cdot C \cdot D^{1 / 2} \cdot t^{1 / 2}}{\pi^{1 / 2}}
$$

where $\mathrm{A}$ is area of the substrate, $\mathrm{C}$ is the concentration, $\mathrm{D}$ is the diffusion coefficient $\left(1.0 \times 10^{-5} \mathrm{~cm}^{2} / \mathrm{s}\right),{ }^{91}$ and $\mathrm{t}$ is time. If every mol of $\mathrm{PdCl}_{4}{ }^{2-}$ reacted with the $\mathrm{Ag}$, then the $\% \mathrm{Ag}$ would decrease as shown by the blue diamonds in Figure $3.5 \mathrm{C}$, taking into account that $2 \mathrm{Ag}^{0}$ become oxidized for each $\mathrm{PdCl}_{4}{ }^{2-}$ reduced. There are three important points to note in the plot of Figure 3.5 C. First, the actual composition of Ag does not track well with the normalized absorbance. With only about $10 \%$ of Pd in the nanostructure, the LSPR band of the Ag drops to close to its lowest value. Additional increase in Pd and loss of $\mathrm{Ag}$ does not alter the normalized absorbance appreciably after that. Therefore, the UV-Vis data do not reflect the composition and kinetics of the exchange process accurately. Second, the theoretical plot of $\% \mathrm{Ag}$ versus exchange time, based on diffusion-limited reactivity, does not match well the actual composition of Ag with time. The actual rate is much slower than that expected for a diffusion-limited process. Theoretically, all of the Ag should be oxidized after about 520 s, while in actuality, 30\% of the $\mathrm{Ag}$ remains even after $3600 \mathrm{~s}$. Related to this, the third point is that the reaction does not reach completion as expected. This could not have been determined by SEM or UV-Vis alone. Some Ag remains stable for very long times. It may be trapped in the interior of the structure and not accessible to react with $\mathrm{PdCl}_{4}{ }^{2-}$ or it may have alloyed with Pd to form more stable AgPd. This would shift the thermodynamics of the Ag oxidation.

Since we observed that not all of the Ag oxidized following $3600 \mathrm{~s}$ exchange with $5.0 \times 10^{-5} \mathrm{M} \mathrm{PdCl}_{4}{ }^{2-}$, we decided to determine the amount of $\mathrm{Ag}$ in the nanostructures 
exchanged after $3600 \mathrm{~s}$ for the other $\mathrm{PdCl}_{4}{ }^{2-}$ concentrations. Figure 3.6 shows a plot of $\%$ $\mathrm{Ag}$ as a function of the concentration of $\mathrm{PdCl}_{4}{ }^{2-}$ used in the exchange. Interestingly, the three highest concentrations show the same amount of $\mathrm{Ag}$ in the final structure (20-30\%). These three samples also had similar final normalized absorbance values. The final AgPd seems to reach a stable value independent of the $\mathrm{PdCl}_{4}{ }^{2-}$ concentration or the rate of exchange for these values. The $\% \mathrm{Ag}$ is around $70-80 \%$ for exchange with the two lower $\mathrm{PdCl}_{4}{ }^{2-}$ concentrations. One would expect the exchange with $2.5 \times 10^{-5} \mathrm{M} \mathrm{PdCl}_{4}{ }^{2-}$ to lie in between that with the $1.0 \times 10^{-5} \mathrm{M} \mathrm{PdCl}_{4}{ }^{2-}$ and $5.0 \times 10^{-5} \mathrm{M} \mathrm{PdCl}_{4}{ }^{2-}$. The larger value of $\mathrm{Ag}$ is consistent with the larger normalized absorbance in the UV-Vis spectra (Figure 3.1), but the LSV is more quantitative.

\subsection{CONCLUSIONS.}

A benefit of having Ag nanostructures grown directly on surfaces for galvanic exchange studies is that the exchange can be performed on bare Ag nanostructures in a variety of environments. The exchange conditions can be modified and tailored to study the effect of intentionally changed conditions which may involve different concentrations or the effect of additives or surfactants on the nanostructure morphology. In theory, we can also potentially monitor the same nanostructure during exchange in real time by microscopy on marked samples or performed in-situ. Because the structures are surface-attached, we rely on microscopy and surface analytical methods for imaging and composition analysis, respectively.

Here we showed that the galvanic exchange rate has an effect on the nanostructure morphology. At low concentrations the exchange occurs at the twin-plane sites along the NWs decorating them with small Pd or PdAg nanoparticles. With higher 


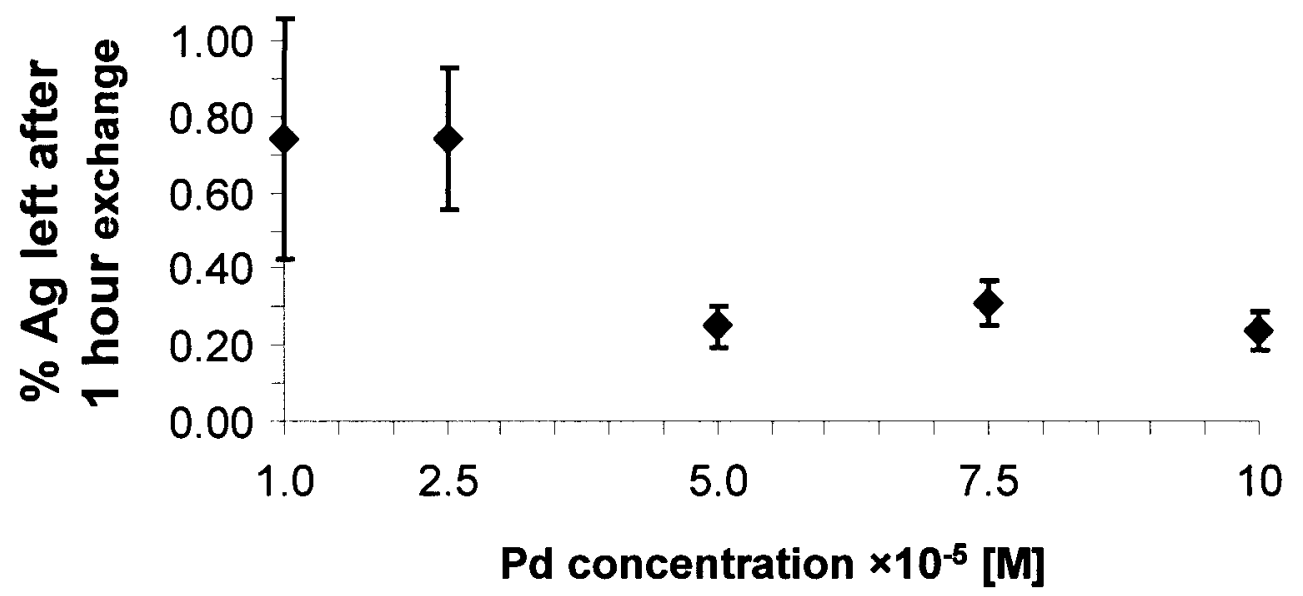

Figure 3.6. $\% \mathrm{Ag}$ vs. Pd concentration used for the galvanic exchange after 1 hour exchange. 
concentrations, the reaction proceeds faster, leading to $\mathrm{Pd}$ deposition and growth evenly over the Ag NW. We used LSV to estimate the Ag and Pd composition on glass/ITO electrodes and correlated the results with UV-Vis data.

The results showed that the actual composition (electrochemical data) does not match the normalized absorbance well. This is due to the fact that the optical properties reflect what is occurring mostly on the surface, whereas the electrochemical data reflect the entire nanostructure. The electrochemical data shows that the rate of the exchange is lower than predicted for a diffusion-limited process and does not reach completion, leaving approximately $30 \%$ of $\mathrm{Ag}$ remaining after an hour of galvanic exchange for higher concentrations and approximately $75 \%$ for lower ones. These results provide new information about galvanic exchange at the nanoscale, but there are several issues that require further attention, such as the effect of surfactants, polymers, and ions on galvanic exchange. We intend to report on these factors in the future as we continue this line of research. 


\section{CHAPTER IV}

\section{EFFECT OF CTAB AND KBr ON THE GALVANIC EXCHANGE REACTION BETWEEN SILVER NANOWIRES AND PdCl ${ }_{4}^{2-}$ GROWN DIRECTLY ON SURFACES}

Here we describe the synthesis and galvanic exchange of surface-grown $\mathrm{Ag}$ nanorods (NRs) and nanowires (NWs) with $\mathrm{PdCl}_{4}{ }^{2-}$ in the presence of surfactants $(\mathrm{CTAB})$ and additives $(\mathrm{KBr})$ as a function of $\mathrm{PdCl}_{4}{ }^{2-}$ concentration. The morphology of the resulting AgPd alloy nanostructures depends on the presence of surfactants or additives during the exchange but not significantly on the galvanic exchange rate. Concentrations of $\mathrm{PdCl}_{4}{ }^{2-} 2.5 \times 10^{-5} \mathrm{M}$ to $1.0 \times 10^{-4} \mathrm{M}$ showed similar rates of exchange in the presence of CTAB based on the UV-Vis measurements with time and similar morphologies of Ag nanostructures after the exchange. The rate was slightly slow for a concentration of $1.0 \times 10^{-5} \mathrm{M} \mathrm{PdCl}_{4}{ }^{2-}$. In the case of exchange of $\mathrm{Ag}$ nanowires with $\mathrm{PdCl}_{4}{ }^{2-}$ in $0.1 \mathrm{M} \mathrm{CTAB}, \mathrm{Pd}$ deposition occurs preferentially at high energy twin plane defects in the form of a continues 'wire' during the early stages of exchange. At later stages of exchange the Pd 'wire' remains the deposition site, while terraces become significantly etched. This morphology is significantly different compared to exchange with $\mathrm{PdCl}_{4}{ }^{2-}$ in the absence of CTAB. UV-Vis and composition analysis by linear sweep voltammetry as a function of time shows that the galvanic exchange rate is slower 
compared to exchange without $\mathrm{CTAB}$ and slower than the diffusion-limited rate. LSV show that after an hour of galvanic exchange in presence of $0.1 \mathrm{M} \mathrm{CTAB}, \mathrm{Ag}$ is completely removed from the sample, which is different when exchange occurs with aqueous $\mathrm{PdCl}_{4}{ }^{2-}$ where $25-30 \% \mathrm{Ag}$ remains on the surface. The exchange in $0.1 \mathrm{M} \mathrm{KBr}$ shows an erratic dependence of $\mathrm{PdCl}_{4}{ }^{2-}$ concentration. The exchange rate is markedly faster compared to that in water only or $\mathrm{CTAB}$ and the morphology is different. At early stages, the wires appear smoothly-coated with some bumps and at later stages the wires appear high etched and disconnected.

\subsection{INTRODUCTION}

Mainly Au and Ag nanostructures have been widely studied because their localized surface plasmon (LSPR) band is located in visible region which allows their easy identification. While these metallic nanostructures have several useful properties and applications, there are also cases where bimetallic or multimetal nanostructures are desirable. Out of several methods for synthesizing bi- or multi-metal nanostructures, galvanic exchange method has recently gained wide interest. In galvanic exchange, a metal in the reduced form becomes replaced by a metal in the oxidized form by a simple oxidation-reduction reaction. The requirement is that the metal initially in the reduced form has a more negative reduction potential than the metal initially in the oxidized form. Galvanic exchange is an example of a very simple chemical reaction and since it occurs spontaneously the process can be controlled and stopped at a desired time to obtain desired composition of the final nanostructure.

It was shown that bimetallic structures, $\mathrm{Pd}-\mathrm{on}-\mathrm{Au}, \mathrm{Au}-\mathrm{Pt}$ or $\mathrm{Au}-\mathrm{Pd}$, show enhanced catalytic properties compared to pure metal. ${ }^{92,93}$ The composition of those 
nanostructures was a key factor in enhancement of catalytic activity. Other nanostructures, obtained through galvanic exchange, showed applications in surfaceenhanced Raman spectroscopy (SERS) ${ }^{38,39,42,57,58}$ possible use as catalysts, ${ }^{59-61}$ or as hydrogen sensors. ${ }^{40,41}$

There are few studies on the effect of several variables, such as the reaction rate, presence of stabilizers (surfactants, polymers), and the effect of various ions in solution on the galvanic exchange rate and nanostructure morphology. The goal of our research is to better understand the effect of these variables on the morphology of galvanicexchanged metal nanostructures and to use the knowledge gained to create unique structures with useful properties for sensing and catalysis applications.

Recently, we showed the dependence of galvanic exchange between $\mathrm{Ag}$ nanostructures and aqueous $\mathrm{PdCl}_{4}{ }^{2-}$ solutions on the rate of exchange, which depended on the $\mathrm{PdCl}_{4}{ }^{2-}$ concentration. $\mathrm{PdCl}_{4}{ }^{2-}$ concentrations higher than $7.5 \times 10^{-5} \mathrm{M}$ resulted in rapid galvanic exchange that led to deposition of Pd over the entire Ag nanostructure. Concentrations from $1.0 \times 10^{-5}$ to $5.0 \times 10^{-5} \mathrm{M}$ led to preferential Pd deposition at high energy twin plane defects. Depositions were in form of well separated particles that grew with increased exchange time. Linear sweep voltammetry allowed us to estimate the composition of the formed $\mathrm{PdAg}$ nanostructures at various times, showing that the galvanic exchange rate was much slower than if it was diffusion-limited.

Here, we describe the galvanic exchange of $\mathrm{Ag} \mathrm{NRs} / \mathrm{NWs}$ with $\mathrm{PdCl}_{4}{ }^{2-}$ as a function of $\mathrm{PdCl}_{4}{ }^{2-}$ concentration in the presence of $\mathrm{CTAB}$ and $\mathrm{KBr}$. We first synthesized the $\mathrm{Ag} \mathrm{NRs} / \mathrm{NWs}$ directly on glass or $\mathrm{Si} / \mathrm{SiO}_{\mathrm{x}}$ surfaces. The advantage of surface-attached growth is that we can intentionally add surfactants, polymers, or other 
additives to study their effect on the process of galvanic exchange. It is not always possible to completely control the exchange conditions for nanostructures in solution. We performed the exchange reaction on the surface-attached nanostructures in $\mathrm{PdCl}_{4}{ }^{2-}$ solutions containing $\mathrm{CTAB}$ or $\mathrm{KBr}$. We also varied the bulk $\mathrm{PdCl}_{4}{ }^{2-}$ concentration. In this work we show that the morphology of the galvanically-exchanged $\mathrm{Ag}$ nanostructures in the presence of $\mathrm{CTAB}$ or $\mathrm{KBr}$ is drastically different to these prepared by exchange in aqueous $\mathrm{PdCl}_{4}{ }^{2-}$ only. We also show that the reaction rate and morphology does not significantly depend on the $\mathrm{PdCl}_{4}{ }^{2-}$ concentration over this range.

\subsection{EXPERIMENTAL SECTION}

\subsubsection{Chemicals and materials}

Silver nitrate $\left(\mathrm{AgNO}_{3}, 99+\%\right)$, sodium borohydride $\left(\mathrm{NaBH}_{4}, 98 \%\right)$, potassium tetrachloropalladate (II) $\left(\mathrm{K}_{2} \mathrm{PdCl}_{4}, 98 \%\right)$, and L-ascorbic acid (99.9\%) were purchased from Sigma-Aldrich. Hydrogen tetrachloroaurate trihydrate $\left(\mathrm{HAuCl}_{4} \cdot 3 \mathrm{H}_{2} \mathrm{O}\right)$ was synthesized according to a literature procedure ${ }^{66}$ Citric acid trisodium salt was purchased from Bio-Rad Laboratories. Sodium phosphate dibasic and sodium phosphate tribasic were purchased from Fisher Scientific Company. Potassium bromide (min 99.0\%), perchloric acid (60\%), hydrogen peroxide $\left(\mathrm{H}_{2} \mathrm{O}_{2} 30 \%\right.$ solution), and 2-propanol (HPLC grade, 99.99\%) were purchased from EMD. Sulfuric acid was purchased from BDH Aristar (distributed by VWR). Cetyltrimethylammonium bromide (CTAB) was purchased from Fluka (Assay $\geq 99.0 \%$ ). NANOpure ultrapure water (Barnstead Nanopure Deionization System, resistivity of $18 \mathrm{M} \Omega-\mathrm{cm}$ ) was used for all aqueous solutions. Indium-tin-oxide (ITO) - coated glass (Glass/ITO, $\mathrm{R}_{s}=8-12 \Omega$ ) substrates were purchased from Delta Technologies Limited (Stillwater, MN). 


\subsubsection{Synthesis of Ag nanostructures directly on surfaces}

We synthesized Ag nanostructures directly on surfaces as described previously. ${ }^{7}$ First, glass or $\mathrm{Si} / \mathrm{SiO}_{\mathrm{x}}$ substrates were cleaned and functionalized with mercaptopropyltrimethoxysilane (MPTMS). (Glass or $\mathrm{Si} / \mathrm{SiO}_{\mathrm{x}}$ )/MPTMS substrates were then placed in an aqueous solution of 3-5 nm Au seed nanoparticles (Au NPs) ${ }^{13,29}$ for 20 minutes. Finally, (glass or $\mathrm{Si} / \mathrm{SiO}_{\mathrm{x}}$ )/MPTMS/Au NP substrates were placed in an $\mathrm{Ag}$ growth solution, containing $10 \mathrm{~mL}$ of $\mathrm{pH} 10.6$ phosphate buffered $0.08 \mathrm{M} \mathrm{CTAB}, 250 \mu \mathrm{L}$ of $0.01 \mathrm{M} \mathrm{AgNO}_{3}$, and $500 \mu \mathrm{L}$ of $0.1 \mathrm{M}$ ascorbic acid, for 30 minutes in a $28^{\circ} \mathrm{C}$ temperature bath. This procedure leads to Ag nanostructures grown on the surface with a density of $26 \pm 14 \mu \mathrm{m}^{-2}$ and a $~ 3 \%$ yield of $1 \mathrm{D}$ Ag nanorods (NRs) and nanowires (NWs) on the surface with a diameter of $34 \pm 14 \mathrm{~nm}$ and lengths ranging from $200 \mathrm{~nm}$ to $10 \mu \mathrm{m}{ }^{7}$ Since most of the structures have an aspect ratio (AR) greater than 20, we will refer to all 1D nanostructures as NWs in the text, even though some may technically be NRs (AR < 20).

\subsubsection{Galvanic exchange between $\mathrm{Ag} \mathrm{NWs}$ and $\mathrm{PdCl}_{4}{ }^{2-}$ in $\mathrm{CTAB}$ and $\mathrm{KBr}$}

The surface-attached (glass or $\mathrm{Si} / \mathrm{SiO}_{\mathrm{x}}$ )/MPTMS/Ag NWs were placed into 0.01 , $0.001,0.0001,0.000075,0.000050,0.000025$, or $0.000010 \mathrm{M} \mathrm{PdCl}_{4}{ }^{2-}$ solutions containing $0.1 \mathrm{M} \mathrm{CTAB}$ or $0.1 \mathrm{M} \mathrm{KBr}$ for times ranging from 0 to $3600 \mathrm{sec}$. Glass samples were placed in the appropriate solution for a desired period of time, removed, rinsed with nanopure $\mathrm{H}_{2} \mathrm{O}$, and dried under a stream of nitrogen prior to UV-Vis analysis. $\mathrm{Si} / \mathrm{SiO}_{\mathrm{x}}$ samples were placed in the appropriate solution, removed at a desired time, rinsed with nanopure $\mathrm{H}_{2} \mathrm{O}$, dried under $\mathrm{N}_{2}$, and characterized by scanning electron microscopy (SEM) with our focus on NWs. 


\subsubsection{Electrochemical characterization by Linear Sweep Voltammetry}

We previously developed a compositional analysis by linear sweep stripping voltammetry (LSV) in order to obtain the approximate metal composition of the galvanically-exchanged nanostructures. We used a three electrode setup where glass/ITO/MPTMS/Au seed/Ag nanostructures (before and after galvanic exchange with $\left.\mathrm{PdCl}_{4}{ }^{2-}\right)$ served as the working electrode, $\mathrm{Ag} / \mathrm{AgCl}(3 \mathrm{M} \mathrm{KCl})$ as a reference, and $\mathrm{Pt}$ wire as a counter electrode. We ran the $1^{\text {st }} \mathrm{LSV}$ in $0.5 \mathrm{M} \mathrm{H}_{2} \mathrm{SO}_{4}$ from 0.0 to $0.6 \mathrm{~V}$ at 10 $\mathrm{mV} / \mathrm{sec}$ in order to obtain an $\mathrm{Ag}$ oxidation (or stripping) peak. Next, the sample was gently rinsed in nanopure $\mathrm{H}_{2} \mathrm{O}$ and a $2^{\text {nd }} \mathrm{LSV}$ scan was obtained in $0.01 \mathrm{M} \mathrm{KBr}$ plus 0.1 $\mathrm{M} \mathrm{HClO}_{4}$ from 0.0 to $0.8 \mathrm{~V}$ at $10 \mathrm{mV} / \mathrm{sec}$ in order to monitor the Pd striping peak. Linear sweep voltammograms were analyzed and the composition of the nanostructures was determined by integrating the areas under the oxidation peaks.

\subsubsection{Instrumentation}

Scanning Electron Microscopy images were obtained at different magnifications using a Carl Zeiss SMT AG SUPRA 35VP field emission scanning electron microscope (FESEM) operating at an accelerating voltage of 5.00 to $20.00 \mathrm{kV}$ and using an in-lens ion annular secondary electron detector. UV-Vis spectra were obtained using a Varian Cary 50 Bio UV-Visible Spectrophotometer. A CH Instruments (Austin, TX) 630C electrochemical analyzer/workstation was used for electrochemical stripping analysis of $\mathrm{Ag}$ and galvanically exchanged $\mathrm{AgPd}$ alloy nanostructures. 


\subsection{RESULTS AND DISCUSSION}

We recently described the galvanic exchange of Ag nanostructures grown directly on surfaces in aqueous $\mathrm{PdCl}_{4}{ }^{2-}$ solutions. The exchange environment was stabilizer-free and showed decoration with Pd particles along the twin-plane defects of $\mathrm{Ag}$ nanowires. Here we intentionally add a surfactant $\mathrm{CTAB}$ or $\mathrm{KBr}$ salt in excess to the reaction to study the effect of these additives on the galvanic exchange rate and morphology of the PdAg NWs. The focus of our study is on Ag NWs because of our interest in 1D metallic nanostructures. Ag is useful as a template metal for forming alloys of pure metals that are more noble such as $\mathrm{Pt}, \mathrm{Au}$, and $\mathrm{Pd}$.

Figure 4.1 A shows UV-Vis spectra of a sample of Ag nanostructures grown on glass before and at various times during galvanic exchange for $3600 \mathrm{~s}$ with an aqueous solution of aqueous $5.0 \times 10^{-5} \mathrm{PdCl}_{4}{ }^{2-}$ in $0.1 \mathrm{M} \mathrm{CTAB}$ solution. At $0 \mathrm{~s}$ of exchange, the pure Ag nanostructure exhibited a prominent, well-known localized surface plasmon (LSPR) band at about $420 \mathrm{~nm}$. As the exchange with $\mathrm{PdCl}_{4}{ }^{2-}$ proceeded, the $\mathrm{Ag} \mathrm{LSPR}$ band decreased in intensity and red shifted as shown previously. The red shift appears smaller compared to exchange in only aqueous $\mathrm{PdCl}_{4}{ }^{2-}$. This is consistent with $\mathrm{PdAg}$ alloy formation as the exchange process occurs.

Figure 4.1 B shows the average, normalized peak absorbance of the LSPR band $(n=3)$ as a function of exchange time for concentrations of $\mathrm{PdCl}_{4}{ }^{2-}$ ranging from $1.0 \times 10^{-5}$ $\mathrm{M}$ to $1.0 \times 10^{-4} \mathrm{M}$ as shown plus $0.1 \mathrm{M} \mathrm{CTAB}$. The values of absorbance were measured at the peak maxima. The plot shows that all concentrations behave similarly during the exchange, except for the slightly slower rate of exchange with $1.0 \times 10^{-5} \mathrm{M} \mathrm{PdCl}_{4}{ }^{2-}$ plus 

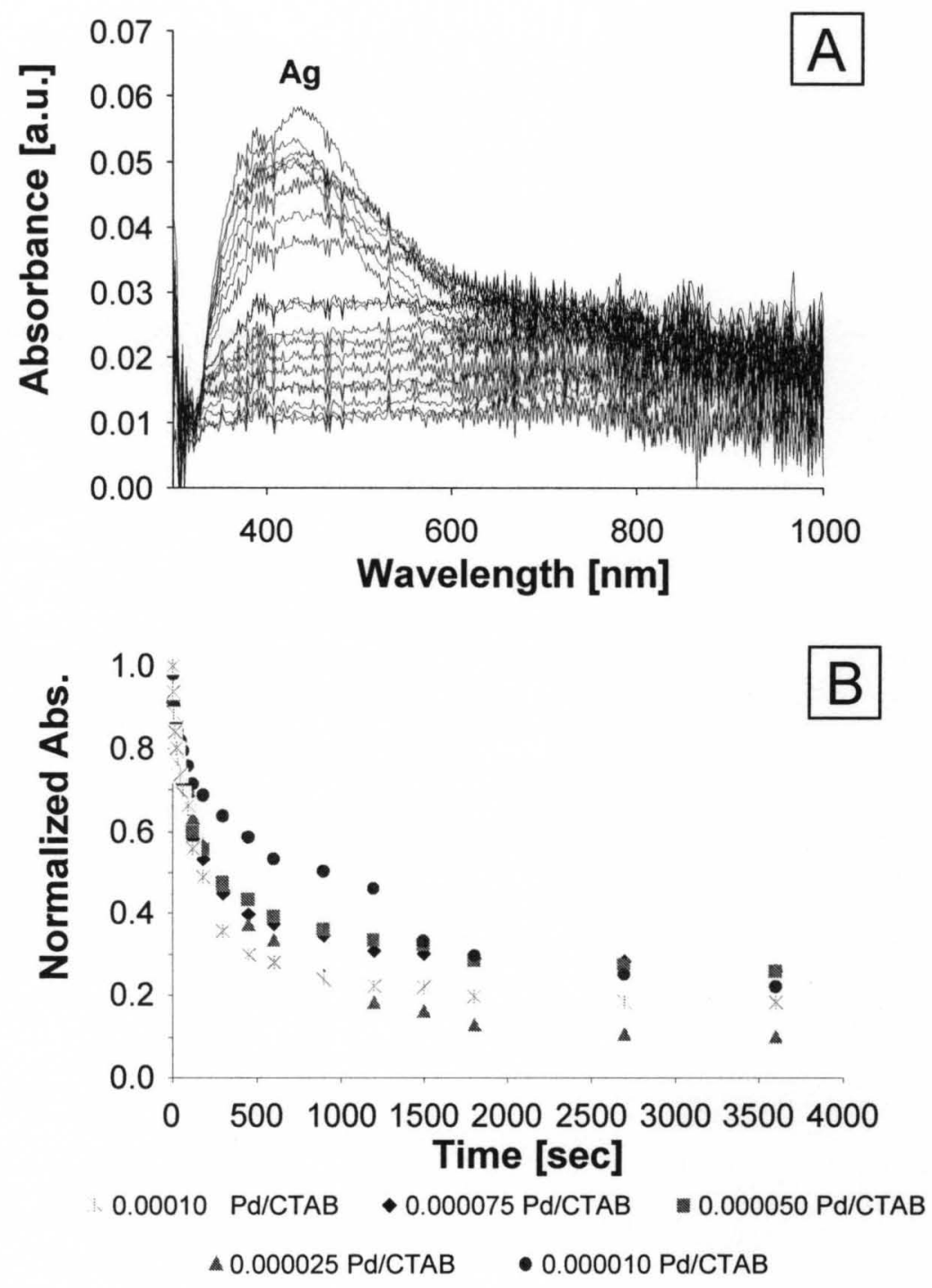

Figure 4.1. (A) UV-Vis spectra of an Ag NW sample exchanged with $5.0 \times 10^{-5} \mathrm{M}$ $\mathrm{PdCl}_{4}{ }^{2-}$ in $0.1 \mathrm{M}$ CTAB solution. (B) A plot of the normalized absorbance of the LSPR band as a function of time for galvanic exchange in $1.0 \times 10^{-5}, 2.5 \times 10^{-5}, 5.0 \times 10^{-5}, 7.5 \times 10^{-5}$, and $1.0 \times 10^{-4} \mathrm{PdCl}_{4}{ }^{2-}$ concentrations in $0.1 \mathrm{M} \mathrm{CTAB}$. 
0.1 M CTAB. There is not a significant dependence of exchange rate on the $\mathrm{PdCl}_{4}{ }^{2-}$ concentration as we observed for exchange in the absence of $0.1 \mathrm{M} \mathrm{CTAB}$ previously. Also, all concentrations show a similar final normalized absorbance from 0.1 to 0.3 , which is drastically different compared to exchange in water only with various $\mathrm{PdCl}_{4}{ }^{2-}$ concentrations. To estimate the rate of the exchange we calculated the initial slope of the curve over the first 30 seconds. The average from the plots for $1.0 \times 10^{-4} \mathrm{M}, 7.5 \times 10^{-5} \mathrm{M}$, $5.0 \times 10^{-5} \mathrm{M}, 2.5 \times 10^{-5} \mathrm{M}$, and $1.0 \times 10^{-5} \mathrm{M} \mathrm{PdCl}_{4}{ }^{2-}$ concentrations were $0.0078,0.0072$, $0.0060,0.0064$, and 0.0052 , respectively, indicating a slight trend to slower exchange with decreasing $\mathrm{PdCl}_{4}{ }^{2-}$ and a slower rate of exchange compared to exchange in water only for the three highest concentrations and faster rate for the two lowest concentrations. We expected the rate of exchange to decrease with decreasing $\mathrm{PdCl}_{4}{ }^{2-}$ concentrations, since the flux of $\mathrm{PdCl}_{4}{ }^{2-}$ to the $\mathrm{Ag}$-coated surface depends on the bulk $\mathrm{PdCl}_{4}{ }^{2-}$ concentration. From this data, the rate appears to be zero order in $\mathrm{PdCl}_{4}{ }^{2-}$ concentration.

Figure 4.2 A shows the UV-Vis spectra of a sample of Ag nanostructures grown on glass before and at various times during the galvanic exchange for $3600 \mathrm{~s}$ with a $5.0 \times 10^{-5} \mathrm{M} \mathrm{PdCl}_{4}{ }^{2-}$ plus $0.1 \mathrm{M} \mathrm{KBr}$ solution. Similarly, as in the previous case, at $0 \mathrm{~s}$ of exchange the pure Ag nanostructure shows a LSPR band at $\sim 420 \mathrm{~nm}$. As the exchange progresses the Ag LSPR band decreases in intensity and red shifts as shown in water only and CTAB. Figure 4.2 B shows the normalized peak absorbance of the LSPR band as a function of exchange time with a concentrations range from $1.0 \times 10^{-5} \mathrm{M}$ to $7.5 \times 10^{-5} \mathrm{M}$ $\mathrm{PdCl}_{4}^{2-}$. The rate of exchange in the presence of $0.1 \mathrm{M} \mathrm{KBr}$ does not vary systematically with the change of $\mathrm{PdCl}_{4}{ }^{2-}$ concentration; it is erratic. Oddly, the highest concentrations 

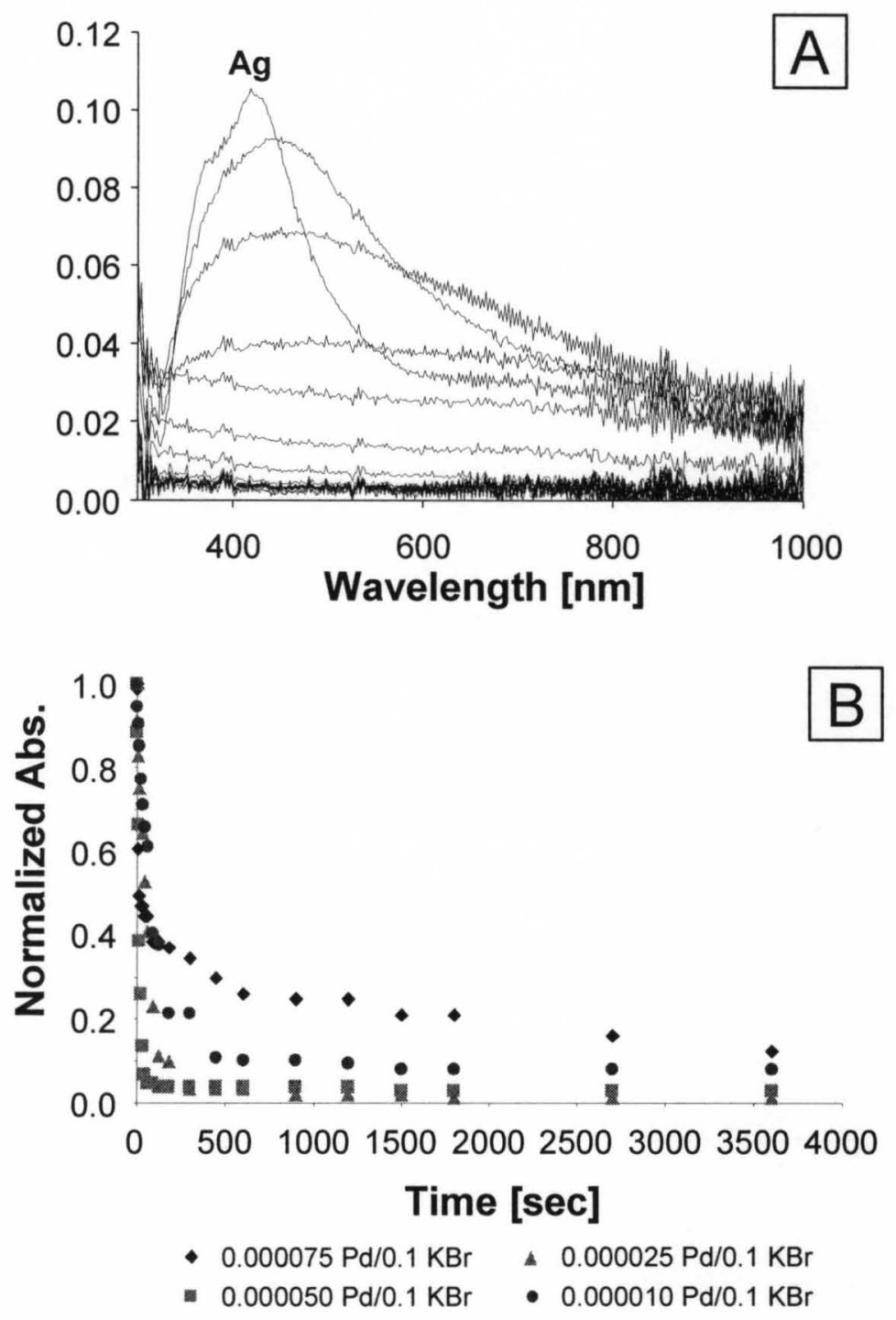

Figure 4.2. (A) UV-Vis spectra of an Ag NW sample exchanged with $5.0 \times 10^{-5} \mathrm{M}$ $\mathrm{PdCl}_{4}{ }^{2-}$ in $0.1 \mathrm{M} \mathrm{KBr}$ solution. (B) A plot of the normalized absorbance as a function of time for $1.0 \times 10^{-5}, 2.5 \times 10^{-5}, 5.0 \times 10^{-5}$, and $7.5 \times 10^{-5} \mathrm{M} \mathrm{PdCl}_{4}{ }^{2-}$ concentrations plus $0.1 \mathrm{M}$ $\mathrm{KBr}$. 
in $\mathrm{KBr}$ show a slightly slower exchange rate compared to lower concentrations. The slopes for the first 30 s are faster compared to exchange in $\mathrm{CTAB}$ and water only. All concentrations seem to reach completion within approximately 10 minutes and the final absorbance values did not change significantly $(0-0.2)$. The absorbance value of zero was odd since even pure Pd has some absorbance at all wavelengths.

In order to determine how the rate of galvanic exchange affects the morphology of the exchanged structure, we performed exchange reactions at three different concentrations and stopped them at the same level of exchange as judged by the normalized UV-Vis absorbance value.

Figure 4.3 shows SEM images of Ag NWs galvanically exchanged with $2.5 \times 10^{-5}$ $\mathrm{M}, 5.0 \times 10^{-5} \mathrm{M}$, and $7.5 \times 10^{-5} \mathrm{M} \mathrm{PdCl}_{4}{ }^{2-}$ in $0.1 \mathrm{M} \mathrm{CTAB}(\mathrm{A}-\mathrm{C})$ and in $0.1 \mathrm{M} \mathrm{KBr}(\mathrm{D}-\mathrm{F})$ until the normalized absorbance reached $\sim 0.6$. Based on the previous assumption that the absorbance is closely related to the composition, these AgPd NWs should have a similar composition that was reached at different rates. It took 180,120 , and $120 \mathrm{~s}$, respectively, with increasing $\mathrm{PdCl}_{4}{ }^{2-}$ in $0.1 \mathrm{M} \mathrm{CTAB}$ concentration, to reach the normalized value of 0.6. It took 40,6 , and $5 \mathrm{~s}$, respectively with increasing $\mathrm{PdCl}_{4}{ }^{2-}$ in $0.1 \mathrm{M} \mathrm{KBr}$ concentration to reach a similar normalized absorbance value of 0.6 . The similar exchange times to reach a similar absorbance shows that there is almost no dependence of exchange rate on $\mathrm{PdCl}_{4}{ }^{2-}$ concentration. The morphology of the nanostructures does not vary significantly in the case of exchange in $\mathrm{CTAB}$. In all cases the resulting final structures are decorated along the twin-plane defects of $\mathrm{Ag}$ nanowires with $\mathrm{Pd}$, which forms a continuous 'wire' along the entire structure. This is similar for all structures, 

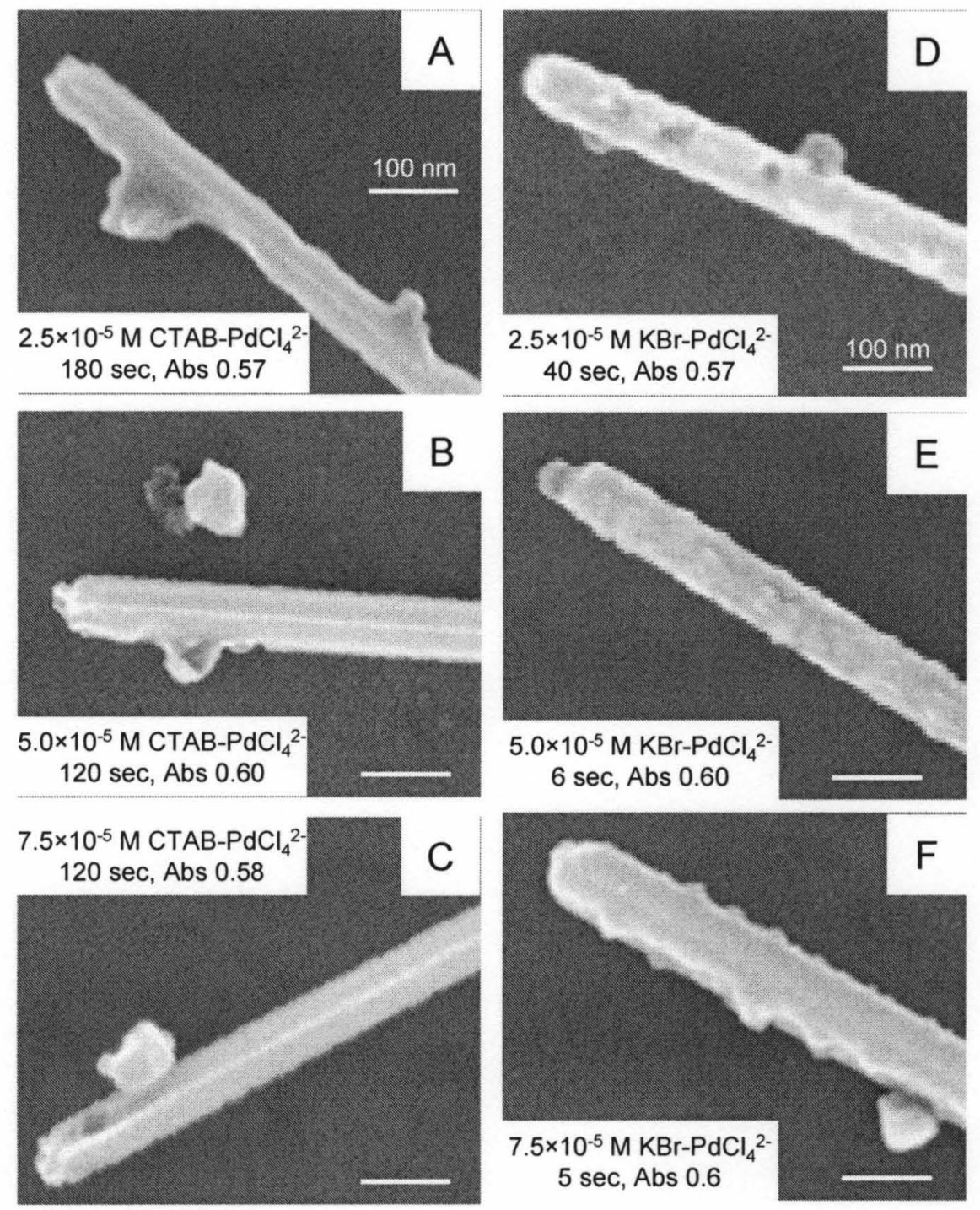

Figure 4.3. SEM images of Ag nanostructures galvanically-exchanged with different concentrations of $\mathrm{PdCl}_{4}{ }^{2-}$ in $0.1 \mathrm{M} \mathrm{CTAB}(\mathrm{A}-\mathrm{C})$ and $0.1 \mathrm{M} \mathrm{KBr}(\mathrm{D}-\mathrm{F})$ until the normalized absorbance reaches $\sim 0.6$. 
although slightly more pronounced at higher concentrations. The 'wire' is decorating the twin plane edge uniformly along the entire Ag nanowire structure.

The galvanic exchange in $0.1 \mathrm{M} \mathrm{KBr}$ leads to slight deformations of the Ag NWs. Concentrations of $2.5 \times 10^{-5} \mathrm{M}$ and $5.0 \times 10^{-5} \mathrm{M}$ show the deposition of $\mathrm{Pd}$ in random areas which show on the images as 'bumps' and also show pitting of the Ag wire. This morphology is dramatically different from that obtained in the presence of CTAB or water only. The highest concentration $\left(7.5 \times 10^{-5} \mathrm{M} \mathrm{PdCl}_{4}{ }^{2-}\right.$ in $\left.0.1 \mathrm{M} \mathrm{KBr}\right)$ shows more bumps along the exterior and some twin-plane decoration, slightly different compared to the lower concentration. These structures are not dramatically different with $\mathrm{PdCl}_{4}{ }^{2-}$ concentration since the rates are similar.

To learn how the normalized intensity of the LSPR band correlates with the Ag and $\mathrm{Pd}$ composition in the nanostructures we used linear sweep voltammetry (LSV) to roughly estimate the $\mathrm{Ag}$ and $\mathrm{Pd}$ composition on glass/ITO electrodes during the galvanic exchange process. First we acquired the Ag oxidation peak by obtaining a LSV in $0.5 \mathrm{M}$ $\mathrm{H}_{2} \mathrm{SO}_{4}$ of the glass/ITO/AgPd electrodes from 0 to $0.6 \mathrm{~V}$. Next, we obtained LSVs of the same electrode from 0 to $0.8 \mathrm{~V}$ in $10 \mathrm{mM} \mathrm{KBr} / 0.1 \mathrm{M} \mathrm{HClO}_{4}$ to acquire the $\mathrm{Pd}$ oxidation peak.

Figure 4.4 shows SEM images of Ag NWs galvanically exchanged with $2.5 \times 10^{-5} \mathrm{M}, 5.0 \times 10^{-5} \mathrm{M}$, and $7.5 \times 10^{-5} \mathrm{M} \mathrm{PdCl}_{4}{ }^{2-}$ in $0.1 \mathrm{M} \mathrm{CTAB}(\mathrm{A}-\mathrm{C}$ ) and in $0.1 \mathrm{M}$ $\mathrm{KBr}(\mathrm{D}-\mathrm{F})$ until the normalized absorbance reached $\sim 0.4$. It took 450,600 , and $450 \mathrm{~s}$ in the case of $\mathrm{CTAB}$, and 60,10 , and $90 \mathrm{~s}$ in the case of $\mathrm{KBr}$ to reach the normalized absorbance of 0.4 . Based on the electrochemical composition analysis shown later, the samples contained $\sim 80 \% \mathrm{Ag}$ (based on exchange in $5 \times 10^{-5} \mathrm{M} \mathrm{PdCl}_{4}{ }^{2-}$ plus $0.1 \mathrm{M}$ 

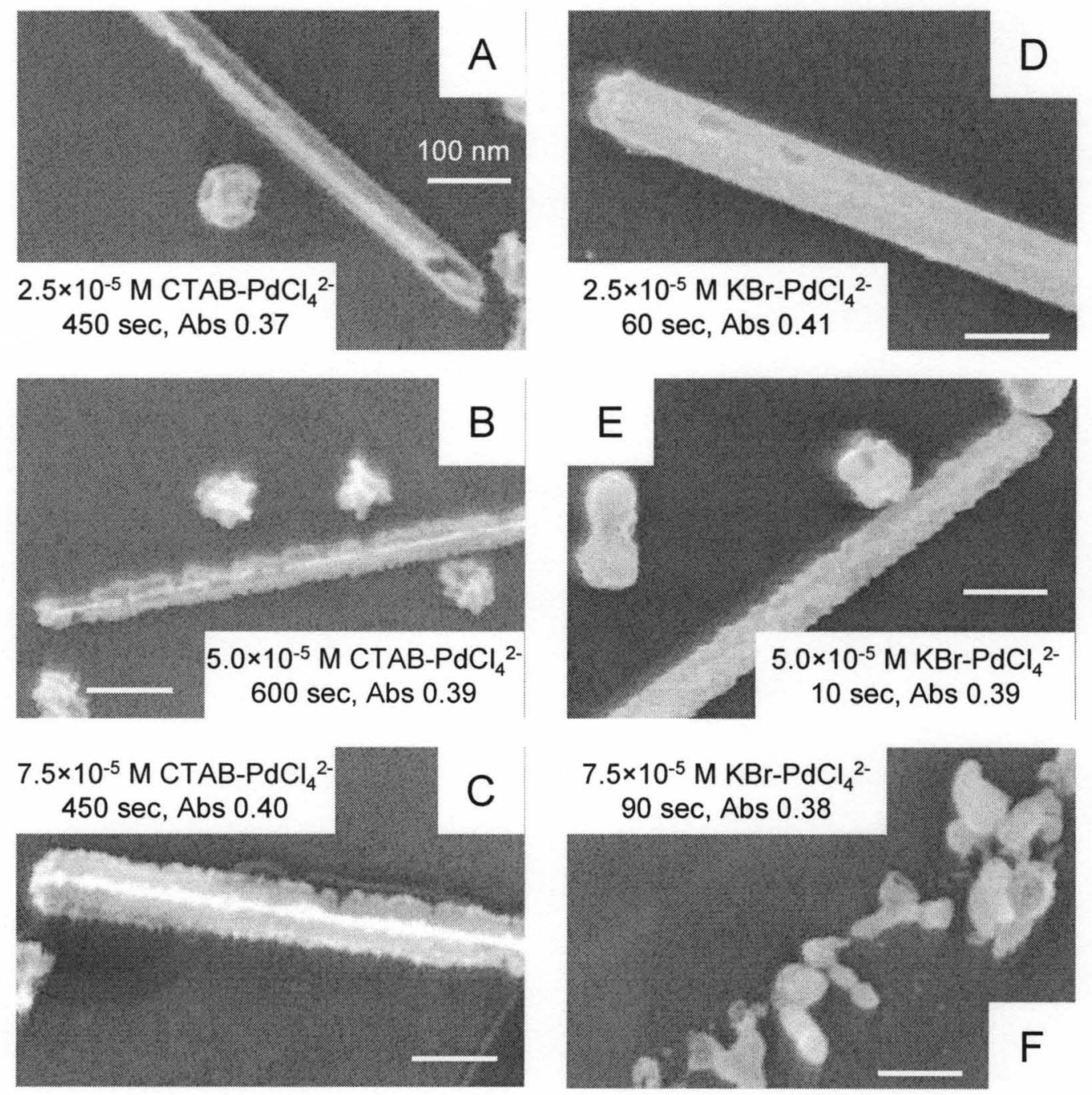

Figure 4.4. SEM images of galvanically exchanged $\mathrm{Ag}$ nanostructures in different concentrations of $\mathrm{PdCl}_{4}{ }^{2-}$ and $0.1 \mathrm{M} \mathrm{CTAB}(\mathrm{A}-\mathrm{C})$ and $0.1 \mathrm{M} \mathrm{KBr}(\mathrm{D}-\mathrm{F})$ until normalized absorbance reached of $\sim 0.4(\sim 70 \% \mathrm{Ag})$. 
$\mathrm{CTAB}$ ). Exchange in $\mathrm{CTAB}$ shows more pronounced deposition at the twin plane sites and increased etching where the terraces were for all samples. An increase in Pd concentration in the presence of $\mathrm{CTAB}$ again did not significantly change the final morphology. In $0.1 \mathrm{M} \mathrm{KBr}$, the nanostructures appear uniform across the entire surface with some bumps and pits, except for at $7.5 \times 10^{-5} \mathrm{M}$, where the structure was completely disconnected. This is an interesting result. In this last case the morphology depended on $\mathrm{PdCl}_{4}{ }^{2-}$ concentration.

Figure 4.5A shows the plots of normalized absorbance with time comparing all three different conditions of exchange for $5.0 \times 10^{-5} \mathrm{M} \mathrm{PdCl}_{4}^{2-}$ concentration. The normalized plots of exchange of $\mathrm{Ag}$ in water are shown as red squares. Exchange in presence of $0.1 \mathrm{M} \mathrm{CTAB}$ is represented by black diamonds and exchange in presence of $0.1 \mathrm{M} \mathrm{KBr}$ is represented by blue triangles. The exchange rate for the $5.0 \times 10^{-5} \mathrm{M} \mathrm{PdCl}_{4}^{2-}$ concentration is clearly fastest in case of $0.1 \mathrm{M} \mathrm{KBr}$, followed by exchange in water and exchange in presence of $0.1 \mathrm{M} \mathrm{CTAB}$.

Figure 4.5 also shows that the exchange medium drastically affects the morphology. In water, the exchange results in the deposition of Pd nanoparticles on twin-plane sites. In 0.1 M CTAB, the deposition on twin-plane sited results in continues lines. In $0.1 \mathrm{M} \mathrm{KBr}$, the NW is uniformly bumpy all over the NW structure.

Figure 4.6A and B shows LSVs of galvanically exchanged $\mathrm{Ag}$ nanostructures after different exchange time with $5.0 \times 10^{-5} \mathrm{M} \mathrm{PdCl}_{4}{ }^{2-}$ in $0.1 \mathrm{M} \mathrm{CTAB}$, which correlates to the SEM images in Figure 4.3 and UV-Vis data in Figure 4.1 A. Figure 4.6 A shows 


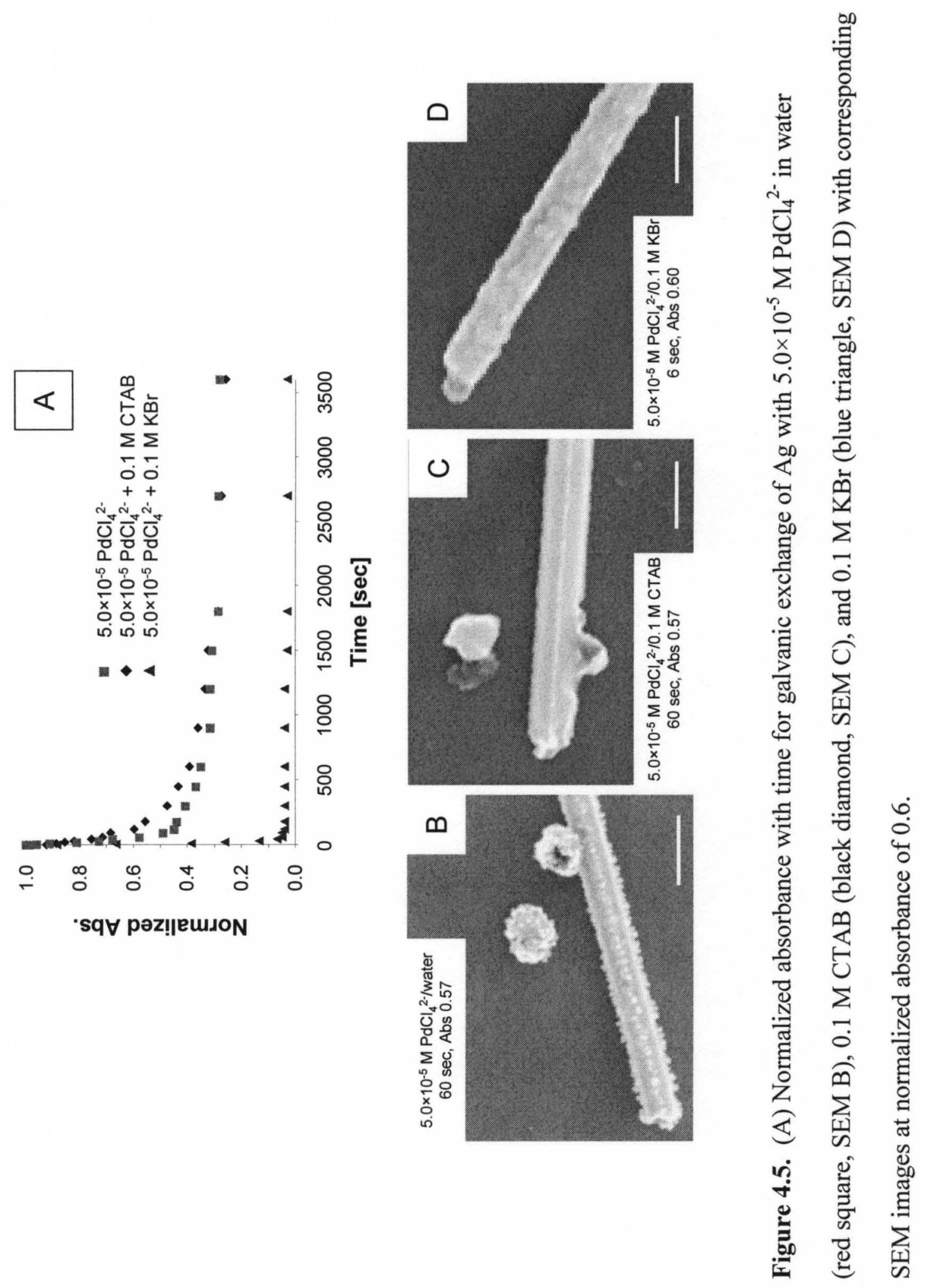



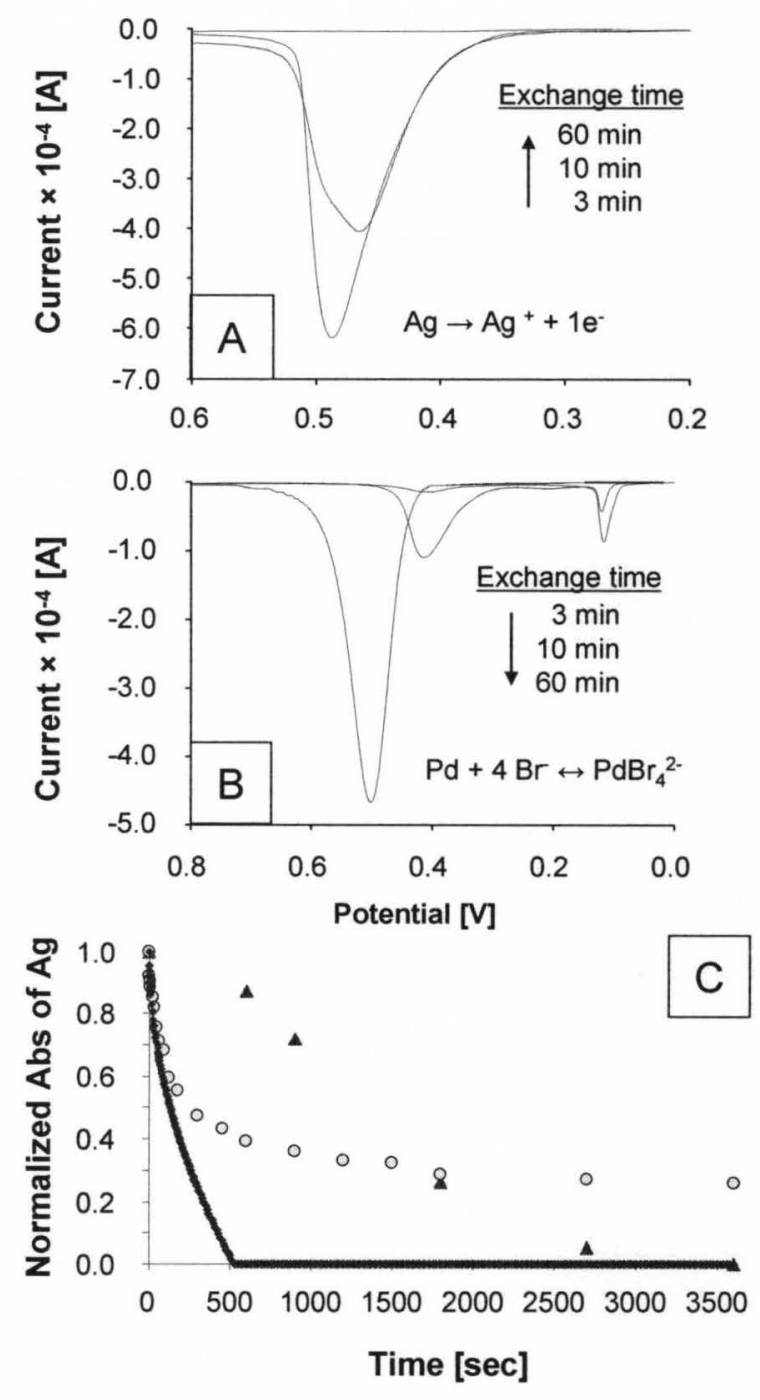

Figure 4.6. LSVs of ITO/MPTMS/Auseed/AgNW in (A) $0.5 \mathrm{M} \mathrm{H}_{2} \mathrm{SO}_{4}$ and (B) $0.01 \mathrm{M}$ $\mathrm{KBr}$ and $0.1 \mathrm{M} \mathrm{HClO}_{4}$ after exchange with $5.0 \times 10^{-5} \mathrm{M} \mathrm{PdCl}_{4}{ }^{2-}$ in $0.1 \mathrm{M} \mathrm{CTAB}$ for various times. (C) A comparison between the experimental normalized absorbance (yellow circles), \%Ag determined by LSV (red triangles), and theoretical (calculated) (blue diamonds) $\% \mathrm{Ag}$ based on a diffusion-limited reaction rate as a function of exchange time in $5.0 \times 10^{-5} \mathrm{M} \mathrm{PdCl}_{4}{ }^{2-}$ plus $0.1 \mathrm{M} \mathrm{CTAB}$. 
that the amount of $\mathrm{Ag}$ in the sample decreases with time during the exchange. We determined the amount of silver from the area under the Ag oxidation peak of the voltammograms. The Ag decrease is expected since $\mathrm{Pd}$ replaces $\mathrm{Ag}$ during exchange. After 60 min of exchange, the $\mathrm{Ag}$ peak is not visible, showing that all of the Ag became oxidized during the reaction. Figure 4.6 B. shows that the Pd oxidation peak increased as a function of exchange time, as expected since Pd deposited on the surface and replaced the $\mathrm{Ag}$. The peak at $\sim 0.1 \mathrm{~V}$ is due to oxidation of leftover $\mathrm{Ag}$ in $\mathrm{Br}^{-}$(to form $\mathrm{AgBr}$ ) after the first scan in $\mathrm{H}_{2} \mathrm{SO}_{4}$. The amount of leftover $\mathrm{Ag}$ during the Pd oxidation is less than $10 \%$ of the Ag oxidation in $\mathrm{H}_{2} \mathrm{SO}_{4}$ and $0 \%$ after $60 \mathrm{~min}$. We used the LSV data to calculate the ratio of the mol of $\mathrm{Ag}$ and Pd present in the sample to roughly estimate the composition of the nanostructures. We calculated the mol of metal from the Coulombs of charge (Q) from the LSV as follows:

$$
\mathrm{mol}=\mathrm{Q} / \mathrm{nF}
$$

where $\mathrm{Q}$ is the charge under the LSV peak, $\mathrm{F}$ is Faradays constant, and $\mathrm{n}$ is number of electrons participating in the oxidation reaction.

Figure 4.6 C shows a comparison of the normalized absorbance obtained by UV-Vis (yellow circles) with the Ag composition determined by LSV (red triangles) as compared to a theoretical plot of the $\% \mathrm{Ag}$ as a function of time based on the assumption that all of the $\mathrm{PdCl}_{4}{ }^{2-}$ molecules reacted with $\mathrm{Ag}$ on the surface at a diffusion-controlled rate. The mol of $\mathrm{PdCl}_{4}{ }^{2-}$ to reach the surface with time, assuming linear diffusion, is given by:

$$
m o l=\frac{2 \cdot A \cdot C \cdot D^{1 / 2} \cdot t^{1 / 2}}{\pi^{1 / 2}}
$$


where $\mathrm{A}$ is area of the electrode, $\mathrm{C}$ is the concentration, $\mathrm{D}$ is the diffusion coefficient $\left(1.0 \times 10^{-5} \mathrm{~cm}^{2} / \mathrm{s}\right),{ }^{91}$ and $\mathrm{t}$ is time. Assuming that every molecule of $\mathrm{PdCl}_{4}{ }^{2-}$ reacted with the $\mathrm{Ag}$ and produced $\mathrm{Ag}^{+}$, the $\% \mathrm{Ag}$ would decrease following the theoretical calculated line of blue diamonds as shown in Figure 4.6 C. There are a few key points about the plots in Figure 4.6 C. First, the actual composition of Ag does not track well with the normalized absorbance. This is similar to the case of galvanic exchange in aqueous $\mathrm{PdCl}_{4}{ }^{2-}$. About $10 \%$ of $\mathrm{Pd}$ in the nanostructure drops the LSPR band of the $\mathrm{Ag}$ close to its lowest absorbance. The difference is that galvanic exchange in CTAB is slow compared to without $\mathrm{CTAB}$ or in $\mathrm{KBr}$. It takes 10 min versus $5 \mathrm{~min}$ for this drop in absorbance to occur. An additional increase in Pd and loss of Ag does not alter the normalized absorbance appreciably after that. At 30 minutes of galvanic exchange in $\mathrm{CTAB}$, the amount of Ag based on the LSVs is lower than the normalized absorbance value. At 45 and 60 minutes of exchange, even though the LSV data shows little or no $\mathrm{Ag}$, the normalized absorbance is $\sim 0.3$. This is because $\mathrm{Pd}^{0}$ also absorbs/scatters light in the visible range, so the extinction will not reach 0 with all of the $\mathrm{Ag}$ removed. The theoretical plot based on the diffusion-limited reactivity does not match the actual composition of Ag with time. This shows that the actual rate of the exchange is slower than predicted for a diffusion-limited process. Clearly, not every $\mathrm{PdCl}_{4}{ }^{2-}$ molecule reacts instantly with $\mathrm{Ag}^{0}$. This can be expected for a few reasons. First, the diffusion coefficient of $\mathrm{PdCl}_{4}{ }^{2-}$ in CTAB is slower compared to free $\mathrm{PdCl}_{4}{ }^{2-}$, which we did not take into account in the theoretical plot. Second, the galvanic exchange involves the breaking of $\mathrm{Pd}-\mathrm{Cl}$ bonds for Pd reduction, which may slow down the kinetics. Third, the formation of insoluble $\mathrm{AgBr}_{(\mathrm{s})}$ may hinder the exchange. Finally, the formation of a 
PdAg alloy may block access to the $\mathrm{Ag}$ or change the oxidation potential of $\mathrm{Ag}$, slowing down the rate.

Previously we used LSV to approximate the composition of the final nanostructures after exchange in aqueous $\mathrm{PdCl}_{4}{ }^{2-}$. Here, we determined the composition of the final structure in the presence of $\mathrm{CTAB}$. In the presence of $\mathrm{CTAB}$ the exchange occurs slower initially, but the composition of $\mathrm{Ag}$ eventually reaches $0 \%$ after 60 minutes. In water only $\sim 25 \%$ of $\mathrm{Ag}$ remained stable on the surface after $60 \mathrm{~min}$ of exchange even at higher $\mathrm{PdCl}_{4}{ }^{2-}$ concentration. We attribute the more complete reaction to the presence of $\mathrm{Br}^{-}$, making the oxidation of $\mathrm{Ag}^{0}$ more favorable thermodinamically.

\subsection{CONCLUSIONS}

Here we described the galvanic exchange of $\mathrm{Ag}$ with $\mathrm{PdCl}_{4}{ }^{2-}$ in the presence of $\mathrm{CTAB}$ and $\mathrm{KBr}$. We showed that the exchange rate and resulting morphology depends weakly on the $\mathrm{PdCl}_{4}{ }^{2-}$ concentration. With $\sim 90 \% \mathrm{Ag}$ in the sample $\left(\mathrm{A}_{\text {norm. }} \sim 0.6\right)$, exchange in $\mathrm{CTAB}$ shows structures decorated along the twin planes with continuous 'wire' - like morphology. Exchange in $\mathrm{KBr}$ shows NWs with pitting and bumps at random areas on the surface. Both structures are different compared to exchange in water only. With $\sim 80 \% \mathrm{Ag}$, the terraces become significantly etched while deposition continues at the twin planes in the presence of $\mathrm{CTAB}$. In the case of exchange in $\mathrm{KBr}$, exchange leads to the destruction of the nanostructures after the exchange in $7.5 \times 10^{-5} \mathrm{M}$ $\mathrm{PdCl}_{4}{ }^{2-}$ and an evenly distributed rough morphology after exchange in $2.5 \times 10^{-5}$ and $5.0 \times 10^{-5} \mathrm{M} \mathrm{PdCl}_{4}{ }^{2-}$. We used LSV to estimate the $\mathrm{Ag}$ and $\mathrm{Pd}$ composition for $\mathrm{Ag}$ exchanged with $5.0 \times 10^{-5} \mathrm{M} \mathrm{PdCl}_{4}{ }^{2-}$ in $0.1 \mathrm{M} \mathrm{CTAB}$ on the glass/ITO electrodes and correlated it with the normalized absorbance data. The results showed that the actual 
composition does not match the normalized absorbance. This is due to the fact that the optical properties are dominated by surface atoms. The properties change dramatically with small changes in the surface composition and do not reflect the bulk reactivity. The rate of exchange is slower than the diffusion-limited rate and slower than exchange in water initially. The LSV shows that after one hour of galvanic exchange, Ag oxidized completely in $\mathrm{CTAB}$, which is different compared to exchange in water only, where 25$30 \% \mathrm{Ag}$ remained unoxidized. In conclusion, the morphology of PdAg alloys formed by exchange of $\mathrm{Ag}$ with $\mathrm{PdCl}_{4}{ }^{2-}$ depends on the rate of exchange, the presence of surfactants, and the presence of ions, such as $\mathrm{Br}^{-}$. A better understanding of these variables will lead to better control over nanostructure morphology, composition and properties. 


\section{CHAPTER V}

\section{ELECTROCHEMICAL SEED-MEDIATED GROWTH OF Ag NANOSTRUCTURES DIRECTLY ON ELECTRODE SURFACES}

\subsection{INTRODUCTION}

Previously our group used seed-mediated electrochemical growth in the presence of CTAB for the synthesis of Au directly on glass/ITO electrodes. By varying the deposition potential and the growth time, different aspect ratio rods were synthesized. The optimal potential for the growth of $\mathrm{Au}$ NRs was found to be $350 \mathrm{mV}$ (vs. Ag/AgCl electrode), resulting in an average length of $389 \mathrm{~nm}$ with aspect ratio of 15.7 for a 2 hour growth time. The key feature of the experimental setup was the presence of Au seed NPs on the surface of the glass/ITO electrode. Without seed particles, Au was deposited in the form of branches and snowflake structures, or no Au deposited at all, depending on the applied potential. In the presence of Au seed, Au deposited at any potentials from $-0.30 \mathrm{~V}$ to $-0.35 \mathrm{~V}$. The coverage of the Au deposits was greater than on non-seeded ITO and the presence of seed led to the formation of $\mathrm{Au}$ NRs at particular potentials $(0.3-$ $0.35 \mathrm{~V})$

Here we describe the electrochemical seed-mediated synthesis of $\mathrm{Ag}$ nanostructures on indium tin oxide (ITO) - coated glass electrodes. The electrochemical deposition was performed in $10.6 \mathrm{pH}$ phosphate buffer solution with $0.08 \mathrm{M}$ CTAB. The conditions were identical to the chemical seed-mediated growth of Ag NRs/NWs directly 
on surfaces as reported by our group previously, except the reducing agent was electrochemical potential, instead of ascorbic acid in the case of chemical seed-mediated growth.

\subsection{EXPEREIMENTAL SECTION}

\subsubsection{Chemicals and materials}

Silver nitrate $\left(\mathrm{AgNO}_{3}, 99+\%\right)$, and sodium borohydride $\left(\mathrm{NaBH}_{4}, 98 \%\right)$ were purchased from Sigma-Aldrich. Hydrogen tetrachloroaurate trihydrate $\left(\mathrm{HAuCl}_{4} \cdot 3 \mathrm{H}_{2} \mathrm{O}\right)$ was synthesized according to a literature procedure. ${ }^{66}$ Citric acid trisodium salt was purchased from Bio-Rad Laboratories. Sodium phosphate dibasic and sodium phosphate tribasic was purchased from Fisher Scientific Company. Cetyltrimethylammonium bromide (CTAB) and mercaptopropyltrimethoxysilane (MPTMS, >97\%) were purchased from Fluka (Assay $\geq 99.0 \%$ ). NANOpure ultrapure water (Barnstead Nanopure Deionization System, resistivity of $18 \mathrm{M} \Omega-\mathrm{cm}$ ) was used for all aqueous solutions. Indium-tin-oxide (ITO) - coated glass (Glass/ITO, $\mathrm{R}_{s}=8-12 \Omega$ ) substrates were purchased from Delta Technologies Limited (Stillwater, MN).

\subsubsection{Glass/ITO electrode Functionalization}

$\mathrm{Au}$ "Seed" nanoparticles (NPs) were synthesized by the reduction of $\mathrm{AuCl}_{4}$ " with borohydride in the presence of citrate as described in Chapter 2. The synthesis resulted in particles with a diameter of 3 to $5 \mathrm{~nm}$. The Au NPs serve as nucleation sites on glass/ITO electrodes during the electrochemical growth of the Ag nanostructures. The glass/ITO was functionalized with MPTMS prior to attachment of Au seed NPs, to form glass/ITO/MPTMS/Au seed electrodes. 


\subsubsection{Electrochemical setup}

A three electrodes setup was used in order to deposit Ag directly on glass/ITO/MPTMS/Au seed electrodes as shown in Figure 5.1 Glass/ITO/MPTMS/Au seed was used as a working electrode. $\mathrm{Ag} / \mathrm{AgCl}$ was used as a reference electrode and $\mathrm{Pt}$ wire was used as a counter electrode. The deposition solution consisted of $2.5 \times 10^{-4} \mathrm{M}$ $\mathrm{AgNO}_{3}$ and $0.1 \mathrm{M} \mathrm{CTAB}$ in $\mathrm{pH} 10.6$ phosphate buffer.

\subsubsection{Ag electrodeposition}

Ag electrodeposition was performed using a $\mathrm{CH}$ Instruments $630 \mathrm{C}$ electrochemical workstation in cyclic voltammetry mode. All three electrodes were immersed into the electrolyte solution and linear sweep voltammograms were ran from $0.2 \mathrm{~V}$ to the final desired deposition potential at a scan rate of $20 \mathrm{mV} / \mathrm{s}$. Once this potential was reached it was paused and held constant for 30 minutes. Next, the working electrode was removed from the electrolyte solution under potential control, rinsed with nanopure $\mathrm{H}_{2} \mathrm{O}$, dried under a $\mathrm{N}_{2}$ stream, and characterized with SEM.

\subsection{RESULTS}

Figure 5.2 shows a cyclic voltammogram of clean glass/ITO (Frame A), glass/ITO/MPTMS (Frame B), and glass/ITO/MPTMS/Au seed (Frame C) performed in $2.5 \times 10^{-4} \mathrm{M} \mathrm{AgNO}_{3}$ and $0.1 \mathrm{M} \mathrm{CTAB}$ in $\mathrm{pH} 10.6$ phosphate buffer. Frame A shows that a cathodic current begins to flow at approximately $-350 \mathrm{mV}$ on glass/ITO, which is due to the electrodeposition of $\mathrm{Ag}^{+}$by the reaction:

$$
\mathrm{Ag}^{+}+1 \mathrm{e}^{-} \rightarrow \mathrm{Ag}^{0}
$$

The current reaches a maximum at $-780 \mathrm{mV}$.

The oxidation occurs at $\sim 50 \mathrm{mV}$ due to: 


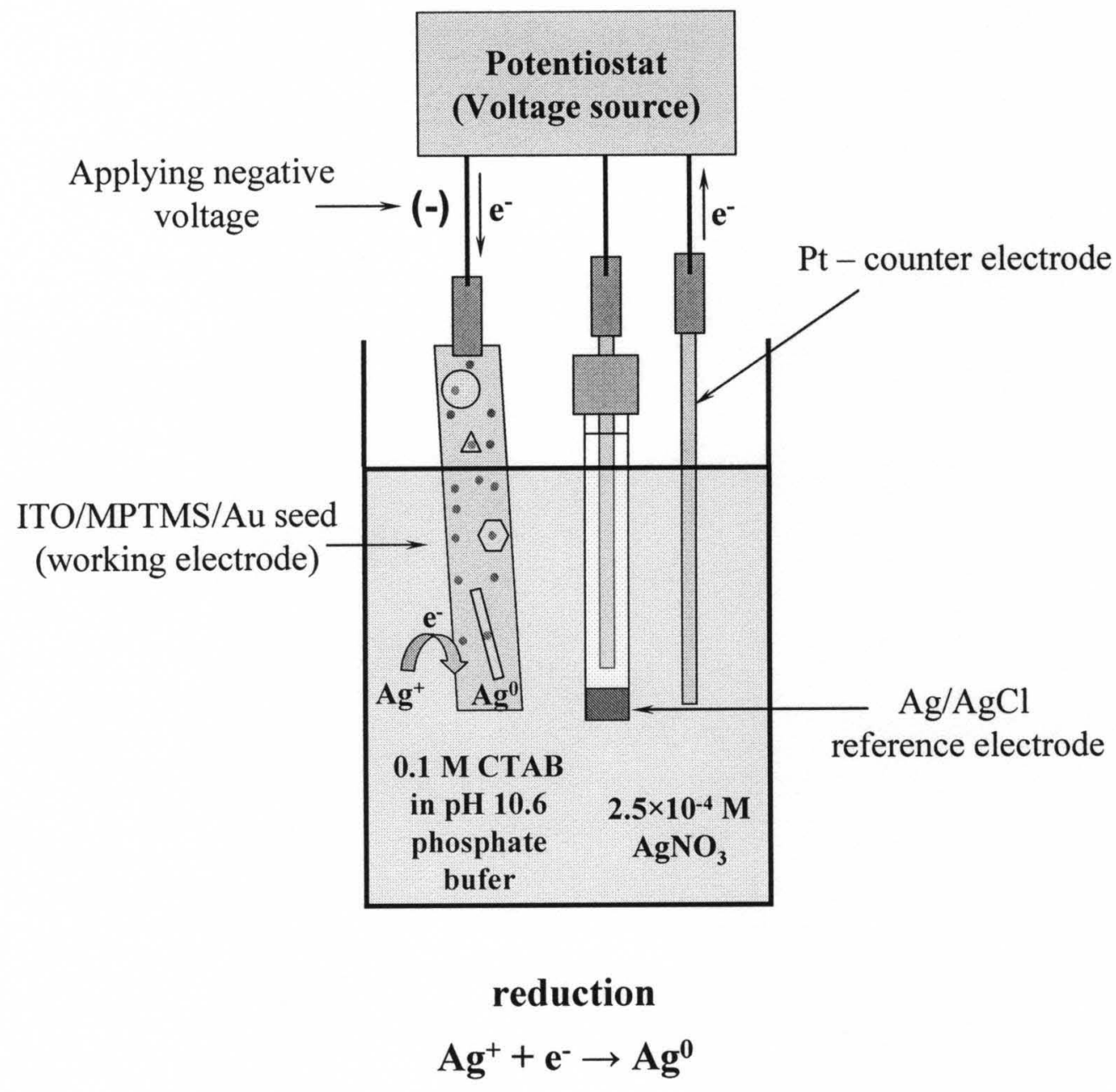

Figure 5.1. Electrochemical setup for Ag electrodeposition. 


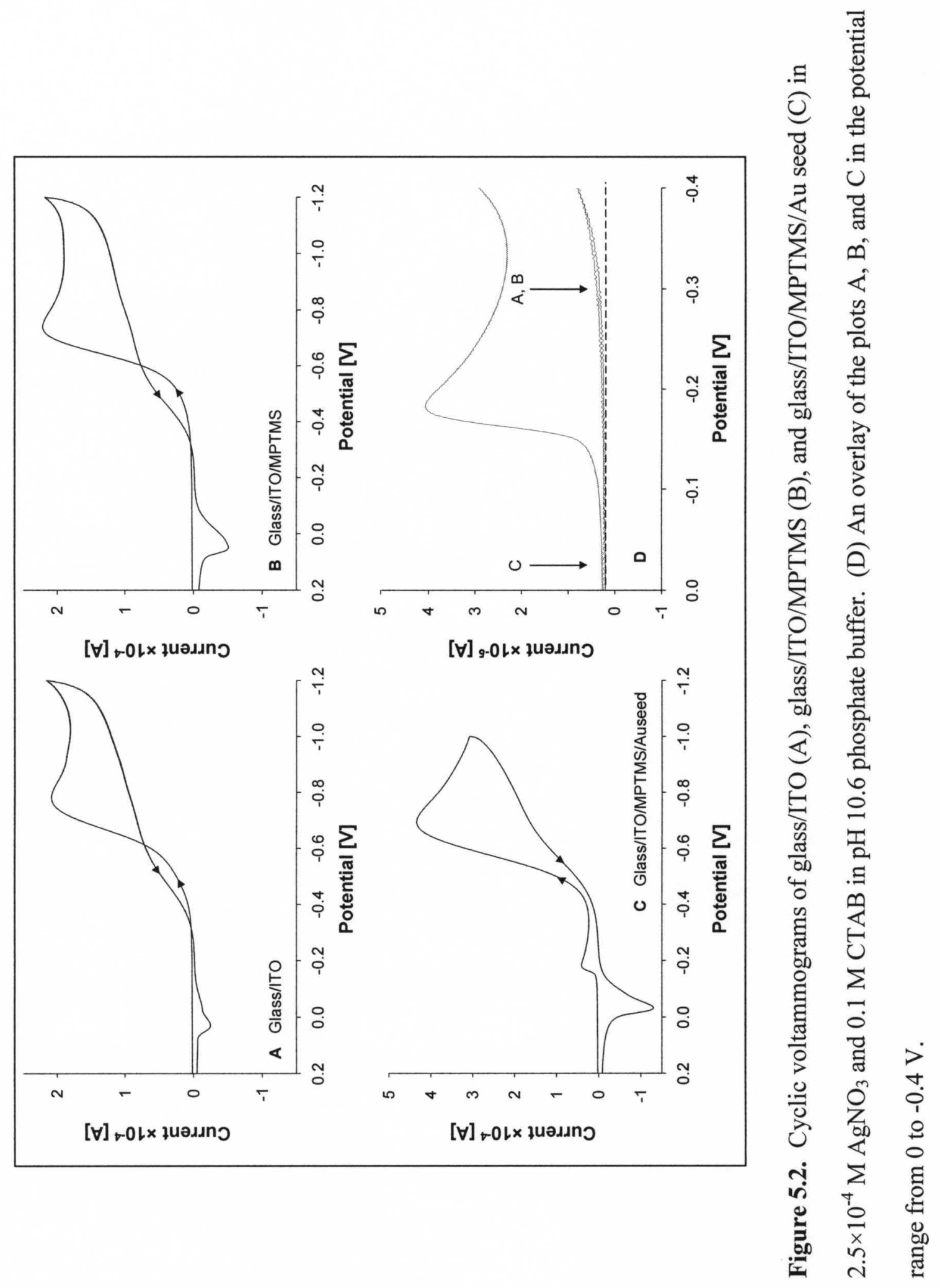




$$
\mathrm{Ag}^{0}+\mathrm{Br}^{-} \rightarrow \mathrm{AgBr}_{(\mathrm{S})}+1 \mathrm{e}^{-}
$$

The crossover visible in Frame A is characteristic for electrochemical nucleation growth process. The crossover of the CV during the reverse scan in Frame A occurs because the reduction potential of $\mathrm{AgNO}_{3}$ shifts positively after some $\mathrm{Ag}^{0}$ is deposited on the surface. This leads to a significant cathodic current at $\sim-0.5 \mathrm{~V}$ on the reverse scan because the $\mathrm{Ag}$ deposited on the forward scan catalyzes the reduction of $\mathrm{AgNO}_{3}$ in solution at more positive potentials. Similar behavior is visible in Frame B, where CV was performed on glass/ITO/MPTMS substrate. Frame $\mathrm{C}$ shows CV performed on glass/ITO/Au seeds substrate with visible reduction peak at $\sim-0.2 \mathrm{~V}$. This is the basis for seed-mediated growth, where metal ion reduction is more favorable on existing metal seed particles in comparison to reduction on a nonactive surface.

Frame B shows that Ag deposition on glass/ITO/MPTMS begins at the same potential as on clean glass/ITO but reaches its maximum faster at approximately $-740 \mathrm{mV}$. The oxidation also occurs at $\sim 50 \mathrm{mV}$. On glass/ITO/MPTMS/Au seed (Frame C), a new cathodic current appears at $\sim-150 \mathrm{mV}$, which we ascribe to $\mathrm{Ag}$ deposition on Au seed. As shown in the overlay of the three plots in Frame D, Ag electrodeposition on $\mathrm{Au}$ NP seeds occurred much earlier compared to glass/ITO. The same level of current did not flow on non-seeded electrodes until $\sim-400 \mathrm{mV}$; a $250 \mathrm{mV}$ difference compared to glass/ITO/MPTMS/Au seed. The oxidation of $\mathrm{Ag}$ occurred at about $-20 \mathrm{mV}$, which is also more negative compared to the oxidation on glass/ITO or glass/ITO/MPTMS. The most important observation from this experiment is that Ag deposition on seeded ITO starts at approximately $250 \mathrm{mV}$ earlier than on samples without seed. This shift in 
potential is due to the presence of Au seed NPs which play the role of nucleation sites for Ag growth.

It is more favorable to deposit metal on top Au seeds versus a bare glass/ITO electrode surface. We studied deposition potentials further in the region before the deposition on glass/ITO and into the beginning of the peak, from 0 to $-600 \mathrm{mV}$. Figure 5.3 shows representative SEM images of Au seeded ITO electrodes held at different potentials. Frame A, shows no growth occurred on the electrode surface when the potential for electrochemical $\mathrm{Ag}$ deposition was held at $0 \mathrm{mV}$. This is well before the onset of deposition at $-150 \mathrm{mV}$. The SEM images of samples grown at $0 \mathrm{mV}$ look identical to clean glass/ITO, which is shown in the Frame H. Deposition at $-150 \mathrm{mV}$ (Frame B) leads to deposition of Ag nanostructures on the electrode surface. The nanostructures present on the surface are in the shape of particles, platelets, and $\sim 6 \%$ nanorods. The average length of the NRs was $310 \pm 120 \mathrm{~nm}$. Frame C shows a typical SEM for Ag nanostructures deposited at $-200 \mathrm{mV}$, which is still well before the deposition on glass/ITO. Most of particles are spherical, with some sporadically NRs present. Frame D shows nanostructures obtained at $-300 \mathrm{mV}$. The particles vary in size there aren't any that small and no NRs grew on samples. Frame E shows Ag deposited on a seeded ITO surface at $-400 \mathrm{mV}$. In this case, deposition could likely occur on $\mathrm{Au}$ seeds and on glass/ITO. The majority of the particles are of a 'flower-like' shape and their dimensions range from tens to hundreds of nm. Frame F shows deposition of $\mathrm{Ag}$ nanostructures at $-500 \mathrm{mV}$. At these conditions we can observe a huge dispersity in the nanoparticles sizes present on the surface. At this potential Ag deposition again occurs 


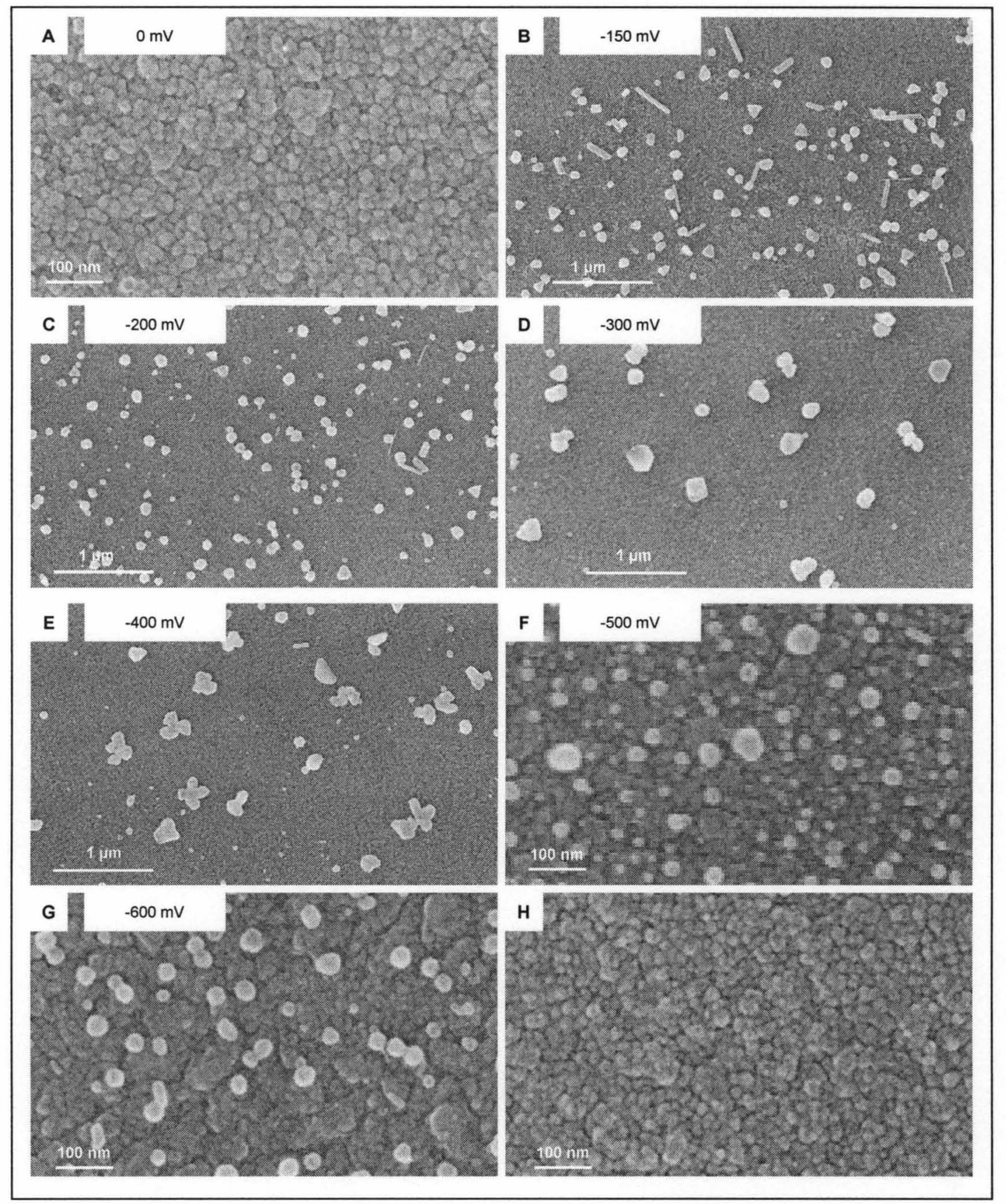

Figure 5.3. SEM images of ITO/MPTMS/Au seed Ag nanostructures deposited at $0 \mathrm{mV}$ (A), $-150 \mathrm{mV}$ (B), $-200 \mathrm{mV}(\mathrm{C}),-300 \mathrm{mV}$ (D), $-400 \mathrm{mV}(\mathrm{E}),-500 \mathrm{mV}(\mathrm{F})$, and $-600 \mathrm{mV}$ (G). A clean glass/ITO surface is shown in $(\mathrm{H})$. 
both on seeds and glass/ITO/MPTMS. A similar situation occurred when the deposition potential was $-600 \mathrm{mV}$.

\subsection{CONCLUSIONS}

Here we showed the electrochemical seed-mediated growth of $\mathrm{Ag}$ nanostructures directly on glass/ITO/MPTMS/Au seed electrodes in presence of CTAB at $\mathrm{pH} 10.6$. Cyclic Voltammetry clearly showed that Ag deposition is more favorable on Au seeds by $\sim 250 \mathrm{mV}$ versus glass/ITO or glass/ITO/MPTMS electrodes. Ag oxidation also occurred at more negative potentials. The morphology of the $\mathrm{Ag}$ was highly sensitive to deposition potential. The formation of $1 \mathrm{D}$ Ag NRs occurred over a narrow potential range near $-150 \mathrm{mV}$. These results could lead to improved nanoparticle synthesis. 


\section{CHAPTER VI}

\section{SURFACE-ENHANCED RAMAN SPECTROSCOPY OF THIN GRAPHENE SHEETS FUNCTIONALIZED WITH Au AND Ag NRs BY SEED-MEDIATED GROWTH}

\subsection{ABSTRACT}

Here we describe a simple method for decorating graphene (1-5 layers) with $\mathrm{Au}$ and $\mathrm{Ag}$ nanostructures (nanoparticles, nanorods, and nanoplates). Graphene was deposited electrostatically from highly-oriented pyrolytic graphite (HOPG) onto $\mathrm{Si} / \mathrm{SiO}_{2}$ surfaces functionalized with (aminopropyl)trimethoxysilane. Metal nanostructures were grown by a seed-mediated growth method from hexanethiolate-coated Au monolayerprotected cluster (MPC) "seeds" that are attached to the graphene by hydrophobic interactions. Scanning electron microscopy (SEM) reveals the selective growth of Au or $\mathrm{Ag}$ nanostructures on the graphene. In the case of $\mathrm{Au}$, the low $\mathrm{pH} 2.8$ growth solution causes the etching of graphene and formation of scroll-like structures. For Ag, the high $\mathrm{pH} 9.3$ solution does not seem to affect the graphene morphology. Raman spectroscopy is consistent with the graphene morphology and reveals that the presence of $\mathrm{Au}$ and $\mathrm{Ag}$ enhances the Raman scattering from the graphene by a factor of about 45 and 150 , respectively. This work demonstrates a simple method for decorating graphene with noble metal nanostructures that may have interesting optical, electronic, and chemical properties for applications in nanoelectronics, sensing, and catalysis. 


\subsection{INTRODUCTION}

Chemical functionalization of graphene offers the means of modifying its already existing fascinating electronic properties leading to potentially useful applications such as (i) opening up of a band gap for electronics devices, ${ }^{94,95}$ (ii) enhanced adsorption for hydrogen storage, and (iii) edge functionalization of nanoribbons for spintronics. ${ }^{96}$ Functionalization of graphene can result in the formation of covalent and ionic bonds as well as non-covalent van der Walls interactions. Heterostructures consisting of carbon materials and metals are of great interest due to the potential influence of their fundametal properties on each other. For example, noble metals have been observed to enhance the Raman scattering of carbon materials due to their localized surface plasmon resonance properties. These types of heterostructures may find applications in chemical/biological sensing, catalysis, and optoelectronics. While there are numerous reports based on heterostructures of carbon and metal nanoparticles, heterostructures of carbon and high aspect ratio metal nanorods are limited. We previously described the fabrication of 1-D heterojunctions between Au nanorods and single-walled carbon nanotubes (SWCNTs) by combining chemical assembly and seed-mediated growth directly on a silicon substrate. An intimate contact between the Au nanostructures and SWCNTs resulted from our procedure as evidenced by the surface-enhanced Raman spectroscopy (SERS) signal for the SWCNTs by 50 -fold. ${ }^{11,12}$

Recently, few layer and single layer graphene has been a subject of great interest, not only due its interesting physical and chemical properties, but also as a potential material for future electronic and opto-electronic devices. ${ }^{97}$ The charge carriers in graphene have zero effective mass and the transport is governed by the relativistic Dirac 
equation rather than the Schrodinger equation. Graphene posseses excellent transport properties such as high carrier mobility, room temperature quantum hall effect, and ballistic transport. ${ }^{98,99}$ Metal nanoparticles dispersed on graphene have already shown enhanced catalytic activity as well as novel optoelectronic properties. Recently, Au nanoparticles anchored on octadecylamine functionalized graphene have been suspended in THF to prepare graphene sheets coated with well-dispersed Au nanoparticles. ${ }^{100}$ More recently, Kim et al. synthesized Au nanorods on a reduced graphene oxide (RGO) surface by seedless and seed-mediated methods using an amine-terminated pyrene linker to attach negatively-charged Au seeds and subsequently grow nanorods. They reported a 34-fold enhancement of the Raman scattering. ${ }^{101}$

Here we report the synthesis of $\mathrm{Au}$ and $\mathrm{Ag}$ nanorods on graphene layers attached to $\mathrm{Si} / \mathrm{SiO}_{2}$ substrates using a similar approach that we described for the synthesis of $\mathrm{Au}$ nanorods on SWCNTs and Ag NRs directly on surfaces previously. ${ }^{12}$ There are several differences between our work and that recently published by Kim et al. First, we deposited the graphene on $\mathrm{Si} / \mathrm{SiO}_{2}$ by an electrostatic method. Second, we synthesize the nanorods by the seed-mediated growth of hydrophobic hexanethiolate-coated Au seed nanoparticles that are attached to the graphene by van der Waals interactions. These weak interactions are beneficial as they will not alter the properties of the graphene. Third, we demonstrate the synthesis of both $\mathrm{Au}$ and $\mathrm{Ag}$ nanorods, where the latter has a three-fold stronger Raman enhancement than that reported for Au previously and in this paper. Finally, we describe the effect of $\mathrm{pH}$ on the graphene since the solution $\mathrm{pH}$ is different when synthesizing $\mathrm{Au}$ and $\mathrm{Ag}$ nanorods by seed-mediated growth. A low $\mathrm{pH}$ causes some structural damage that is observed in the Raman spectrum. This work is 
important as heterojunctions between one-dimensional nanoscale metals and graphene may have applications in catalysis, sensing, and optoelectronics.

\subsection{EXPERIMENTAL SECTION}

\subsubsection{Chemicals and materials}

Silver nitrate $\left(\mathrm{AgNO}_{3}, 99+\%\right)$ and $\mathrm{L}$-Ascorbic acid $(99+\%)$ were purchased from Sigma-Aldrich. Cetyltrimethylammonium bromide (CTAB, $\geq 99.0 \%$ ) was purchased from Fluka. Tetra-n-octylammonium bromide ( $\mathrm{TOABr}, 98+\%)$ was purchased from Alfa Aesar. Sodium borohydride (98\%), 3-aminopropyltriethoxysilane (APTES, 99\%), and 1-hexanethiol (95\%) were purchased from Aldrich. Citric acid, trisodium salt was purchased from Bio-Rad Laboratories. Toluene $(>99.99 \%)$ and hydrogen peroxide $\left(\mathrm{H}_{2} \mathrm{O}_{2}, 30 \%\right.$ solution) were purchased from EMD. Acetonitrile (99.9+\%) was purchased from Burdick\&Jackson. Isopropyl alcohol (99.8\%) was purchased from PharmcoAAPER. Sodium phosphate dibasic $\left(\mathrm{Na}_{2} \mathrm{HPO}_{4}\right)$ was purchased from Fisher Scientific Company. Sodium phosphate tribasic $\left(\mathrm{Na}_{3} \mathrm{PO}_{4}\right)$ was purchased from Mallinckrodt. Hydrogen tetrachloroaureate trihydrate $\left(\mathrm{HAuCl}_{4} \cdot 3 \mathrm{H}_{2} \mathrm{O}\right)$ was synthesized from metallic $\mathrm{Au}$. NANOpure ultrapure water (resistivity of $18 \mathrm{M} \Omega-\mathrm{cm}$ ) was used for all aqueous solutions.

\subsubsection{Graphene Deposition}

Si substrates with a native oxide layer $\left(\mathrm{Si} / \mathrm{SiO}_{2}\right)$ were cut from a 6" diameter wafer. The substrates were cleaned in piranha solution $\left(3: 1 \mathrm{H}_{2} \mathrm{SO}_{4}: \mathrm{H}_{2} \mathrm{O}_{2}\right)$ for $10-15$ minutes, rinsed thoroughly with water, rinsed with isopropanol, and dried under $\mathrm{N}_{2}$. The substrates were then functionalized with APTES by placing them in a solution containing $10 \mathrm{~mL}$ isopropanol, $100 \mu \mathrm{L}$ of APTES, and a few drops of water and heating just below 
boiling. After 30 minutes, the samples were removed, rinsed thoroughly with isopropanol, and dried under $\mathrm{N}_{2}$. Graphene was deposited from freshly cleaved highly oriented pyrolytic graphite (HOPG) onto the APTES-functionalized $\mathrm{Si} / \mathrm{SiO}_{2}$ substrate by an electrostatic technique deveopled in the Sumanasekera laboratory as shown schematically in Figure $6.1 .^{102}$ In short, the procedure involved cleavage of a piece of HOPG and connection to the positive terminal of a voltage source via a copper plate. A second copper electrode was connected to a grounded terminal of the source. A mica sheet was placed on top of the grounded electrode. $\mathrm{The} \mathrm{Si} / \mathrm{SiO}_{2}$ substrate functionalized with APTES was placed over the mica sheet. Next, an electric field between the terminals was applied, resulting in the electrostatic deposition of graphene sheets on the $\mathrm{Si} / \mathrm{SiO}_{2} / \mathrm{APTES}$ surfaces. Most of the sheets were $4-15 \mu \mathrm{m}$ in diameter along the long axis and 1-5 layers in thickness. ${ }^{102}$

\subsubsection{Au monolayer-protected cluster (MPC) Seeds.}

Hexanethiolate (C6S)-coated Au MPCs were synthesized according to the Brust reaction. ${ }^{67}$ Briefly, $2.40 \mathrm{~g}$ of $\mathrm{HAuCl}_{4}$ were dissolved in $25 \mathrm{~mL}$ of water, and $4.89 \mathrm{~g}$ of tetra-n-octylammonium bromide were dissolved in $150 \mathrm{~mL}$ of toluene. The solutions were mixed and stirred until all of the $\mathrm{AuCl}_{4}{ }^{-}$transferred into the toluene phase. The two phases were separated and $2.60 \mathrm{~mL}$ of hexanethiolate in a 3:1 ratio to Au were added to the toluene phase and stirred until the solution became colorless. The solution was then cooled to $\sim 0^{\circ} \mathrm{C}$, and a 10 -fold excess of $\mathrm{NaBH}_{4}(2.30 \mathrm{~g}$ in $10 \mathrm{~mL}$ of water) was added to the solution and stirred. The solution turned black indicating the formation of Au MPCs. An additional $10 \mathrm{~mL}$ of water was added and the solution stirred overnight. The toluene was removed and the solid powder was collected, and washed thoroughly to remove side 


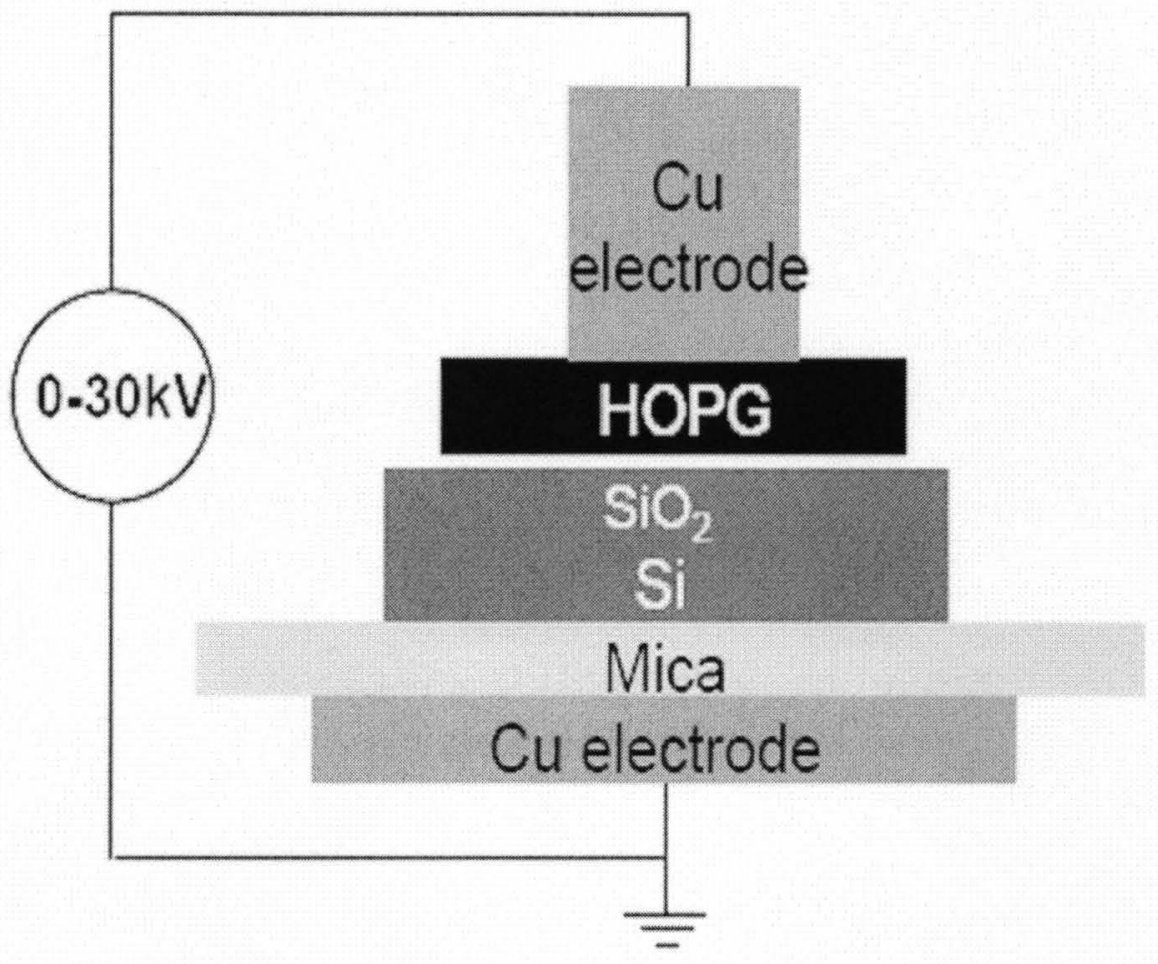

Figure 6.1. Schematic of the experimental set-up for the electrostatic deposition of graphene sheets onto an APTES-functionalized $\mathrm{Si} / \mathrm{SiO}_{2}$ substrate. (Schematic adapted from Anton Sidorov's unpublished results). 
products and other impurities. ${ }^{103}$ These Au MPCs have an average diameter of $1.6 \mathrm{~nm}$ according to literature. ${ }^{67}$

\subsubsection{Seed-Mediated Growth of Au and Ag Nanorods on Graphene}

For the synthesis of $\mathrm{Au}$ or $\mathrm{Ag}$ nanostructures on the $\mathrm{Si} / \mathrm{SiO}_{2} / \mathrm{APTES} / \mathrm{Graphene}$ substrate, the first step in both cases was to place the substrate into a $2.5 \mathrm{mg} / \mathrm{mL}(0.005 \mathrm{~g}$ in $20 \mathrm{~mL}$ ) solution of the $1.6 \mathrm{~nm}$ average diameter $\mathrm{C} 6 \mathrm{~S}$ Au MPCs for $10-15 \mathrm{~min}$. For $\mathrm{Au}$, the substrate was then placed into a growth solution containing $4.5 \times 10^{-4} \mathrm{M} \mathrm{HAuCl}_{4}$, $0.1 \mathrm{M} \mathrm{CTAB}$, and $5.0 \times 10^{-4} \mathrm{M}$ ascorbic acid for one hour at $25^{\circ} \mathrm{C}$. The $\mathrm{pH}$ measured for the Au growth solution was 2.8. This led to the seed-mediated growth of the graphene-bound Au MPCs into Au nanoparticles (NPs), nanorods (NRs), and other shapes. ${ }^{9,13,27}$ For $\mathrm{Ag}$, the substrate was placed into a growth solution containing $2.5 \mathrm{x}$ $10^{-4} \mathrm{M} \mathrm{AgNO}_{3}, 0.08 \mathrm{M} \mathrm{CTAB}$, and $5.0 \times 10^{-3} \mathrm{M}$ ascorbic acid at $28^{\circ} \mathrm{C}$ for 30 minutes. The $\mathrm{AgNO}_{3}, \mathrm{CTAB}$, and ascorbic acid were dissolved in a $0.2 \mathrm{M}$ ionic strength $\mathrm{pH} 10.6$ phosphate buffer. The high $\mathrm{pH}$ was necessary to increase the reducing strength of ascorbic acid, which allows the reduction of $\mathrm{Ag}^{+}$in the presence of CTAB. The final $\mathrm{pH}$ of the Ag growth solutions was 9.3. This leads to the seed-mediated growth of the graphene-bound Au MPCs into Ag nanoparticles, NRs, and other shapes. ${ }^{7,9,13,27}$

\subsubsection{Characterization}

Electron microscopy images were obtained at different magnifications using a Carl Zeiss SMT AG Supra 35VP field-emission scanning electron microscope (FESEM) operating at an accelerating voltage of $15.00 \mathrm{kV}$ and using an in-lens ion annular secondary electron detector. The Raman spectra of graphene with and without $\mathrm{Au}$ or $\mathrm{Ag}$ nanostructures attached were obtained at room temperature with a Renishaw inVia 
Micro-Raman spectrometer in back-scattering geometry with the laser excitaton of $632.8 \mathrm{~nm}$ at a power level of $1.7 \mathrm{~mW}$. The Raman spectra were taken at $10 \%, 50 \%$ and $100 \%$ of the laser power.

\subsection{RESULTS AND DISCUSSION}

$\mathrm{Au}$ and $\mathrm{Ag}$ nanostructures were synthesized directly on $\mathrm{Si} / \mathrm{SiO}_{2} / \mathrm{APTES} / \mathrm{Graphene}$ substrates by the four steps sequentially shown in Figure 6.2. First, APTES was deposited onto $\mathrm{Si} / \mathrm{SiO}_{2}$. Second, graphene sheets were deposited onto the $\mathrm{Si} / \mathrm{SiO}_{2} / \mathrm{APTES}$ by a recently published elctrostatic deposition method. ${ }^{102}$ Third, Au MPCs were assembled on the graphene sheets by weak hydrophobic interactions.

Finally, Au or Ag nanostructures were synthesized directly on the $\mathrm{Si} / \mathrm{SiO}_{2} / \mathrm{APTES} / \mathrm{Graphene} / \mathrm{Au}$ MPCs surface by seed-mediated growth.

Figure 6.3 shows $\mathrm{SEM}$ images of $(\mathrm{A})$ bare graphene on $\mathrm{Si} / \mathrm{SiO}_{2} / \mathrm{APTES}$, (B) $\mathrm{Si} / \mathrm{SiO}_{2} / \mathrm{APTES} /$ graphene/Au nanostructures, and (C) $\mathrm{Si} / \mathrm{SiO}_{2} / \mathrm{APTES} /$ graphene/Ag nanostructures. Typically, the presence of graphene on the substrate is confirmed using Scanning electron microscopy. It is possible to estimate the approximate thickness of the graphene sheets by the color contrast that can be seen in SEM. The Raman spectrum can also be used to identify the number of layers as described later. The dense growth of Au and $\mathrm{Ag}$ nanostructures on and underneath graphene is evident in Figures $6.3(\mathrm{~B})$ and $(\mathrm{C})$. There is usually a gap between the graphene and the substrate that can allow chemical species to reach under the graphene. The $1.6 \mathrm{~nm}$ diameter hydrophobic $\mathrm{Au}$ MPCs apparently attach to the underside of the graphene sheets and subsequently grow by seed-mediated growth. There are a large number of metal nanostructures that grew on 


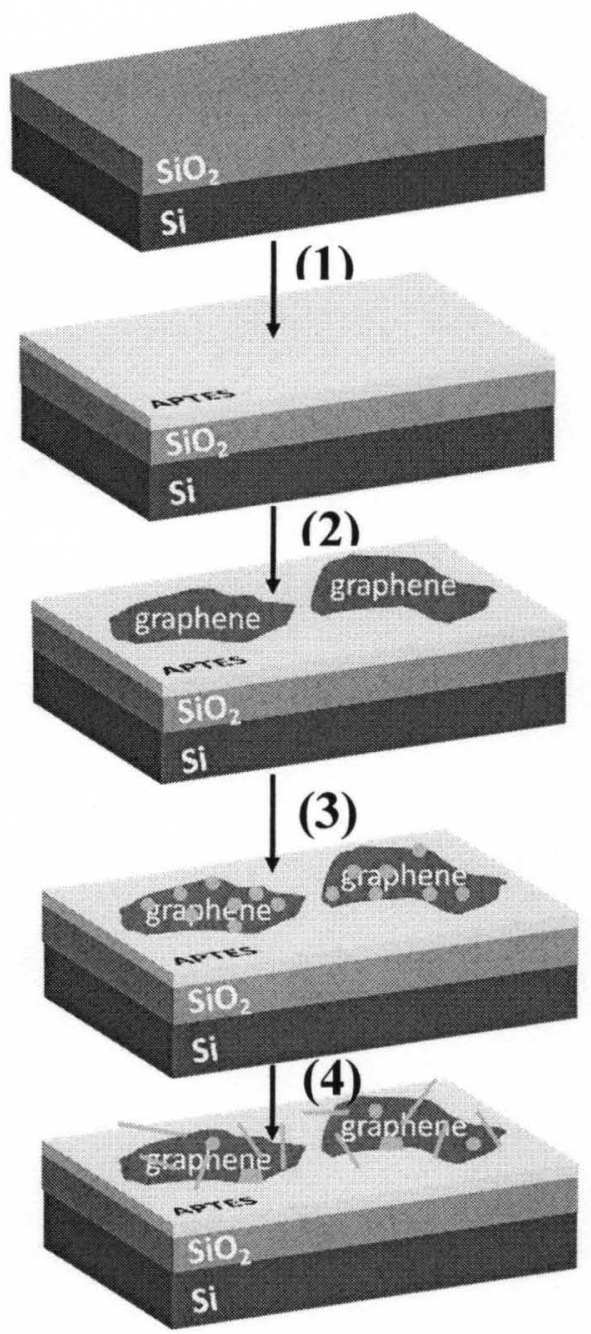

Figure 6.2. Procedure for the synthesis of $\mathrm{Au}$ and $\mathrm{Ag}$ nanorods on graphene, involving (1) modification of the $\mathrm{Si} / \mathrm{SiO}_{2}$ surface with APTES, (2) electrostatic deposition of the graphene on of the $\mathrm{Si} / \mathrm{SiO}_{2} / \mathrm{APTES}$ substrate, (3) chemisorption of the C6S Au MPCs ("seeds"), and (4) decoration of the graphene with Au or Ag nanostructures by seedmediated growth of the Au MPC seeds. (Adapted from Anton Sidorov's unpublished results). 

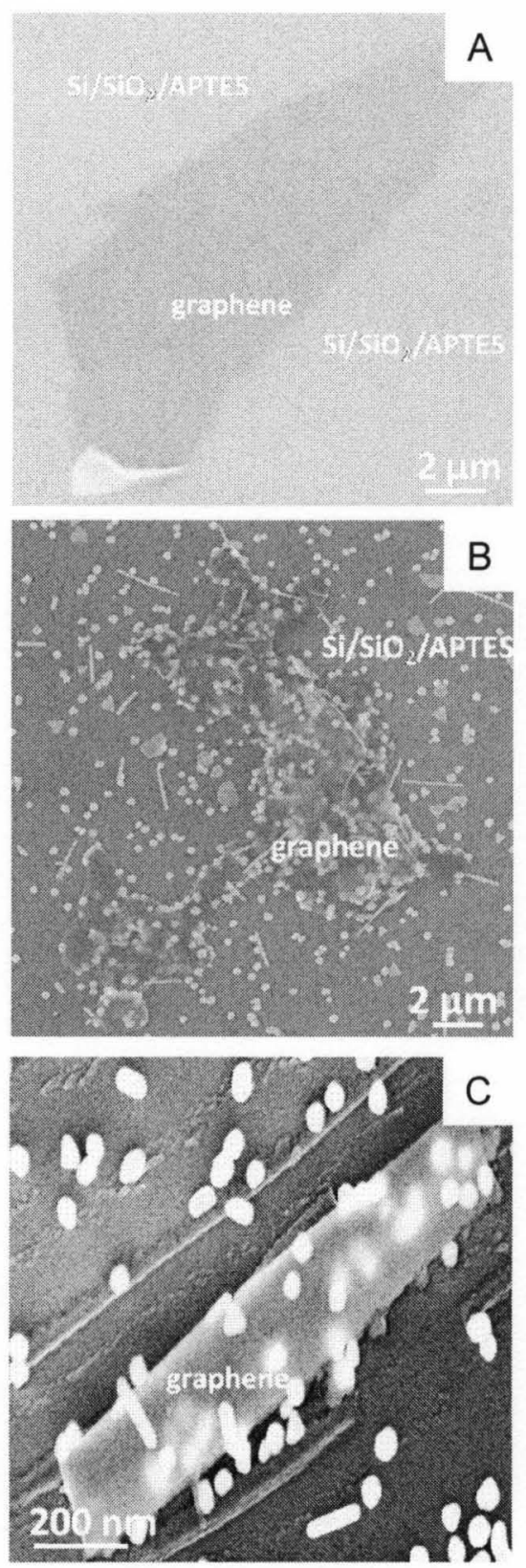

Figure 6.3. $\mathrm{SEM}$ images of (A) $\mathrm{Si} / \mathrm{SiO}_{2} / \mathrm{APTES} /$ graphene, (B)

$\mathrm{Si} / \mathrm{SiO}_{2} / \mathrm{APTES} /$ graphene/Au nanostructures, and (C) $\mathrm{Si} / \mathrm{SiO}_{2} / \mathrm{APTES} /$ graphene/Ag nanostructures. 
the $\mathrm{Si} / \mathrm{SiO}_{2} / \mathrm{APTES}$ substrate as well. We performed a control experiment where we placed a $\mathrm{Si} / \mathrm{SiO}_{2} / \mathrm{APTES}$ substrate (no graphene) into C6S Au MPCs and Au growth solution, but observed no deposition on the surface, showing that the Au MPCs do not adsorb onto the APTES surface. ${ }^{11} \mathrm{We}$, therefore conclude that there are small carbon features on the surface that are not observable in the SEM images in Figure 6.1 and these account for the growth of $\mathrm{Au}$ and $\mathrm{Ag}$ nanostructures all over the $\mathrm{Si} / \mathrm{SiO}_{2} / \mathrm{APTES}$ surface.

Figure 6.4 shows SEM images of different regions of a $\mathrm{Si} / \mathrm{SiO}_{2} / \mathrm{APTES} /$ graphene substrate that was placed into a $9 \mathrm{mg} / \mathrm{mL}$ solution of $1.6 \mathrm{~nm}$ average diameter hexanethiolate Au monolayer-protected clusters (MPCs) for 10-15 min followed by placing into an Au growth solution. As seen in the SEM images this leads to the seedmediated growth of the graphene-bound Au MPCs into Au nanoparticles, nanorods, and other shapes. Au nanorods (NRs) have the average length of $605 \pm 298 \mathrm{~nm}$ with a yield of $\sim 8 \%$ and the average diameter of the Au nanoparticles is $30-40 \mathrm{~nm}$. Interestingly, the graphene underwent an etching process, resulting in wrinkles and scroll-like structures. We attribute this to the acidity of the growth solution, which has a $\mathrm{pH}$ of $\sim 2.8$. This can be explained by the presence of excess protons which leads to the breaking of $\mathrm{C}=\mathrm{C}$ bonds in the benzene rings, and formation of $\mathrm{C}-\mathrm{H}$ bonds. This may lead to formation of defects in the graphene layers. Such a reaction can not occur at the higher $\mathrm{pH}$.

Figure 6.5 shows SEM images of graphene layers deposited on APTES-functionalized $\mathrm{Si} / \mathrm{SiO}_{2}$ substrates after being placed in Au growth solution without first exposing the substrate to C6S Au MPC seeds. The gold growth solution had a final pH of 2.8. Without exposure to the C6S Au MPC "seeds", no growth of $\mathrm{Au}$ 

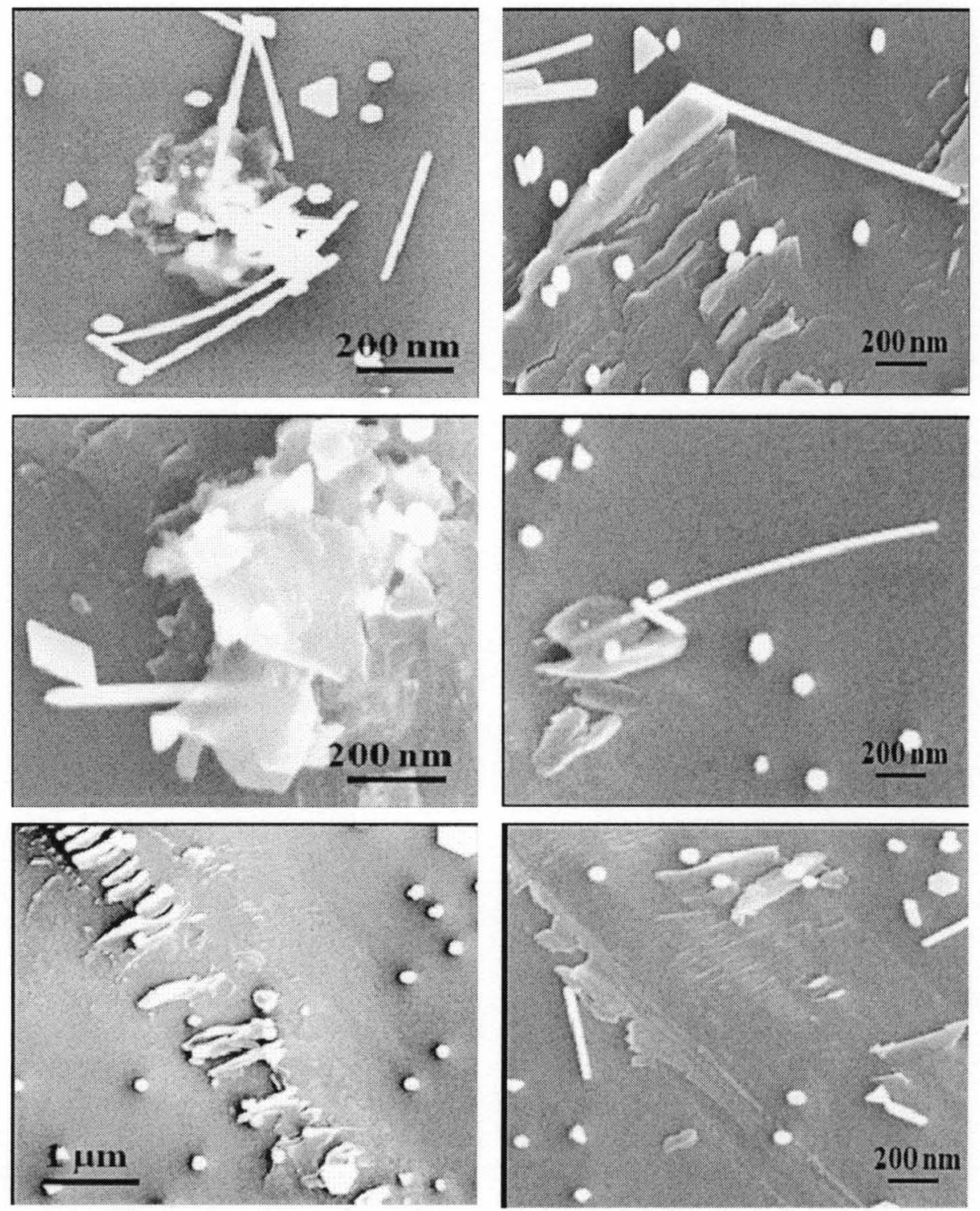

Figure 6.4. SEM images of a sample of Au nanoparticles and nanorods grown on few layer graphene sheets. We regularly observed wrinkles and the formation of scroll-like structures for these graphene structures. 

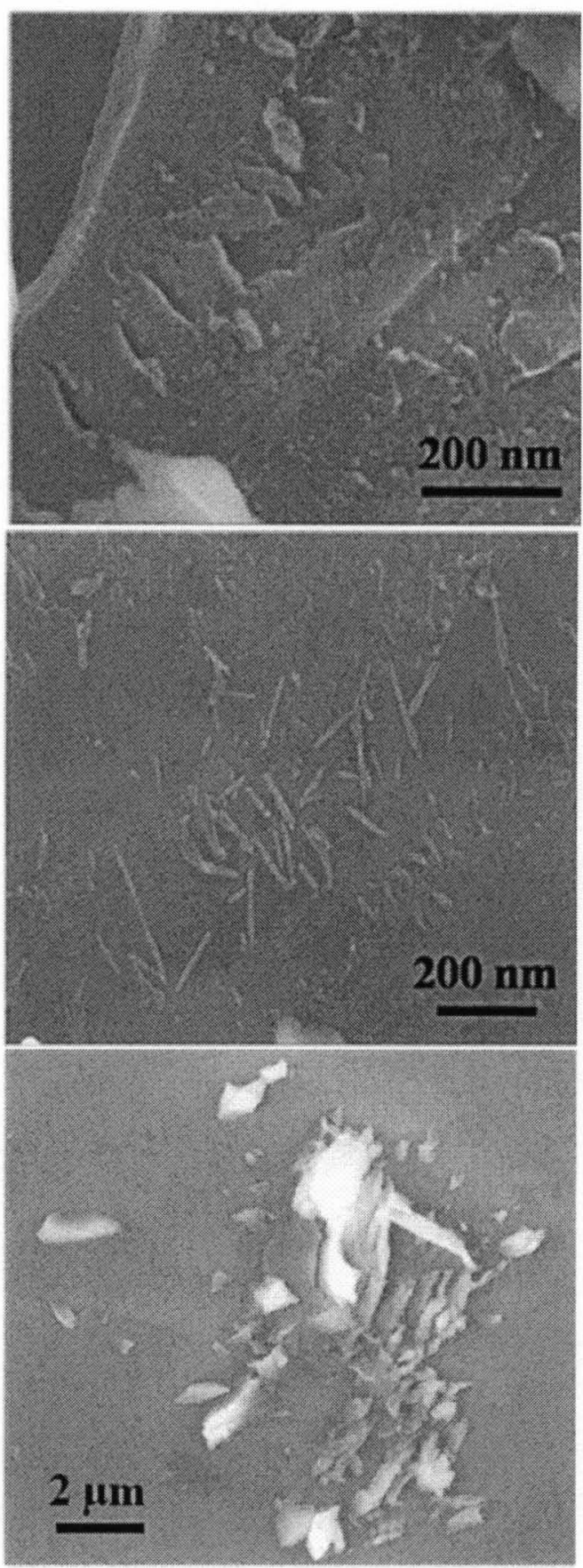

Figure 6.5. SEM images of graphene exposed to $\mathrm{pH} 2.8 \mathrm{Au}$ growth solution without exposure to $\mathrm{Au}$ MPCs first. 
nanostructures occurred on the graphene. This confirms that the Au nanostructures formed by seed-mediated growth. In addition, the images reveal etching of the graphene sheets to form scroll-like structures. This suggests that the low $\mathrm{pH}$ is responsible for the etching and scroll formation.

Figure 6.6 shows $\mathrm{SEM}$ images of a $\mathrm{Si} / \mathrm{SiO}_{2} / \mathrm{APTES} /$ graphene substrate that was placed into a $9 \mathrm{mg} / \mathrm{mL}$ solution of $1.6 \mathrm{~nm}$ average diameter C6S Au MPCs for 10-15 min followed by placing into an $\mathrm{Ag}$ growth solution. This leads to the seed-mediated growth of the graphene-bound Au MPCs into Ag nanoparticles, NRs, and other shapes. The yield of grown $\mathrm{Ag}$ nanorods/nanowires (NRs/NWs) is lower than those of gold $(\sim 3 \%)$. The length dispersity in Ag NRs/NWs is also larger leading to the growth of NRs/NWs as short as $\sim 50 \mathrm{~nm}$ and as long as a few $\mu \mathrm{m}$. The average particle size was in the $30-40$ $\mathrm{nm}$ range. Interestingly, no wrinkles or scroll-like structures appeared on these graphene sheets as was the case for $\mathrm{Au}$ nanostructure growth. The main difference between the $\mathrm{Ag}$ and $\mathrm{Au}$ growth solutions is the $\mathrm{pH}$, which is $\sim 9.3$ for the former and $\sim 2.8$ for the later. This is likely the reason for the difference in the graphene morphology.

Figure 6.7 shows SEM images of graphene layers deposited on APTESfunctionalized $\mathrm{Si} / \mathrm{SiO}_{2}$ substrates after being subjected to the $\mathrm{Ag}$ growth growth solution without previous exposure to the C6S Au MPC "seeds". As with Au, no growth of Ag nanostructures occurred on graphene in this case, confirming that the $\mathrm{Ag}$ nanostructures also grow by the seed-mediated growth process. Interestingly, the graphene layers do not appear to undergo any etching process as observed for graphene exposed to the acidic $\mathrm{Au}$ growth solution. This shows that the graphene is stable at high $\mathrm{pH}$, but susceptible to 

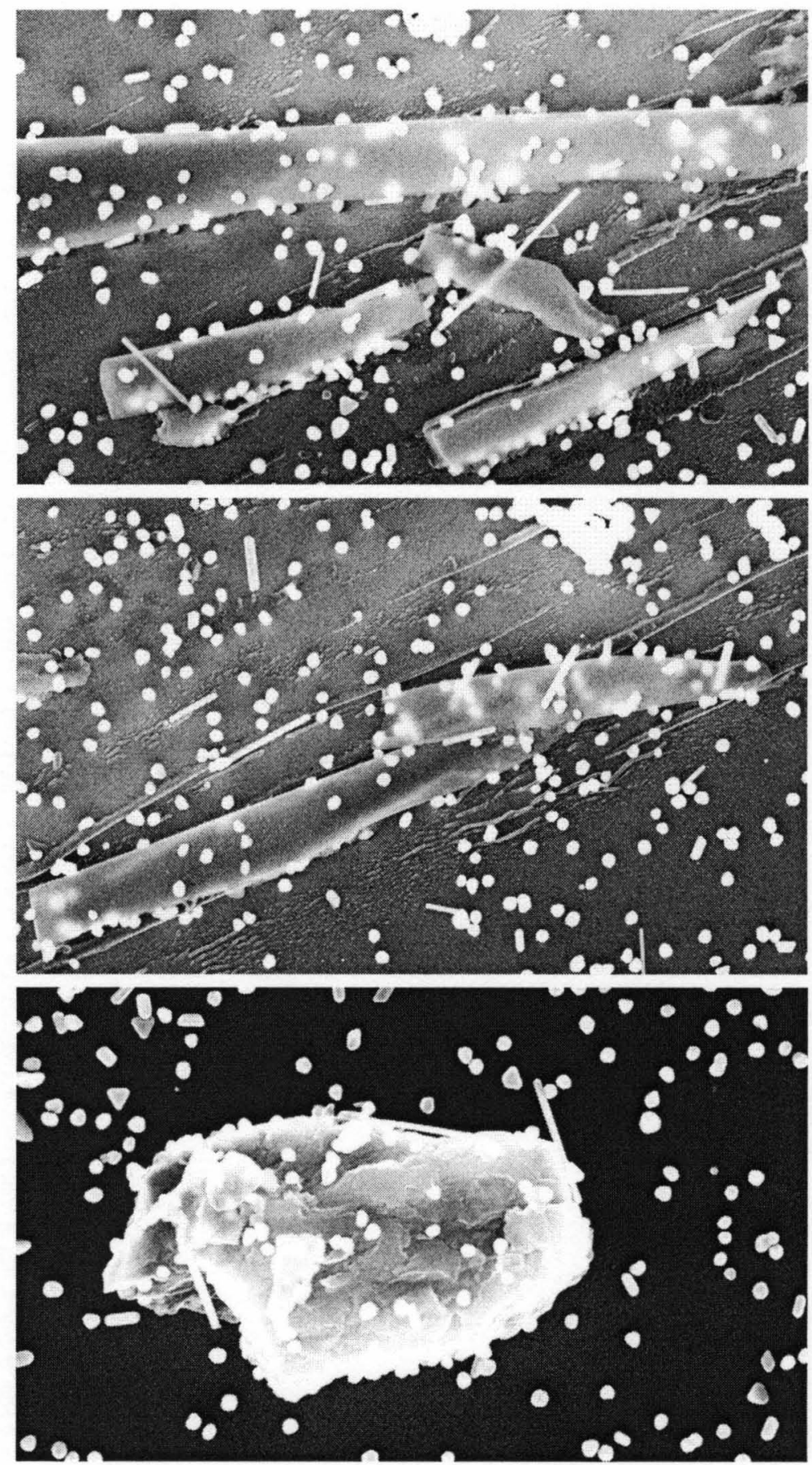

Figure 6.6. $\mathrm{SEM}$ images of a $\mathrm{Si} / \mathrm{SiO}_{2} / \mathrm{APTES} /$ graphene substrate coated with $\mathrm{Ag}$ nanostructures by seed-mediated growth. In contrast to those coated with $\mathrm{Au}$, these graphene sheets usually appeared intact and smooth. 

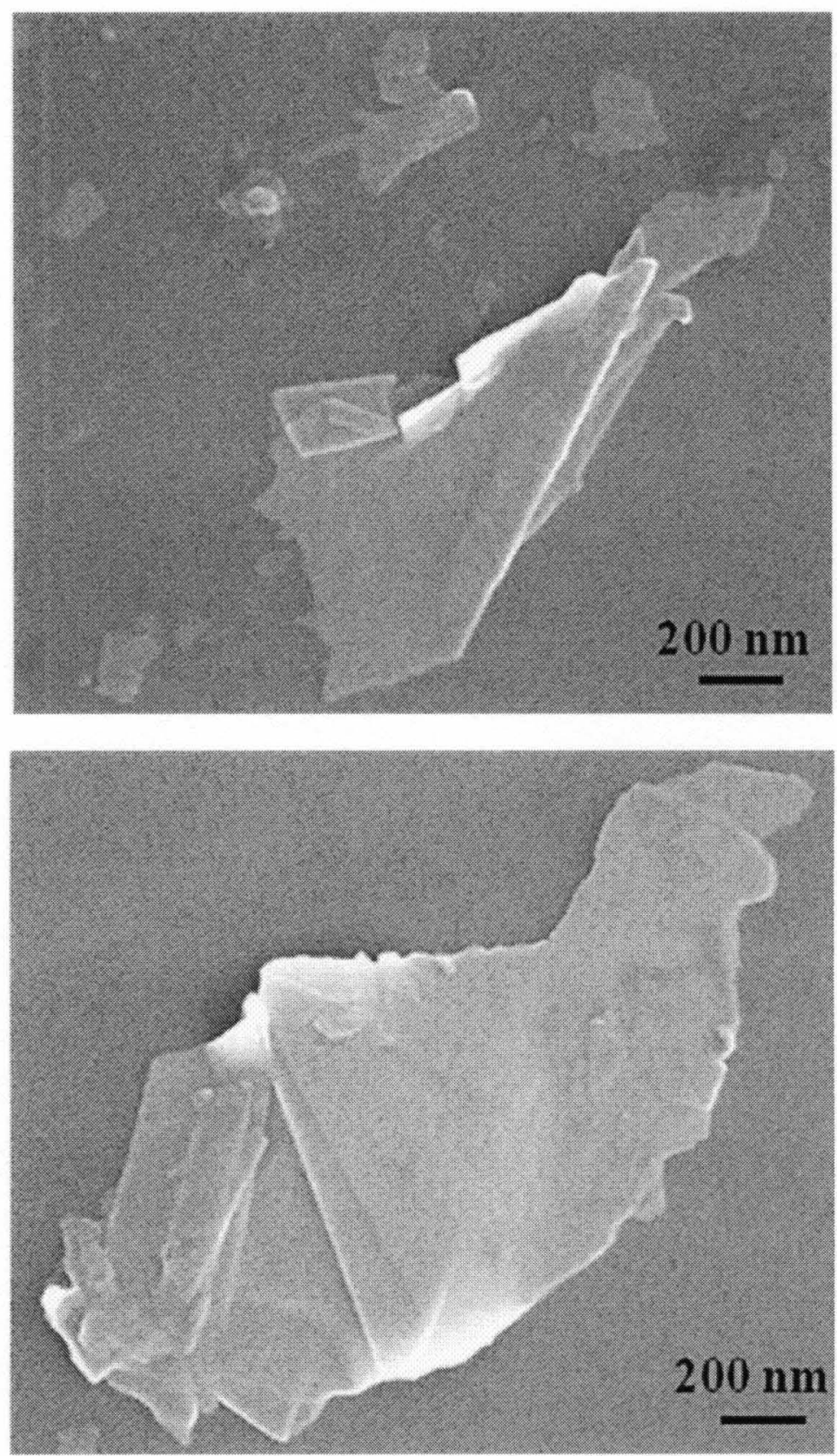

Figure 6.7. $\mathrm{SEM}$ images of an $\mathrm{Si} / \mathrm{SiO}_{2} / \mathrm{APTES} /$ graphene substrate exposed to the $\mathrm{pH} \mathrm{Ag}$ growth solution without any exposure to C6S Au MPC seeds. No nanostructures grow in the absence of seed and the graphene sheets are stable at high $\mathrm{pH}$. 
etching at lower $\mathrm{pH}$. We do not know if the $\mathrm{CTAB}, \mathrm{AA}$, or $\mathrm{AuCl}_{4}{ }^{2-}$ plays role in the etching process.

Figure 6.8 shows the Raman spectrum of as deposited graphene in the absence of Au nanostructures (top) with a $45 \mathrm{x}$ magnification in comparison to the spectrum of the same graphene layer decorated with Au nanostructures (bottom). Both spectra consist of Raman Peaks corresponding to the D band $\left(\sim 1330 \mathrm{~cm}^{-1}\right), \mathrm{G}$ band $\left(\sim 1583 \mathrm{~cm}^{-1}\right)$, and $\mathrm{G}^{\prime}$ (2D peak) band $\left(2600 \mathrm{~cm}^{-1}\right)$. The appearance of a single band for the $\mathrm{G}^{\prime}$ band is evident for the presence of a monolayer of graphene. ${ }^{104-106}$ The strong D band compared to the $G$ band along with the presence of a shoulder peak at $\sim 1620 \mathrm{~cm}^{-1}$ also confirms the presence of monolayer graphene deposited by the electrostatic technique. This band has been observed previously for monolayer graphene and has been attributed to the maximum in the phonon density of states associated with mid-zone phonons. ${ }^{107}$ For multilayer graphene the G' band is known to split into multiple bands while the peak at $1620 \mathrm{~cm}^{-1}$ disappears.

Figure 6.8 shows an enhancement in the Raman signal of $\sim 45$ fold by decorating the monolayer graphene with the Au nanostructures, which is slightly larger than the 34fold enhancement observed by Kim et al. ${ }^{101}$ and similar to the 50 -fold enhancement observed for SWCNTs. ${ }^{11}$

A similar enhancement was observed at almost all locations of the sample. The enhancement of the localized electric field at the surface of the Au nanostructures in intimate contact with the graphene is presumably responsible for this Raman enhancement. The intensity of the D-band relative to the G-band for the graphene decorated with Au nanoparticles samples is consistent with the infliction of defects due to 


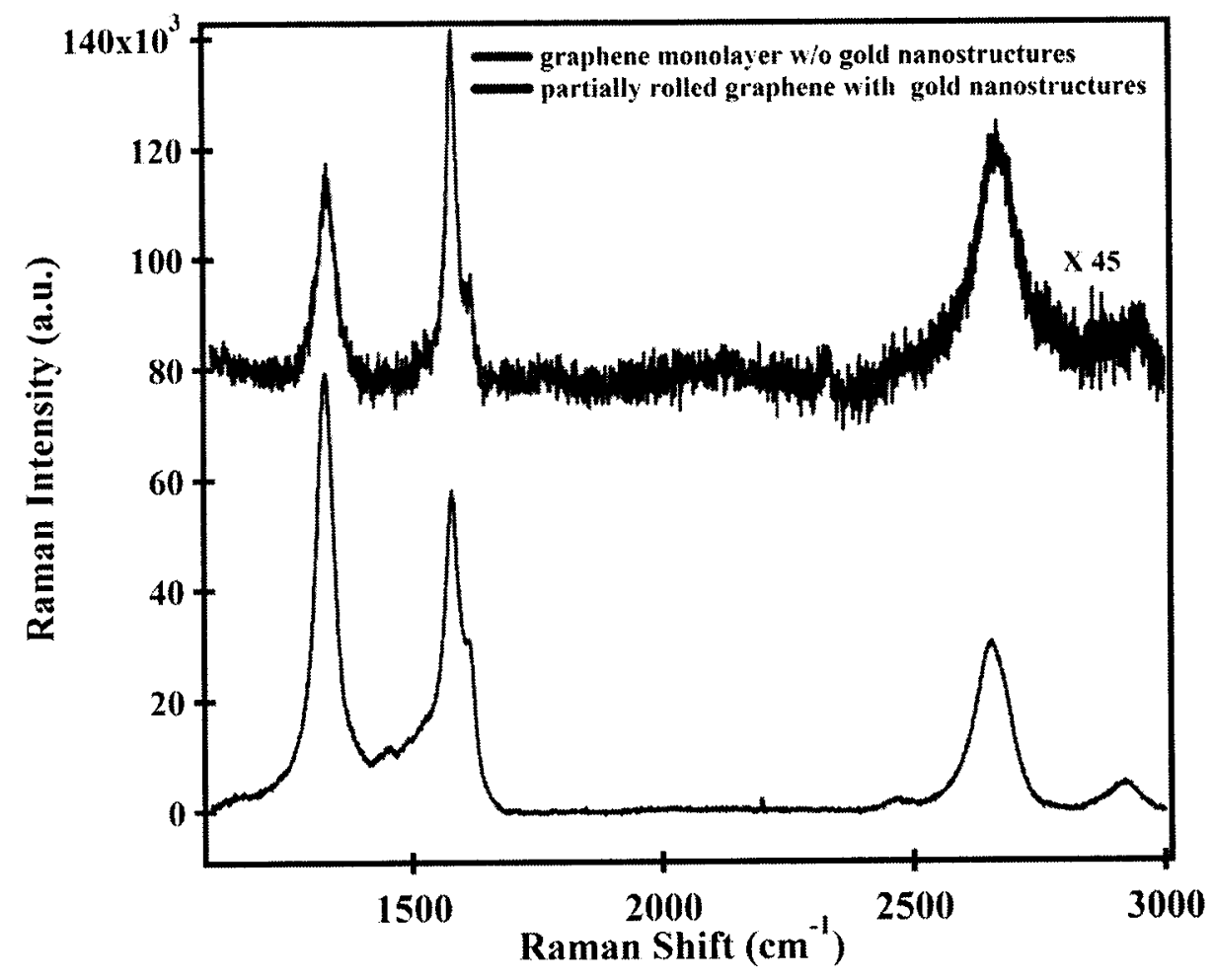

Figure 6.8. Raman spectra of the graphene monolayer with and without $\mathrm{Au}$ nanostructures. 
the etching of the graphene during exposure to the Au growth solution as shown in Figures 6.4 and 6.5. The monolayer graphene without Au shows a less intense D-band compared to the G-band since it was not exposed to the low $\mathrm{pH}$ growth solution and did not incur any etching.

Figure 6.9 shows the Raman spectra of a pristine graphene layer (top) (with $147 \mathrm{x}$ magnification) and the same graphene layer decorated with Ag nanostructure (bottom). Again, the graphene layer under study proves to be a monolayer as evidenced by the presence of a single $G^{\prime}$ band and shoulder peak at $1620 \mathrm{~cm}^{-1}$. Interestingly, the Raman enhancement was $\sim 147$-fold on average for the monolayer graphene decorated with $\mathrm{Ag}$ nanostructures. This increased enhancement by a factor of $\sim 3$ compared to the $\mathrm{Au}$ nanostructures can be attributed to the different plasmonic properties of $\mathrm{Ag}$ compared to $\mathrm{Au}$. The large enhancement suggests that an intimate contact formed between graphene and the $\mathrm{Ag}$ nanostructures. In contrast to $\mathrm{Au}$ nanostructures on graphene, the intensiy of the $\mathrm{D}$ band for Ag-coated graphene remained well below that of $\mathrm{G}$ band. This is consistent with the minimal effect of the high $\mathrm{pH} \mathrm{Ag}$ growth solution on graphene surface (i.e. no etching).

\subsection{CONCLUSIONS}

We developed a simple chemical method to attach $\mathrm{Au}$ and $\mathrm{Ag}$ nanostructures onto monolayer graphene deposited on arbitrary substrates. The useful features of these structures are 1) attachment of metal nanostructures without perturbing the chemical properties of the graphene (other than introduction of etching for $\mathrm{Au}$ ), 2) attachment of two different conductive, stable noble metals with interesting optical properties, 3) Raman enhancement of up to 150 fold for $\mathrm{Ag}$ nanostructures attached to graphene. In 


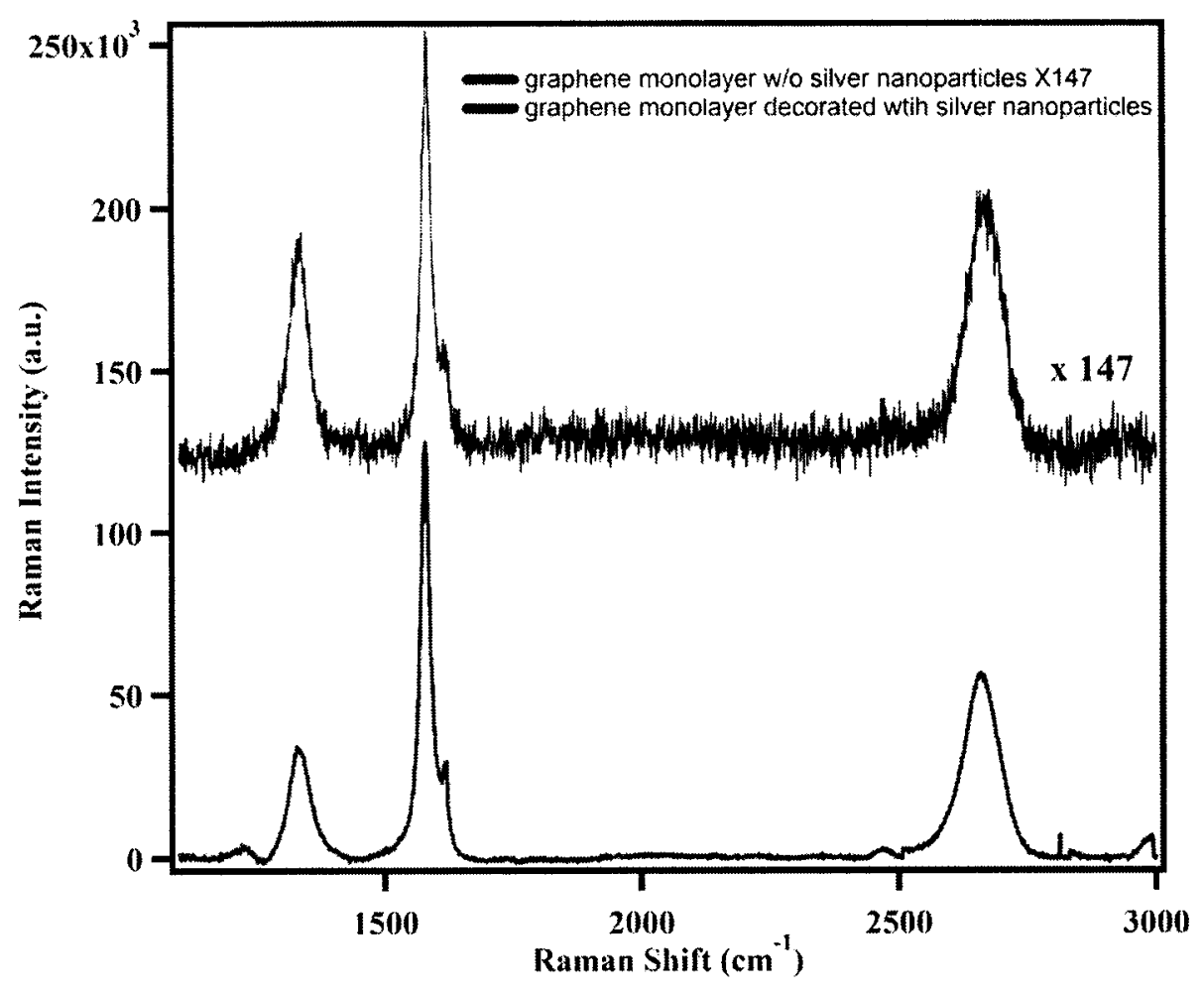

Figure 6.9. Raman spectra of the graphene monolayer with and without attached $\mathrm{Ag}$ nanostructures. 
addition, this work shows that the etching of graphene and formation of scroll-like structures can occur at low $\mathrm{pH}$ under these conditions, but that they are stable at high $\mathrm{pH}$. The Raman spectra were consistent with monolayer graphene structures and absence or presence of defects. These metal/carbon heterostructures are expected to have interesting fundamental properties, which may lead to promising applications in chemical/bio sensing, catalysis, nanoelectronics, and optoelectronics. The Surface-Enhanced Raman (SER) effect ${ }^{108,109}$ may lead to their use as an enhanced Raman scattering platform involving optical fiber integrated waveguides. 


\section{CHAPTER VII \\ SUMMARY AND CONCLUSIONS}

In summary, the combination of seed-mediated growth and galvanic exchange is a promising method for synthesizing metallic nanostructures with unique and interesting morphologies. We synthesized the following metallic nanostructures:

1) AgPd alloy one-dimensional nanostructures with varied morphology and composition.

2) Electrochemical synthesis of Ag nanorods on glass/ITO.

3) Graphene/Au and graphene/Ag heterostructures.

The morphology of Ag nanorods/nanowires depends on the compostion, rate of exchange, and solution composition (water only, $\mathrm{CTAB}, \mathrm{KBr}$ ) during galvanic exchange with $\mathrm{PdCl}_{4}{ }^{2-}$. In water, the rate of exchange decreases with decreasing $\mathrm{PdCl}_{4}{ }^{2-}$ concentration over a range of $1.0 \times 10^{-5}$ to $1.0 \times 10^{-4} \mathrm{M}$. The morphology of the resulting AgPd alloy nanostructures depends on the galvanic exchange rate. At a $\mathrm{PdCl}_{4}{ }^{2-}$ concentration of $7.5 \times 10^{-5} \mathrm{M}$ or higher, rapid galvanic exchange results in Pd deposition over the entire $\mathrm{Ag} \mathrm{NW}$ at the early stages of exchange. When the concentration of $\mathrm{PdCl}_{4}{ }^{2-}$ is in the range of $1.0 \times 10^{-5}$ to $5.0 \times 10^{-5} \mathrm{M}, \mathrm{Pd}$ deposition occurs preferentially at high energy twin plane defects in the form of well-spaced nanoparticles during the early stages of exchange. At $5.0 \times 10^{-5}$ to $1.0 \times 10^{-4} \mathrm{M} \mathrm{PdCl}_{4}{ }^{2-}, 25-30 \% \mathrm{Ag}$ remains in the nanostructure after $1 \mathrm{~h}$ of exchange based on compositional data. Compositional data 
obtained by linear sweep voltammetry showed that the normalized absorbance data does not follow the actual composition of $\mathrm{Ag}$ nanostructures.

In $\mathrm{CTAB}$, concentrations of $\mathrm{PdCl}_{4}{ }^{2-} 1.0 \times 10^{-5} \mathrm{M}$ to $7.5 \times 10^{-5} \mathrm{M}$ show similar rate of exchange and similar morphologies of $\mathrm{Ag}$ nanostructures after the exchange. The morphologies of $\mathrm{Ag}$ nanostructures are completely different when performed in different environments. Absence of surfactants led to particle decoration of twin-plane nanostructures while in CTAB exchange led to 'wire' formation of Pd structures along the Ag twin-planes. Composition analysis by linear sweep voltammetry as a function of time shows that the galvanic exchange rate is much slower than the diffusion-limited rate in both cases of galvanic exchange (no CTAB vs. $\mathrm{CTAB}$ ), and shows that after an hour of exchange samples in aqueous $\mathrm{PdCl}_{4}{ }^{2-}$, the structures still contain $\sim 25 \% \mathrm{Ag}$ while after an hour of exchange in the presence of $\mathrm{CTAB}, \mathrm{Ag}$ is completely removed from the nanostructures.

Electrochemical seed-mediated growth of Ag nanostructures showed that morphology of metallic nanostructures depends on the applied potential during the growth process. The optimum potential for $\mathrm{Ag}$ NRs growth was $-150 \mathrm{mV}$ vs. $\mathrm{Ag} / \mathrm{AgCl}$. These conditions yielded Ag NRs and Ag NWs on the electrode surface along with spherical, hexagonal, and triangular nanostructures. The yield of NRs/NWs is $6 \%$ and the average length is $310 \pm 120 \mathrm{~nm}$. Other potentials yielded nanoparticles and 'flowerlike' structures with high dispersity in size.

$\mathrm{Au}$ or Ag NRs and other shaped structures immobilized on thin sheets of graphene enhanced Raman scattering signals for graphene by 50 and 150 fold, 
respectively. The synthesis of these nanoscale heterostructures could find use in sensing, catalysis, nanoelectronics, and optoelectronics.

\section{FUTURE PROJECTS}

Future projects would include more detailed studies of the electrochemical growth of Ag nanostructures. The study would focus on the effect of potential, reaction time, concentrations of metal salt, and temperature. Different conditions could lead to different morphology of the formed nanostructures as well as the change in the yield and average length of Ag NRs/NWs. Fine tuning of the reduction potential could lead to higher yield of Ag NRs/NWs, or to better control over the high size dispersity of nanostructures that is present in our samples. Changes in concentration of metal salt as well as changes in temperature could lead to faster formation of Ag NRs/NWs.

The galvanic exchange project showed that more detailed composition analysis

could be performed for all $\mathrm{PdCl}_{4}{ }^{2-}$ concentrations and all conditions (water, $\mathrm{CTAB}, \mathrm{KBr}$ ). Detailed composition analysis could help to understand the galvanic exchange on nanoscale. Potential projects should include galvanic exchange in presence of various additives, such as polymers, other ions, other surfactants or thiols. Understanding the role of passivating agent would give important information about the mechanism of the galvanic exchange.

In our studies, the concentrations used during galvanic exchange for CTAB and $\mathrm{KBr}$, showed very similar rates of exchange. A possible project should include galvanic 
exchange at other, possibly lower, concentrations, at which nanostructures may show different rate and behavior of formation.

Galvanic exchange studies performed in this dissertation were focused only on bimetallic structures obtained throughout this process. It is clear that compositional changes give drastically different optical properties of synthesized nanostructures. Future projects should include galvanic exchange between $\mathrm{Ag}$ and other noble metals, such as $\mathrm{Au}$ or Pt to form $\mathrm{AgAu}$ or $\mathrm{AgPt}$ alloy structures. Also, it would be interesting to study subsequent galvanic exchange with different metals. Ag would have to be exchanged to some extent with $\mathrm{Pd}$, after which the exchange would be continued with $\mathrm{Pt}$. Due to different reduction potentials, decoration of $\mathrm{Ag}$ nanostructures could happen at different places.

Also, future project could be focused on the effect temperature on the rate of galvanic exchange. It is well known that increased temperature increases the rate of the exchange. Higher temperature could lead to formation of smoother structures or to decoration of twin plane defects at earlier times. 


\section{REFERENCES}

1. Mieszawska, A. J.; Zamborini, F. P., Chem. Mater. 2005, 17, 3415-3420.

2. Zheng, G.; Lu, W.; Jin, S.; Lieber, C. M., Adv. Mater. 2004, 16, 1890-1893.

3. Cui, Y.; Wei, Q.; Park, H.-Y.; Lieber, C. M., Science 2001, 293, 1289-1292.

4. Favier, F.; Walter, E. C.; Zach, M. P.; Benter, T.; Penner, R. M., Science 2001, 293, 2227.

5. Hahm, J.-i.; Lieber, C. M., Nano Lett. 2004, 4, 51-54.

6. Huang, X.; El-Sayed, I. H.; Qian, W.; El-Sayed, M. A., J. Am. Chem. Soc. 2006, $128,2115-2120$.

7. Slawinski, G. W.; Zamborini, F. P., Langmuir 2007, 23, 10357-10365.

8. Wei, Z.; Mieszawska, A. J.; Zamborini, F. P., Langmuir 2004, 20, 4322-4326.

9. Wei, Z.; Zamborini, F. P., Langmuir 2004, 20, 11301-11304.

10. Mieszawska, A. J.; Slawinski, G. W.; Zamborini, F. P., J. Am. Chem. Soc. 2006, $128,5622-5623$.

11. Mieszawska, A. J.; Jalilian, R.; Sumanasekera, G. U.; Zamborini, F. P., J. Am. Chem. Soc. 2005, 127, 10822-10823.

12. Mieszawska, A. J.; Jalilian, R.; Sumanasekera, G. U.; Zamborini, F. P., Small 2007, 3, 722-756.

13. Jana, N. R.; Gearheart, L.; Murphy, C. J., J. Phys. Chem. B 2001, 105, 4065-4067.

14. Sun, Y.; Gates, B.; Mayers, B.; Xia, Y., Nano Lett. 2002, 2, 165-168.

15. Sun, Y.; Mayers, B.; Herricks, T.; Xia, Y., Nano Lett. 2003, 3, 955-960.

16. Sun, Y.; Xia, Y., Adv. Mater. 2002, 14, 833-837.

17. Sun, Y.; Xia, Y., Science 2002, 298, 2176-2179.

18. Sun, Y.; Yin, Y.; Mayers, B. T.; Herricks, T.; Xia, Y., Chem. Mater. 2002, 14, 4736-4745.

19. Silvert, P.-Y.; Herrera-Urbina, R.; Tekaia-Elhsissen, K., J. Mater. Chem. 1997, 7, 293-299.

20. Zhou, Y.; Yu, S. H.; Wang, C. Y.; Li, X. G.; Zhu, Y. R.; Chen, Z. Y., Adv. Mater. $1999,11,850-852$.

21. Liu, F.-K.; Huang, P.-W.; Chang, Y.-C.; Ko, C.-J.; Ko, F.-H.; Chu, T.-C., J. Cryst. Growth 2005, 273, 439-445.

22. Bhattacharyya, S.; Saha, S. K.; Chakravorty, D., Appl. Phys. Lett. 2000, 77, 37703772 .

23. Huang, M. H.; Choudrey, A.; Yang, P., Chem. Commun. 2000, 1063-1064.

24. Han, Y.-J.; Kim, J. M.; Stucky, G. D., Chem. Mater. 2000, 12, 2068-2069.

25. Kazeminezhad, I.; Barnes, A. C.; Holbrey, J. D.; Seddon, K. R.; Schwarzacher, W., Appl. Phys. A 2007, 86, 373-375.

26. Walter, E. C.; Favier, F.; Penner, R. M., Anal. Chem. 2002, 74, 1546-1553.

27. Taub, N.; Krichevski, O.; Markovich, G., J. Phys. Chem. B 2003, 107, $11579-$ 11582. 
28. Gao, J.; Bender, C. M.; Murphy, C. J., Langmuir 2003, 19, 9065-9070.

29. Gole, A.; Murphy, C. J., Chem. Mater. 2004, 16, 3633-3640.

30. Gole, A.; Orendorff, C. J.; Murphy, C. J., Langmuir 2004, 20, 7177-7182.

31. Jana, N. R.; Gearheart, L.; Murphy, C. J., J. Chem. Mater. 2001, 13, 2313-2322.

32. Jana, N. R.; Gearheart, L.; Murphy, C. J., Adv. Mater. 2001, 13, 1389-1393.

33. Aslan, K.; Lakowicz, J. R.; Geddes, C. D., J. Phys. Chem. B 2005, 109, 62476251.

34. Aslan, K.; Leonenko, Z.; Lakowicz, J. R.; Geddes, C. D., J. Phys. Chem. B 2005, $109,3157-3162$.

35. Lee, G.-J.; Shin, S.-I.; Kim, Y.-C.; Oh, S.-G., Mater. Chem. Phys. 2004, 84, 197204.

36. Lee, K.-H.; Huang, K.-M.; Tseng, W.-L.; Chiu, T.-C.; Lin, Y.-W.; Chang, H.-T., Langmuir 2007, 23, 1435-1442.

37. Wei, G.; Zhou, H.; Liu, Z.; Song, Y.; Wang, L.; Sun, L.; Li, Z., J. Phys. Chem. B 2005, 109, 8738-8743.

38. Sun, Y.; Willey, B.; Li, Z.-Y.; Xia, Y., J. Am. Chem. Soc. 2004, 126, 9399-9406.

39. Skrabalak, S. E.; Chen, J.; Au, L.; Lu, X.; Li, X.; Xia, Y., Adv. Mater. 2007, 19, 3177-3184.

40. Camargo, P. H. C.; Xiong, Y.; Ji, L.; Zuo, J. M.; Xia, Y., J. Am. Chem. Soc. 2007, $129,15452-15453$.

41. Chen, J.; Willey, B.; McLellan, J.; Xiong, Y.; Li, Z.-Y.; Xia, Y., Nano Lett. 2005, 5, 2058-2062.

42. Liu, Y.-C.; Yang, S.-J., Electrochimica Acta 2007, 52, 1925-1931.

43. Bansal, V.; Jani, H.; Plessis, J. D.; Coloe, P. J.; Bhargava, S. K., Adv. Mater. 2008, 20, 717-723.

44. Bi, Y.; Lu, G., Chem. Mater. 2008, 20, 1224-1226.

45. Guo, S.; Dong, S.; Wang, E., Chem. Eur. J. 2008, 14, 4689-4695.

46. Yoo, S.-H.; Park, S., Adv. Mater. 2007, 19, 1612-1615.

47. Teng, X.; Wang, Q.; Liu, P.; Han, W.; Frenkel, A. I.; Wen, W.; Marinkovic, N.;

Hanson, J. C.; Rodriguez, J. A., J. Am. Chem. Soc. 2008, 130, 1093-1101.

48. Chen, H. M.; Hsin, C. F.; Liu, R.-S.; Lee, J.-F.; Jang, L.-Y., J. Phys. Chem. C 2007, 111, 5909-5914.

49. Selvakannan, P.; Sastry, M., Chem. Commun. 2005, 1684-1686.

50. Strasser, P.; Koh, S.; Greeley, J., Phys. Chem. Chem. Phys. 2008, 10, 3670-3683.

51. Yan, C.; Xue, D., Electrochem. Comm. 2007, 9, 1247-1251.

52. Cao, Z.; Xiao, D.; Kang, L.; Wang, Z.; Zhang, S.; Ma, Y.; Fu, H.; Yao, J., Chem. Commun. 2008, 2692-2694.

53. Safaee, A.; Sarkar, D. K.; Farzaneh, M., Appl. Surface Science 2008, 254, 24932498.

54. Lu, X.; Tuan, H.-Y.; Chen, J.; Li, Z.-Y.; Korgel, B. A.; Xia, Y., J. Am. Chem. Soc. 2007, 129, 1733-1742.

55. Willey, B. J.; Chen, Y.; McLellan, J. M.; Xiong, Y.; Li, Z.-Y.; Ginger, D.; Xia, Y., Nano Lett. 2007, 7, 1032-1036.

56. Chen, J.; Wang, D.; Xi, J.; Au, L.; Siekkinen, A.; Warsen, A.; Li, A.-Y.; Zhang, H.; Xia, Y.; Li, X., Nano Lett. 2007, 7, 1318-1322. 
90. Chen, H.; Gao, Y.; Zhang, H.; Liu, L. F.; Yu, H.; Tian, H.; Xie, S.; Li, J., J. Phys. Chem. B 2004, 108, 12038-12043.

91. Matsumoto, T.; Kbayashi, K.; Fukami, K.; Sakka, T.; Ogata, Y. H., Phys. Status Solidi C 2009, 6, 1561-1565.

92. Dimitratos, N.; Porta, F.; Prati, L.; Villa, A., Catl. Lett. 2005, 99, 181-185.

93. Nutt, M. O.; Heck, K. N.; Alvarez, P.; Wong, M. S., Appl. catal. B 2006, 69, $115-$ 125.

94. Boukhvalov, D. W.; Katsnelson, M. I., Phys. Rev. B 2008, 78, 085413/1$085413 / 5$.

95. Sofo, J. O.; Chaudhari, A. S.; Barber, G. D., Phys. Rev. B 2007, 75, 153401/1$153401 / 4$.

96. Roman, T.; Dino, W. A.; Nakanishi, H.; Kasai, H.; Sugimoto, T.; Tange, K., Japan J. Appl. Phys. 2006, 45, 1765-1767.

97. Geim, A. K.; Kim, P., Sci. Am. 2008, 298, 90-97.

98. Bolotin, K. I.; Sikes, K. J.; Hone, J.; Stormer, H. L.; Kim, P., Phys. Rev. Lett. 2008, 101, 096802/1-096802/4.

99. Zhang, Y.; Tan, Y.-W.; Stormer, H. L.; Kim, P., Nature 2005, 438, 201-204.

100. Muszynski, R.; Seger, B.; Kamat, P. V., Langmuir 2008, 112, 5263-5266.

101. Kim, Y.-K.; Na, H.-K.; Min, D.-H., Langmuir 2010, ACS ASAP.

102. Sidorov, A. N.; Yazdanpanah, M. M.; Jalilian, R.; Ouseph, P. J.; Cohn, R. W.;

Sumanasekera, G. U., Nanotechnology 2007, 18, 135301/1-135301/4.

103. Ibanez, F. J.; Gowrishetty, U.; Crain, M. M.; Walsh, K. M.; Zamborini, F. P., Anal. Chem. 2006, 78, 753-761.

104. Ferrari, A. C.; Meyer, J. C.; Scardaci, V.; Casiraghi, C.; Lazzeri, M.; Mauri, F.; Piscanec, S.; Jiang, D.; Novoselov, K. S.; Roth, S.; Geim, A. K., Phys. Rev. Lett. 2006, 97, 187401/1-187401/4.

105. Gupta, A.; Chen, G.; Joshi, P.; Tadigadapa, S.; Eklund, P. C., Nano Lett. 2006, 6, 2667-2673.

106. Sidorov, A. N.; Pabba, S.; Hewaparakrama, K. P.; Cohn, R. W.; Sumanasekera, G. U., Nanotechnology 2008, 19, 195708/1-195708/6.

107. Chieu, T. C.; Dresselhaus, M. S.; Endo, M., Phys. Rev. B 1982, 26, 5867-5877.

108. Kneipp, K.; Perelman, L. T.; Kneipp, H.; Backman, V.; Jorio, A.; Dresselhaus, G.; Dresselhaus, M. S., Phys. Rev. B 2001, 63, 193411/1-193411/4.

109. Rao, A. M.; Richter, E.; Bandow, S.; Chase, B.; Eklund, P. C.; Williams, K. A.; Fang, S.; Subbaswamy, K. R.; Menon, M.; Thess, A.; Smalley, R. E.; Dresselhaus, G.; Dresselhaus, M. S., Science 1997, 275, 197-191. 


\section{CURRICULUM VITAE}

\section{Grzegorz Slawiński}

Department of Chemistry

University of Louisville

Louisville, KY 40292

Telephone: (502) 852-5982

Mobile: (502) 593-9334

E-mail: grzegorz_slawinski@yahoo.com

\section{Objective}

Doctoral and postdoctoral research in analytical chemistry, nanotechnology or material chemistry.

\section{Education}

University of Louisville, Louisville KY

2007-2010

$\mathrm{Ph}$. D. in Chemistry, August 2010

Department of Chemistry, (Dr. Francis P. Zamborini)

Dissertation: The electrochemical synthesis, chemical synthesis, and galvanic exchange of silver nanostructures directly

on surfaces

\section{University of Louisville, Louisville KY}

M.S. in Chemistry, August 2007

Department of Chemistry (Dr. Francis P. Zamborini)

Thesis: The assembly and alignment of one-dimensional Ag, Pt, $P d, A u$, and $A u / P d$ core/shell structures directly on surfaces by chemical methods

Lublin University of Technology, Lublin, Poland

M.S. in Environmental Engineering

Department of Environmental Engineering (Dr. Justyna Jaroszyńska - Wolińska)

Thesis: Design of the low-temperature plasma generator 
Research Experience

University of Louisville, Louisville, USA

Research

$\underline{\text { Research Assistant }}$

2004-Present

- Research on surface Chemistry-Growth of Au NRs, Ag NRs/NWs Pt NRs/NWs, Pd NRs/NWs, Au/Pd core/shell

- Alignment of Au NRs and Ag NRs/NWs on surface

Lublin University of Technology, Lublin, Poland

$2002-2003$

Research Assistant

- Building the apparatus for low-temperature plasma formation.

- Specialization in chemical technology

Publications

1. Mieszawska, Aneta J., Slawinski, Grzegorz W., Zamborini, Francis P. Directing the Growth of Highly Aligned Gold Nanorods through a Surface Chemical Amidation Reaction. Journal of the American Chemical Society, 2006, 128 (17), 5622-5623.

2. Slawinski, Grzegorz W., Zamborini Francis P. Synthesis and Alignment of Silver Nanorods and Nanowires and the Formation of Pt, Pd, and Core/Shell Structures by Galvanic Exchange Directly on Surfaces. Langmuir, 2007, 23 (20), 10357-10365.

3. Slawinski, Grzegorz W., Ivanova, Olga S., Zamborini Francis P. Unique structures through twin plane decoration of Ag nanorods during the galvanic reaction in absence of surfactants. - ready to submit

4. Slawinski, Grzegorz W., Ivanova, Olga S., Zamborini Francis P. Effect of surfactants and additives on galvanic exchange reaction of Ag nanowires grown directly on surfaces - in preparation

5. Sidorov, Anton, Slawinski, Grzegorz W., Sumanasekera, Gamini U., Zamborini, Francis P. Scanning Electron Microscopy and Surface-Enhanced Raman Spectroscopy Study of Thin Graphene Sheets Functionalized with Gold and Silver Nanorods by Seed-Mediated Growth - ready to submit

\section{Presentations}

1. Grzegorz W. Slawinski - Poster at the $39^{\text {th }}$ Central Regional Meeting of the American Chemical Society (CERMACS) in Covington, KY (May 2007). "Synthesis and Alignment of Silver Nanorods/Nanowires Directly on Surfaces 
and the Formation of $\mathrm{Pt}, \mathrm{Pd}$, and Core/Shell Structures by Galvanic Exchange."

2. Grzegorz Slawinski - Poster at KYNANOMAT 2008 in Louisville, KY (March 2008). "Seed-Mediated Growth and Galvanic Exchange of OneDimensional Silver Nanostructures Directly on Surfaces.

3. Grzegorz W. Slawinski - Poster at the Electrochemistry Mini Symposium and Student Poster Session sponsored by the Cleveland section of the Electrochemical Society and the Yeager Center for Electrochemical Sciences at Case Western Reserve University in Cleveland, Ohio (May 2010). "Unique Structures Through Twin Plane Decoration of Silver Nanorods."

\section{Teaching Experience}

- Graduate Teaching Assistant

Taught basic concepts and principles of modern chemistry. Lectured and graded higher level analytical laboratory courses.

Courses Taught:

201 - general chemistry I-S - lab

202 - general chemistry II-S - lab

203 - general chemistry I-SL- lab

207 - intro to chem. analysis I-SL - lab

208 - intro to chem. analysis II-SL - lab

209 - intro to chem. analysis III-SL - lab

210 - intro to chem. analysis IV-SL - lab

470 - Physical chemistry - lab-WR

- Undergraduate and Graduate Research Mentor

Designed experiments, taught laboratory techniques,

explained important laboratory concepts

Undergraduate Students:

Lee Barnwell

Marchello Cavitt

\section{Service Activities}

- Judging at the $3^{\text {rd }}$ and $4^{\text {th }}$ Annual Kentuckiana

2004-2006

Undergraduate Research Symposium in Louisville 


\section{Languages}

English, Polish, Russian (basic),

\section{Professional Affiliations}

American Chemical Society

2004-current

\section{Instrumentation}

Surface techniques: AFM, SEM, XPS, EDAX

Other: Capillary Electrophoresis, FTIR, UV-Vis, GC, E-Chem Workstation

\section{References}

Francis P. Zamborini (Ph.D.)

Department of Chemistry

University of Louisville

2320 South Brook Street

Louisville, KY 40292

Phone: (502) 8526550

Email: f.zamborini@louisville.edu

Mehdi M. Yazdanpanah (Ph.D.)

CEO-Founder NaugaNeedles

11509 Commonwealth Dr., Suite \#2

Louisville, KY 40299

Phone (office): (502) 619-5156

(cell): (502) 807-1199

Email: www.nauganeedles.com mehdi@nauganeedles.com

Aleeta M. Powe (Ph. D.)

Department of Chemistry

University of Louisville

2320 South Brook Street

Louisville, KY 40292

Email: aleeta.powe@louisville.edu 


\author{
Richard P. Baldwin (Ph.D.) \\ Department of Chemistry \\ University of Louisville \\ 2320 South Brook Street \\ Louisville, KY 40292 \\ Phone: (502) 8525892 \\ Email: rick.baldwin@louisville.edu \\ Justyna Jaroszyńska -Wolińska (Ph.D.) \\ Department of Environmental Engineering \\ Technical University of Lublin \\ Nadbystrzycka 38D \\ 20-618 Lublin, Poland \\ Phone: +48 815381452 \\ Email: j.wolinska@pollub.pl
}

